\title{
FISH-CULTURAL PRACTICES IN THE UNITED STATES BUREAU OF FISHERIES
}

From BULLETIN OF THE BUREAU OF FISHERIES, Volume XXVIII, IgO8

Proceedings of the Fourth International Fishery Congress: Washington, 1908



WASHINGTON : : : : : : GOVERNMENT PRINTING OFFICE $:: \quad: \quad: \quad: 1910$ 


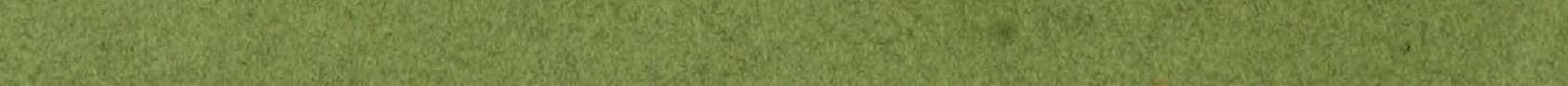

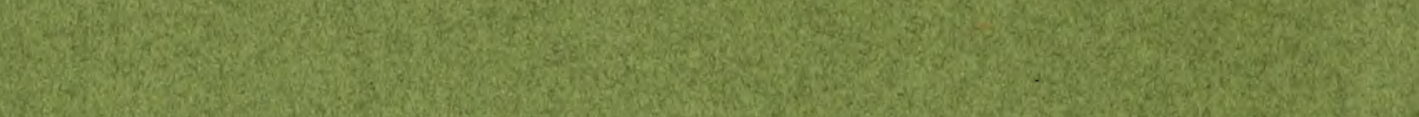
W.

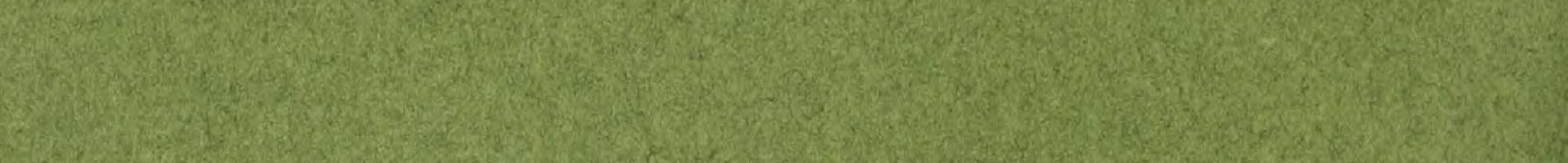

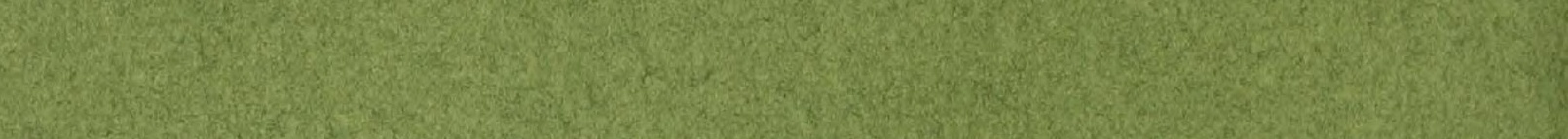

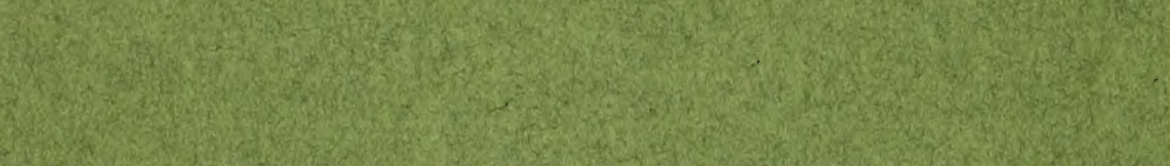

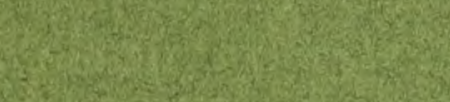

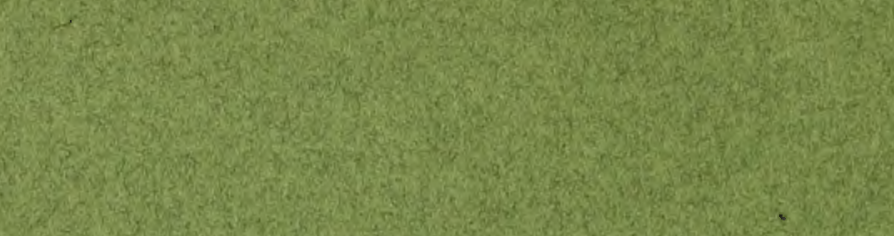

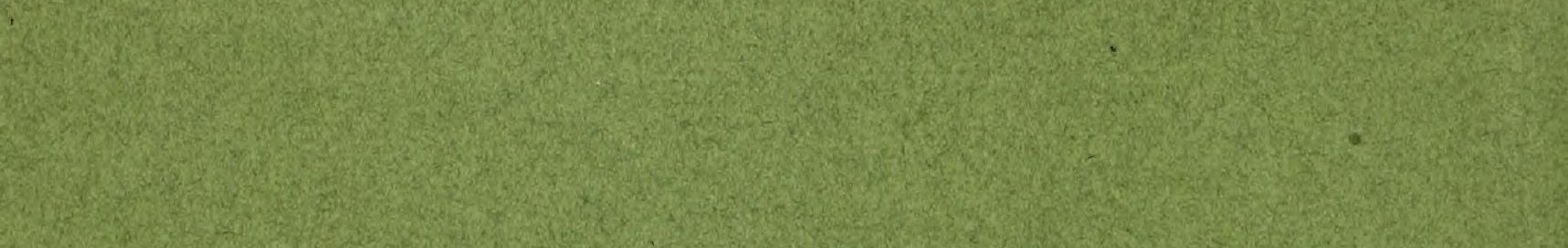

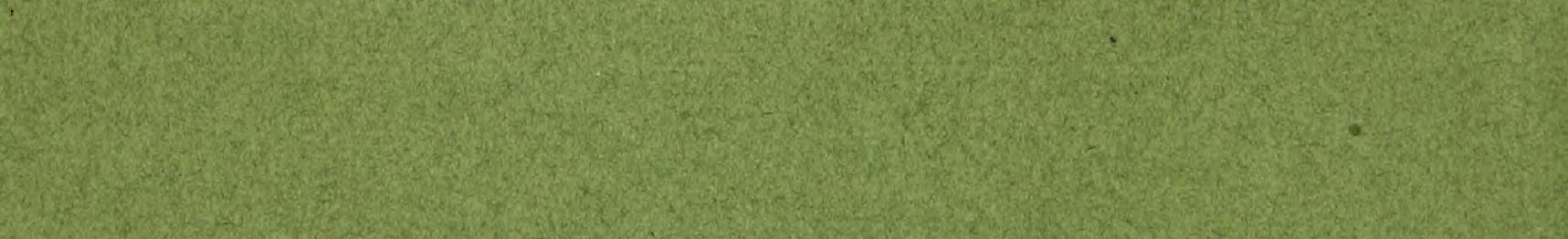

(2)

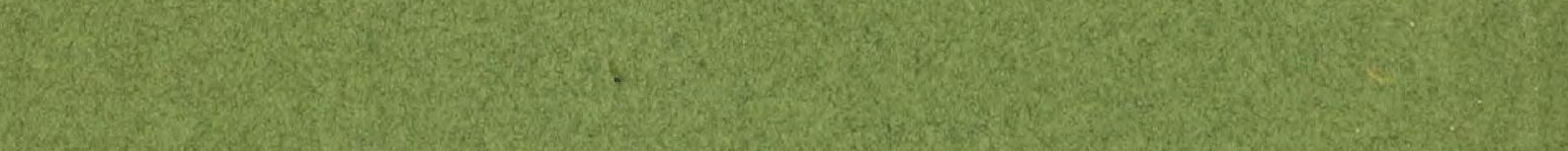

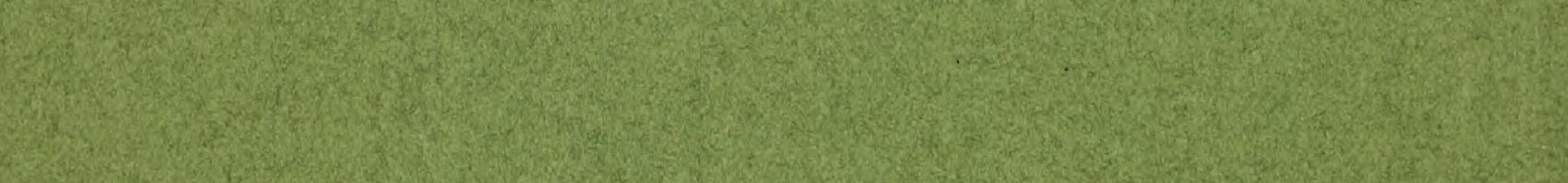
2.

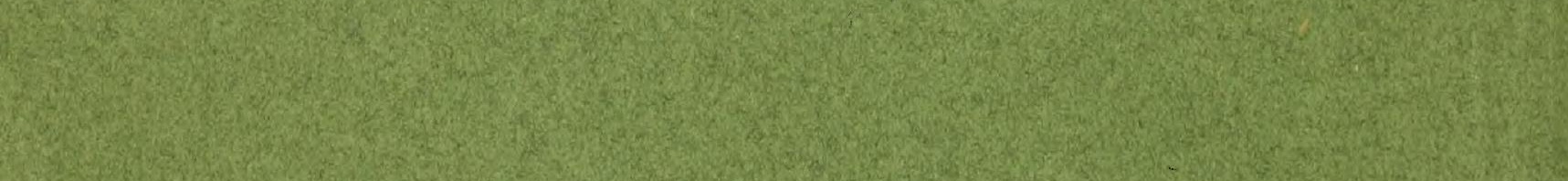

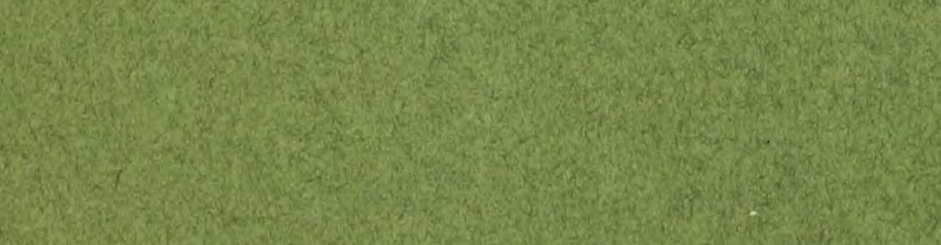
2. (3) 4.

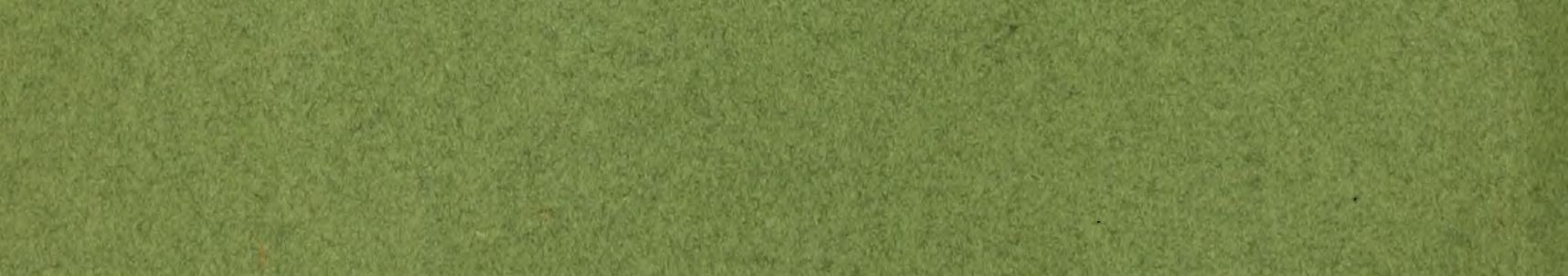

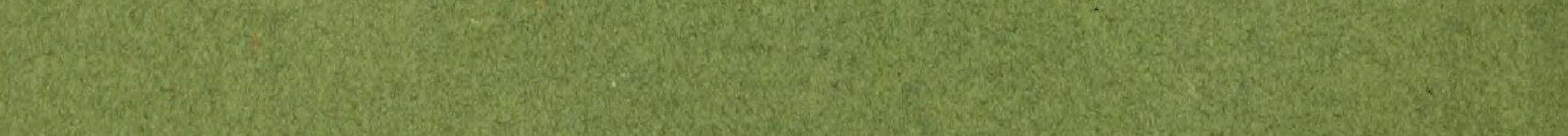

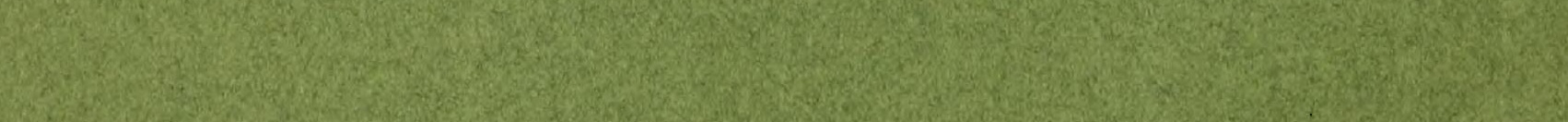
.

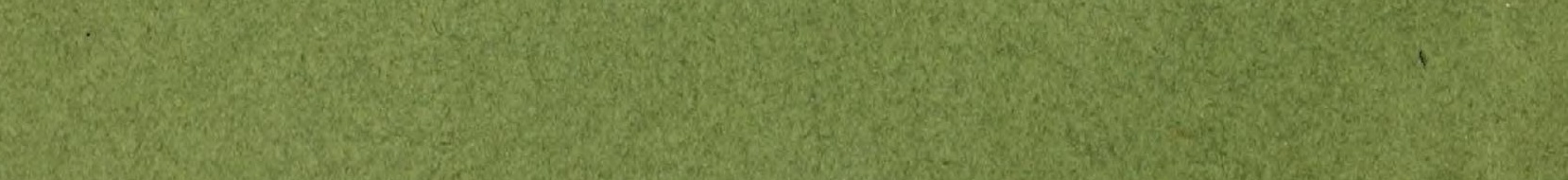

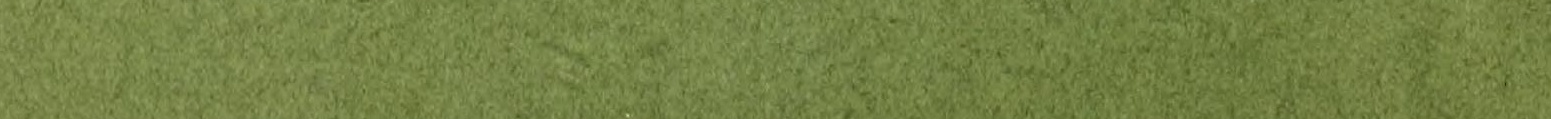

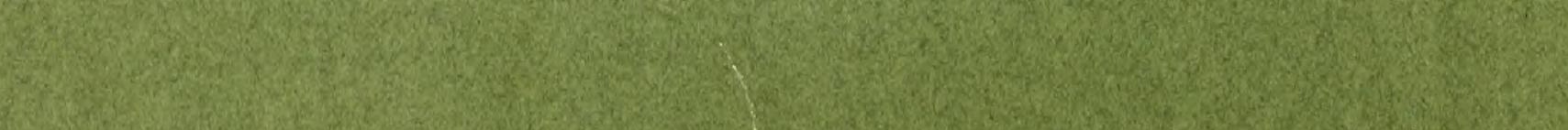




\section{FISH-CULTURAL PRACTICES IN THE UNITED STATES BUREAU OF FISHERIES}

From BULLETIN OF THE BUREAU OF FISHERIES, Volume XXVIII, igos

Proceedings of the Fourth International Fishery Congress : Washington, Igo8

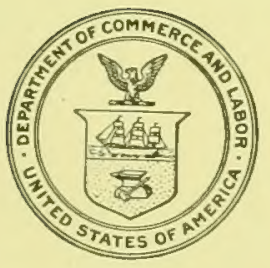




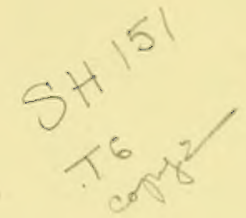

BUREAU OF FISHERIES DOCUMENT NO. 675

Issued April, 1910

\author{
(1) 9 을 의 \\ $016108 \mathrm{ydV}$
}




\title{
FISH-CULTURAL PRACTICES IN THE UNITED STATES BUREAU OF FISHERIES
}

\author{
* \\ By John W. Titcomb \\ Assistant in Charge of the Division of Fish Culture \\ $*$ \\ Address before the Fourth International Fishery Congress \\ held at Washington, U. S. A., September 22 to 26, 1908
}




\section{CONTEN T S.}

2

Page.

Resources of the Bureau

Extent and general methods of the work

River fishes of the east coast _ _

Shad _

White perch _.......

Yellow perch _...

Striped bass _ _ _.

Fishes of the Great Lakes.

Whitefish__ _

Pike perch _...

Lake trout _.

The brook trouts, chars, and eastern salmons _

Spawntaking in Colorado _.................

Rearing methods ........

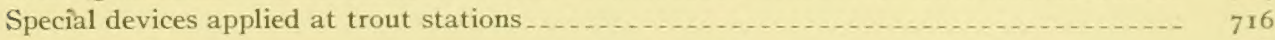

Atlantic salmon

Pond culture

The ponds

Food for the adult fishes___

Artificial nests

Number of brood fish _...

Collecting the young fish_.

Rescue of fishes from overflowed lands _

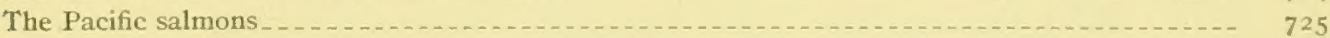

Barricades and traps to intercept spawning runs $\ldots \ldots$

At Baird, Cal _........

At Battle Creek, Cal _. $\ldots \ldots \ldots \ldots \ldots \ldots \ldots \ldots$

At Birdsview, Wash_........

Taking and hatching the eggs _.

Seining operations and spawntaking at California stations _ _ . . . . . .

Local practices in different regions _

Marine fish culture. _...

Cod, pollock, and flatfish _

Lobsters _ _ _ _ _

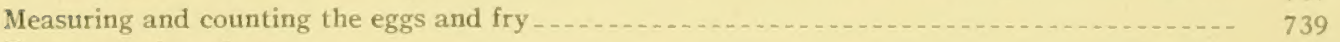

Transportation of eggs _

Usual style of packing case _.

Adaptations and variations of method .

Argentine case .

German-Chile case _...

Transportation of fish.....

Distribution and planting of commercial fishes _........

Distribution of game fishes 


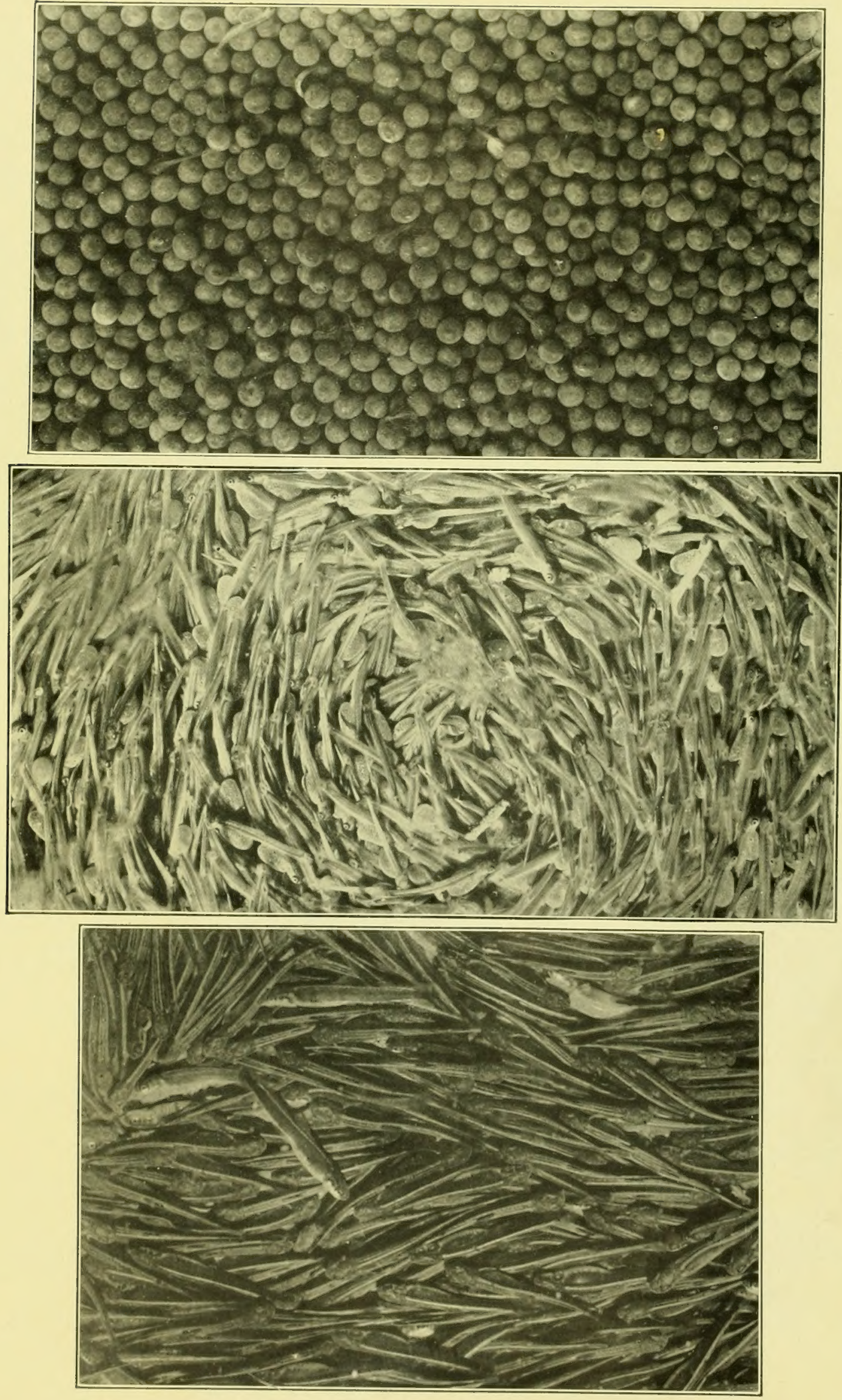


\title{
FISH-CULTURAL PRACTICES IN THE UNITED STATES BUREAU OF FISHERIES. ${ }^{a}$
}

\author{
$\$$ \\ By JOHN W. TITCOMB, \\ Assistant in Charge of the Division of Fish Culture. \\ $*$ \\ RESOURCES OF THE BUREAU.
}

The fish-cultural work of the United States Bureau of Fisheries, administered from headquarters at Washington through the Division of Fish Culture, is conducted by means of numerous hatching stations located in various parts of the country, including Alaska. There are thirty-two such stations recognized for administrative purposes. Auxiliary to these are numerous field stations, some of them equipped as hatcheries and in operation throughout the year, others used only during the spawning season of the fishes they are concerned with. The land owned by the Bureau at its fish-cultural stations has an aggregate area of 12,000 acres, valued at $\$ 225,000$. The improvements on this land in buildings, ponds, and special equipment represent an investment of about \$I, 000,000. The Division of Fish Culture has 225 civil-service employees, whose salaries aggregate approximately $\$ 200,000$; while there is an annual appropriation of $\$ 275,000$ for the maintenance and operation of stations, including the employment of temporary laborers and assistants in fish-cultural work.

It will be my endeavor to allude to some of the more important phases of the fish-cultural work which these resources make possible, and to explain more fully than would otherwise be permissible features of the work in which recent changes in methods or equipment have not heretofore been so fully illustrated or described.

\section{EXTENT AND GENERAL METHODS OF THE WORK.}

During the fiscal year 1908 the Bureau distributed fish and eggs to the number of $2,871,456,280$. The table accompanying gives an idea of the extent of the work for a series of years.

a This paper as read before the International Fishery Congress was illustrated by lantern slides, to supply the absence of which in publication the text has been amplified. 
Aggregate of Adult Fishes, Yearlings, Fry, and Eggs Distributed by the Bureau of Fisheries FROM 1872 TO 1908 .

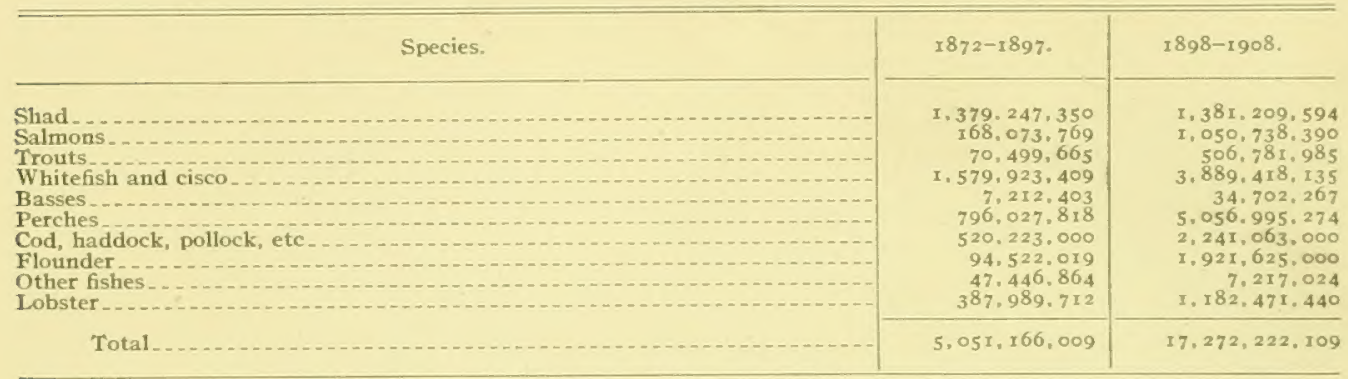

The first column represents the output of the United States Fish Commission from its inception to the beginning of the present Commissioner's administration, a period of twenty-six years. The second column represents the output for the subsequent period of eleven years. The total operating expenses of the entire eleven years, I 898 to 1908 , did not exceed those of the preceding twenty-six years, while the output has been more than trebled. About 50 species of fishes are now handled.

The results of fish culture, as shown by numerous replenished waters and by actual returns in fish, might easily be made the subject of a lengthy discourse, but for present purposes will be alluded to only incidentally. A marked evidence of success may be noted in the constantly increasing demand for young fish to plant. Notwithstanding the fact that the bureau, by the increase of its facilities and by progressive methods, has steadily increased its output, the demand of the public for fish has increased therewith until in some lines of work, notably the production of the basses, crappies, other sunfishes, and the catfishes, it is greater than can be met with present means.

It is a point to be emphasized that the fish-cultural work of the Bureau is of two classes with respect to its economy. Many of the most valuable food fishes, being in their prime for market purposes just prior to the spawning season, are most extensively captured at the very time they should be spared for the perpetuation of their kind. Whenever possible, the Bureau secures the eggs of these fish from the fishermen. Fully 96 per cent of all the eggs collected and hatched by the Bureau are taken and fertilized from fishes destined to the market, and this without detracting from the value or edible qualities of the parent fish.

The collection of fish eggs under these conditions is to be distinguished from the work which utilizes the eggs of fish that have reached their spawning grounds and which it is customary to capture for the express purpose of obtaining and fertilizing their eggs. The latter is fish culture in the usual sense-extensive 
increase of the numbers of young by protecting the eggs and providing the most favorable conditions for hatching. The other is fish culture also, but in addition to conservation of a resource that would otherwise be unavailed of.

Some of the freshwater species, valued chiefly as game fishes although marketed also, are cultivated by confining them under conditions which will secure the maxinum reproduction by natural processes. Practically all of the important commercial fishes, however, can be propagated, and much more numerously, by stripping them of eggs and milt by hand and incubating the fertilized eggs in hatcheries. It is with these that the Bureau is most largely concerned, their numbers being nearly 98 per cent of the entire output of the hatcheries.

There are some variations in the methods of spawntaking, according to species, but in general the operation consists in expelling the eggs by a gentle pressure of the thumb and forefinger along the walls of the abdomen, the strokes being continued until all ripe eggs have been secured. The fish is usually grasped near the head, and to hold it firmly may be pressed against the body of the spawntaker. The receptacle into which the eggs are expelled is usually a 6-quart milk pan which has been dipped into the water and then emptied, thus leaving it slightly moist. Other forms of receptacles, such as marbleized or porcelain-lined pans or wooden vessels are sometimes used where the eggs are especially adhesive. The milt is obtained by the same process as the eggs, and applied to the latter in the pan used to receive them from the fish.

The hatching processes are, generally speaking, of three classes with respect to equipment, determined primarily by the specific gravity of the eggs. Heary eggs, such as those of the trouts, salmons, and the grayling, are incubated in wire-bottom trays or wire baskets set in troughs of running water. The mesh of the wire is of size to suit the size of egg and to permit the young fish as they hatch to drop through into the trough. The troughs are usually plain open boxes varying in length from 12 to 16 feet and in depth from 4 to 12 inches, to suit conditions. An arbitrary width of $\mathrm{I}_{4}$ inches, inside measure, has been adopted, uniformity in width being desirable for economy in interior equipment. For handling large quantities of eggs the troughs are frequently provided with either permanent or removable partitions to regulate the direction of the current of water througl the eggs. 'Thus they may be converted into so-called Williamson and Clark-IVilliamson types of troughs.

Semibuoyant eggs, such as those of the whitefish, pike perch, shad, yellow perch, and white perch, are usually hatched in glass jars. The styles of jar are in general two-closed top and open top, the McDonald Universal liatching jar being of the former pattern, the Chase, McDonald open-top, and Downing being typically the latter. 
The principles of the McDonald I'niversal (patented) jar are familiar." By substituting for the closed top a screw-cap rim to which has been soldered a pitcher-like spout, the Lniversal or antomatic jar may be converted into an open-top jar and thus is the preferable equipment at hatcheries where both closed and open-top jars are required. Is an open-top jar it is operated the same as the Chase and Downing jars. At hatcheries where only open-top jars are used the Downing pattern is preferred.

\section{RIVER FISHES OF THE EAST COAST.}

SHAD.

The most important fish of the east-coast streams, the slad, is the especial object of three hatcheries - at Havre de Grace, Md., on the Susquehanna River; at Bryans Point, Md., on the Potomac; and at Edenton, N. C., on Albemarle Sound. The steamer Fish Hauk is also equipped as a hatchery, and utilized at such points as may be advantageous.

As all of the eggs for the hatcheries are obtained from market fish, the shad work is primarily conservation. The exhaustive fishing at the mouths of the rivers leaves, moreover, so few fish to reach the spawning grounds that the lishery is now, in the northern streams, entirely dependent upon the hatcheries, which are themselves interfered with by the scarcity of ripe fish. Recent legislation in North Carolina has widely restricted fishing so that there has been a notable improvement of conditions in that region, and much larger collection of eggs at Eidenton.

Curiously cnough shad are seldom caught in ripe condition during daylight until late in the afternoon. Thus the fishermen's catch of the late morning or early afternoon is not available for the rescue work of the spawn taker. But on the approach of evening during the spawning season of the shad, the Bureau's agents may be found leaving their camps to embark preparatory to being distributed on the various fishing boats or to fishing shores where shad in ripe spawning condition are to be had.

In the collection of shad eggs the fishermen often personally manipulate the ripe fish for eress and milt, and it is customary for the Bureau to provide all such men with the usual spawntaker's equipment of pans, buckets, etc. It is always necessary to employ a foree of experienced men to go among the fishermen, to see that the espss of all ripe fish are saved, fertilized, and properly cared for mint they reach the hatchery. It may not be aniss to say that spawntakers should also be experienced hoatmen, not only as a matter of safety to themselves, but heauce the fishermen are averse to allowing inexperienced men in their boats.

a Manual of Fish Culture, revised edition, 1900, P. 138. Published by U. S. Bureau of Fisheries. 

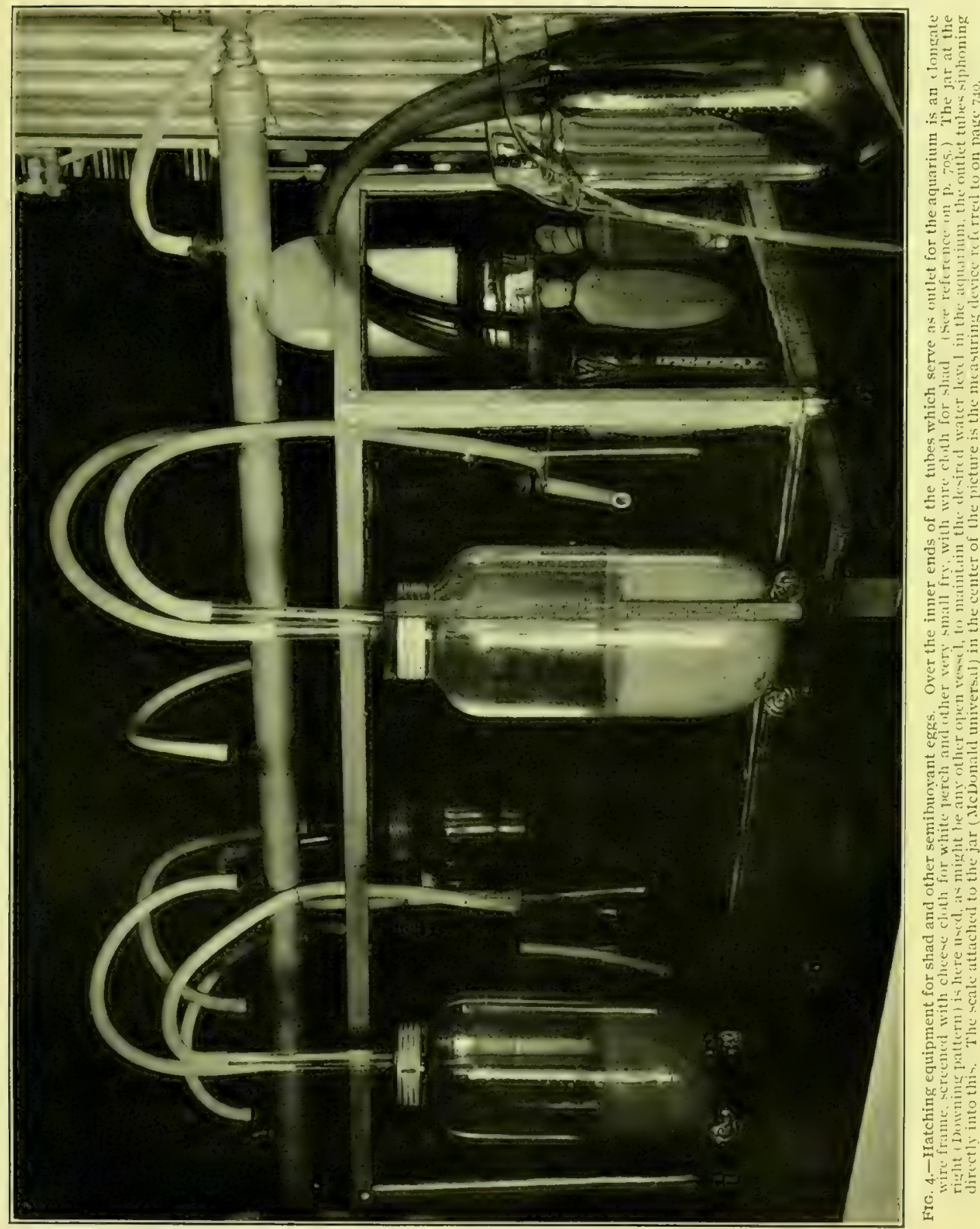

The treatment of eggs of the shad after the milt has been applied is in substance as follows:

About half a pint of water from the river is dipped into the pan, which is then given a slow rotary motion until the milt is thoroughly mixed with the eggs. This pan with its contents is then set aside and another is used in a repetition of the process. After all the stripping has been done the milt is washed from each pan of eggs by dipping water from the river and pouring it off, repeating until the milky color of the water disappears. The pans of eggs, with about $i$ pint of water in each, are then set aside, and after fifteen or twenty minutes it will be noticed that the eggs are absorbing the water. A little more water must then be added from time to time until they have fully expanded, which usually requires from forty to sixty minutes, but varies somewhat with the water temperature. When fully water-hardened, the eggs feel like shot to the touch of the fingers, and now, less sensitive to concussion, are ready to be transferred to the buckets in which it is customary to convey them to the hatchery.

En route to the hatchery it may be necessary every twenty or thirty minutes to replace the water on the eggs with water from the river in order to maintain an even temperature, the air on very cool nights affecting the water in the buckets to such degree as to injure the eggs.

The first thirty-six to forty-eight hours after arrival at the hatchery is the period of greatest mortality to the eggs, and until this has passed they are kept in open-top jars or in McDonald jars without tops, the water flowing through them being allowed to waste over the tops of the jars. The dead eggs being lighter than the live ones work toward the surface and are easily removed with a siphon of ${ }^{2}$-inch rubber tubing. The good eggs are then measured (by means of a device which will be described later) and their number is accredited to the fisherman from whom they were obtained. They are then put up for hatching in the McDonald Lniversal (i. e., closed-top) hatching jars, which are arranged on specially constructed tables in connection with rectangular glass aquaria or receiving tanks and subjected to a current of about 4 or 5 pints of water per minute at 8 pounds pressure, which is sufficient slightly to elevate the eggs from the bottom of the jar, thus giving the entire mass a slow revolving or boiling motion. The number of eggs to each jar is from 85,000 to 100,000 . As the young fish emerge from the eggs they rise toward the surface, where they come in contact with the suction outlet tube of the jar and pass through it with the waste water to the collecting tanks. From this they may be removed to the distributing cans by means of a $1 / 2$-inch rubber siphon. Another method of removing them is to dip them from the aquaria after siphoning off a portion of the water. By this method, emptying an equal number of dippers of fry into each can, it is possible to quite equally distribute the total number to be removed. 
WHITE PERCH.

With the decadence of the valuable shad fishery there has arisen a demand for the artificial propagation of the white perch (Morone americana), and this work has been extensively conducted at the mouth of the Susquehanna River during the past four seasons in connection with the hatching of shad. Like shad culture, the propagation of white perch is purely the conservation of eggs which would otherwise go to market in the parent fish.

The spawning season in the latitude of the Bureau's station at Havre de Grace, Md., is from the middle of April to the latter part of May, the tine varying with the character of season. The eggs are taken and fertilized by the usual dry method, the work being performed ordinarily by the fishermen. Owing to the adhesiveness of the eggs it is preferable to strip them into marbleized or porcelain-lined pans.

As with shad and other spring spawning fishes, the white perch spawns on a rising temperature, ripe fish being taken first when the temperature is about $47^{\circ}$. However, the eggs seem to produce better results when hatched in water of a higher temperature. At about $60^{\circ} \mathrm{F}$. they hatch in forty-eight to fiftytwo hours, while at $68^{\circ}$ to $70^{\circ}$ they hatch in twenty to twenty-four hours. They are sensitive to sudden drops in temperature, and although at $58^{\circ}$ or $60^{\circ}$ about 75 per cent of the eggs produce vigorous fry, at $50^{\circ}$ or lower few if any eggs or fry survive. In one case eggs taken at $56^{\circ}$ and held for twenty-four hours, after which the temperature dropped to $f^{\circ}$, finally hatched at a temperature of $54^{\circ}$, producing a fair percentage of fry. Observations thus far made indicate that eggs taken at mid-day or soon after mid-day produce better results than those taken earlier in the morning, although the reason has not been ascertained.

After being held for from six to twelve hours in jars without tops, white perch eggs are incubated and hatched in McDonald automatic jars on shad tables in the same manner as shad eggs. As they are especially liable to fungus, a crood circulation is particularly important, and it is inadvisable to carry more

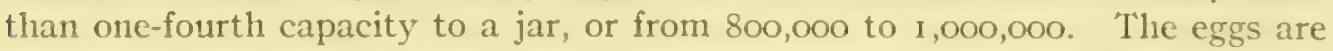
comparatively heavy, and for this additional reason require more water circulation than is needed for shad, or $2 \frac{1}{2}$ to 3 quarts per minute. It is customary to reluce the flow alout one-half cluring the last few hours before hatching, in order that fungussed masses and attached good eggs may not be carried out into the receiving tank.

When undeveloped the eggs are very white and hard, and it is difficult for the novice to tell the live ones from the dead. Some that apparently are dead suddenly eye and hatch, while, on the other hand, some apparently of good quality frequently fungus and prove a total failure. By examining in a glass 
tube, with which a few at a time may readily be removed from the jars, it is usually possible to distinguish the live eggs at any stage of development.

The eggs average 29 to the linear inch when first expelled and 28 to the inch after being water hardened. They are usually measured into the jars with a I-quart apothecary's graduate, and are computed at I,600,000 to the quart.

To guard against the escape of very small fry from the receiving aquarium the usual waste water outlet is closed, and the water is carried off by means of one or more siphons, the suction ends being provided with wire cages covered with two or three thicknesses of cheese cloth. To regulate the level of the water in the receiving tank the outlet ends of the siphons empty into an adjacent receptacle, usually a hatching jar, the rim of which is at the desired water level.

YELLOW PERCH.

It is feasible, and under some conditions desirable, to expel and fertilize yellow perch eggs artificially, but under proper conditions practically all naturally deposited eggs are fertilized. For this reason the Bureau's work largely consists in the incubation of the naturally deposited eggs obtained from fish confined in crates for the purpose, and to some extent by collection of natural spawn in marshes where left by receding waters.

It has been found that the eggs can be hatched in almost any kind of container through which water is flowing-open troughs, open jars, shad aquaria, etc.-but careful experiments indicate that the McDonald open-top and the Downing jar are preferable to other kinds of equipment, the Downing jar possessing the advantage of greater capacity. It will hold 130,000 to 150,000 eggs, and when thus incubated the eggs are subjected to a water circulation of about I pint per minute.

As little has been published on the methods of culture of this fish, the data of the superintendent in charge of the yellow perch operations at Bryans Point, Md., will be given in some detail:

Here the fish are purchased from commercial fishermen, are held in crates having comparatively tight bottoms, and allowed to spawn naturally. The crates are 8 feet long, 4 feet wide, and $2 I / 2$ to 3 feet deep, and are placed in the mouth of a small creek tributary to the Potomac reached by tide water from the river. A small number of fish are also kept in a large tank at the hatchery, through which there is a constant flow of river water in connection with the regular station supply.

The collecting of fish begins about the middle of March or when the water temperature ranges from $34^{\circ}$ to $37^{\circ}$. The water temperature in which spawning occurs ranges from $42^{\circ}$ to $46^{\circ}$. In 1908 the first eggs were: obtained March 
$2 I$ in a water temperature of $46^{\circ}$. Practically all the fish had finished spawning on April I, at which time the water temperature was $58^{\circ}$. The spawn is taken daily from the crates and transferred to the hatchery in buckets.

The eggs are comparatively heavy, and are slightly adhesive when first deposited. The period of incubation in a water temperature of $47^{\circ}$ to $54^{\circ}$ is ten to twenty days. The absorption of the yolk sac requires a period of eight days in a mean temperature of $54^{\circ}$. On the l'otomac River the average number of eggs from fish of one-half pound weight is about i 5,00o.

When measured into the jars the eggs are computed at 100,000 to the quart. Actual measurements of 10 eggs average 1.662 millimeters or 0.065 inch in diameter, but on account of the peculiar gelatinous envelope of the egg, these individual egg measurements are of no use whatever in estimating the number in a given volume.

\section{STRIPED BASS.}

At Weldon, N.C., is a field station for the propagation of the striped bass (Roccus lineatus). It has been operated for a number of years with rather negative results as to the number of egrs collected, but with experience of much value as suggesting lines of improvement in methods of manipulating ripe fish and the eggs.

The chief obstacles to successful work in the propagation of this fish are the difficulties of obtaining ripe spawning females in numbers sufficient to produce large results, and of obtaining a ripe male at the time a female is available. Penning the fish has not proved successful. The delicate nature of the eggs and the limited period of incubation- $\mathrm{I}^{\mathrm{T}}{ }_{2}$ days-are reasons for believing that they can not be successfully transported from the source of supply.

The McDonald automatic hatching jars have been somewhat successfully used at Weldon, but the sac fry of the striped bass are nore tender than those of any other fish and it was found that many were injured in their passage to the aquarium through the rubber tube of the closed top. The style of jar was then changed to open top, and has given highly satisfactory results. An elongation of the pitcher mouth by means of a trough of canvas delivers the fry from the jar to the aquarium without friction and concussion. Owing to the buoyancy of the egges less than one quart of water per minute is supplied to each jar and at time of hatching only about one pint. When water hardened the eggs are computed at 35,000 to the liquid quart and it is customary to incubate 80,000 in each McDonald jar.

In the latitude of Weldon, striped bass spawn in a temperature of $70^{\circ}$ to $77^{\circ}$, the season being from the middle of April to early in June. 


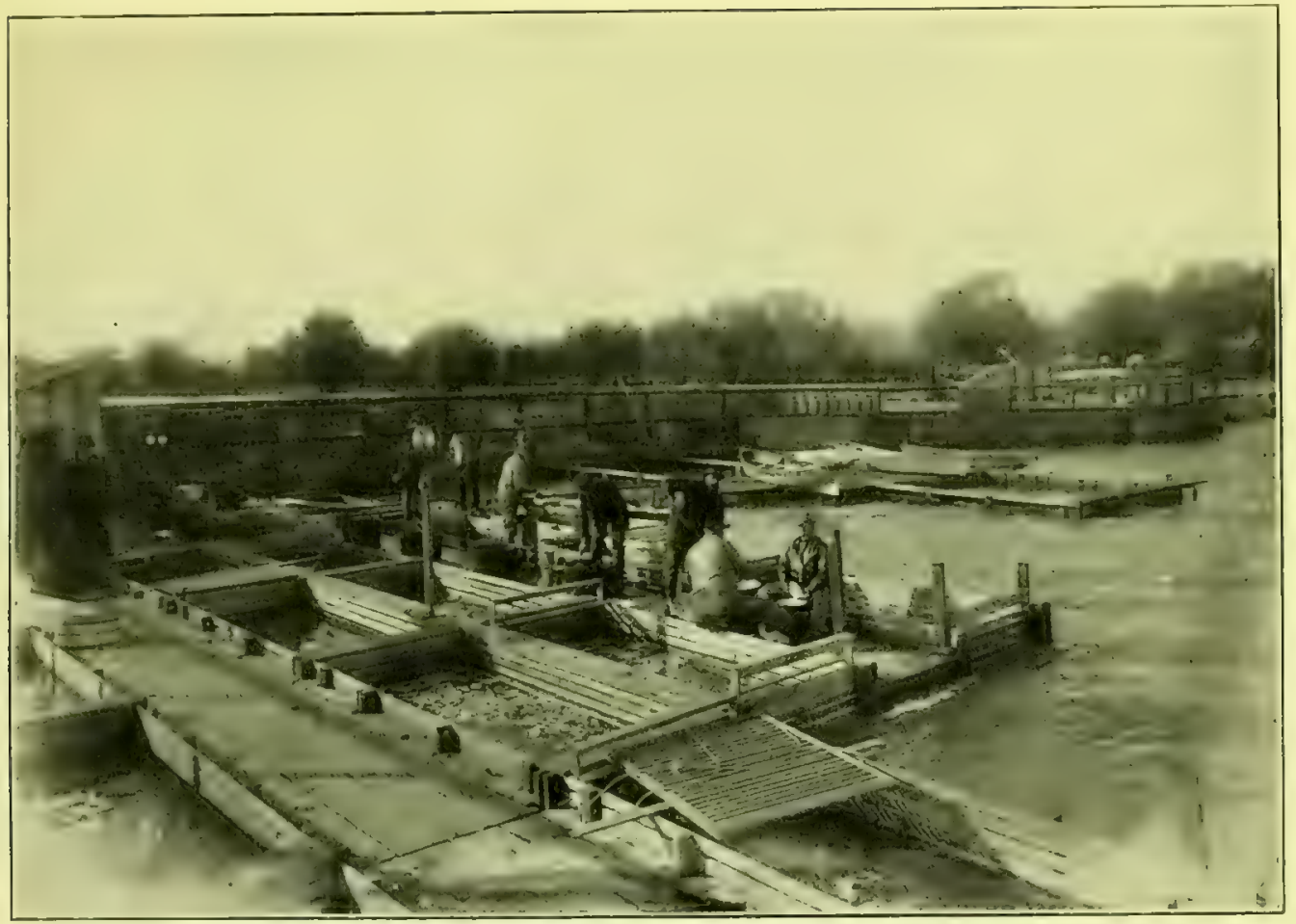

FIG. 5.-Spawutaking operations on the Detroit River, Michigan. Whitefish caught in commercial fishing are held in crates and pounds until ripe. The crates are provided with false bottoms, which may be raised for easier access to the fish.

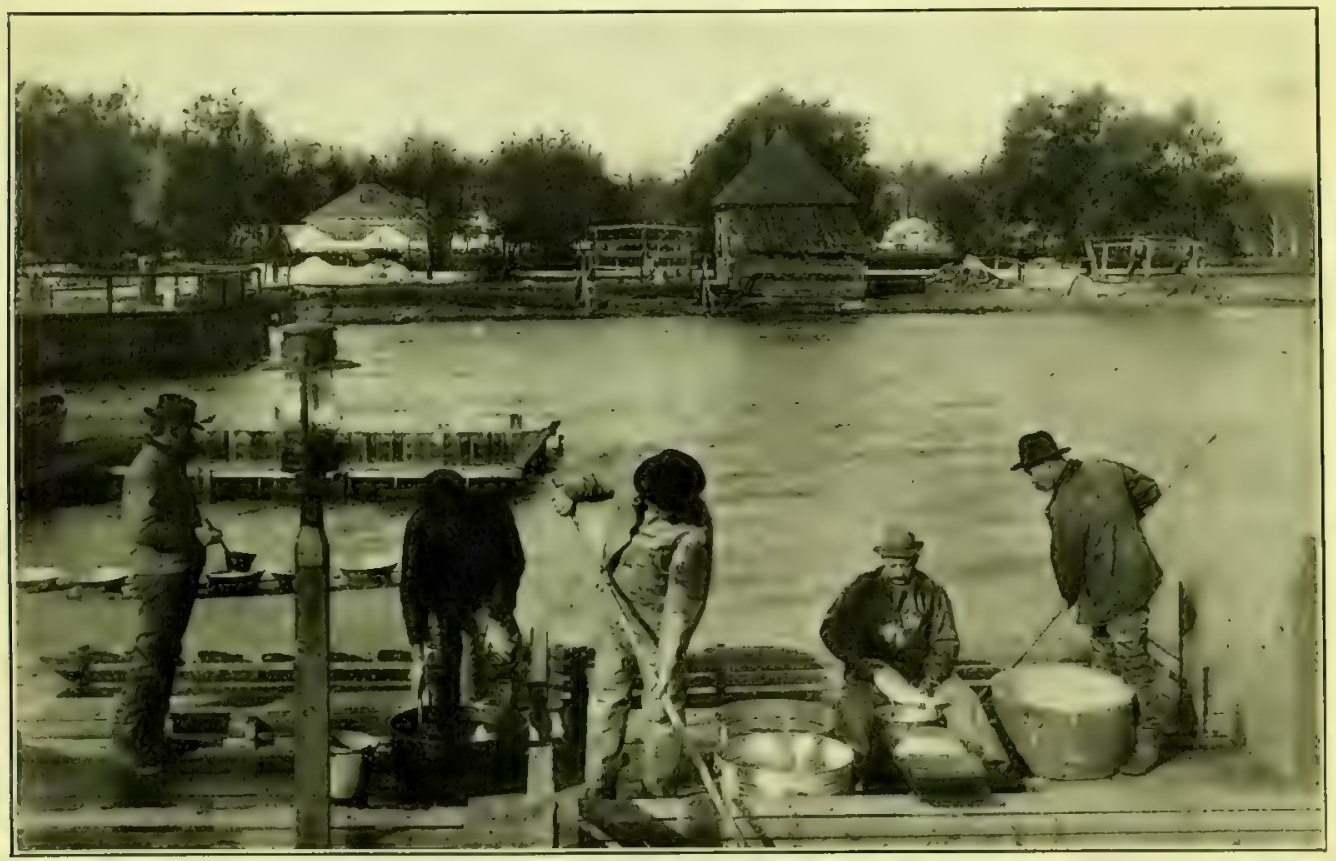

Fitc 6-Two men with dip nets are lifting fish from crates (male whitefisl in one crate, females in another) into the tubs at the spawntaker's right. The pan of eggs is passed to the man at the extreme left, who "washes themi up" before they are put into the neighboring tub for water hardening and removal to the hatchery. (Detroit River, Michigan. 

FISHES OF THE GREAT LAKES.

For the maintenance of the fisheries of the Great Lakes the Bureau operates hatcheries at Put-in Bay, Ohio, Northville, Mich., Duluth, Minn., and Cape Vincent, N. Y. At Cape Vincent the work consists largely in hatching and distributing the product of eggs received from other hatcheries, Lake Ontario not being a fruitful field for the collection of eggs.

\section{WHITEFISH.}

At Put-in Bay station in the fall of 1907 the collections of whitefish eggs reached a total of $336,000,000$, the largest on record for any station. ${ }^{a}$ In this locality the eggs are in large part obtained by direct purcliase from the fishermen, who have expelled and fertilized them as they removed the fish from the nets. In addition it is customary to pen 8,000 to ro,ooo fish in crates at points convenient to the base of operations. These fish are obtained from fishermen at a nominal price for use until after spawning, when they are returned to the fishermen to be marketed. As it has not been practicable to confine the fish successfully for a very long time, this procedure is not undertaken until they are nearly ripe, the total period of confinement from the beginning of the collection to the close being about three weeks.

The crates used for penning the fish are i 6 feet long by 8 feet wide by 6 feet deep, and have a partition dividing each crate into two compartments 8 feet square by 6 feet deep. Each compartment is provided with a false bottom, which may be raised at will while the fish are being manipulated, and can be shoved down against the stationary bottom afterwards. For convenience in handling the crates are made "knock down," and thus can be easily removed from the water and used year after year. While in the water they are held in position by floats 52 feet long, the crates placed between them endwise, five crates forming a raft. Only 12 inches of the crates extends above the surface of the water. The rafts are held in place by stakes driven into the bottom of the bay. Of the total number of eggs collected about 25 per cent are taken from fish confined in crates.

Another important field station for the collection of whitefish eggs is in the Detroit River, where operations are conducted from the Northville (Mich.) station. Here the eggs are derived from fish caught for fish-cultural purposes by market fishermen who operate under permits issued by the Bureau. The fishermen are willing to incur all expenses of the collections, as well as the losses from penning, for the privilege of disposing of all the marketable fish after the Bureau has taken the eggs. Penning stations are located accessible to the seining

a Since this writing another spawning season has passed with a record for the Put-in Bay station of over $373,000,000$ whitefish eggs. 
grounds, and all fish are transferred to the crates before being spawned. Spawntakins operations are conducted daily thronghout the entire period while the fish are penned. About 75 per cent of all the females confined in crates yield good exrss; the remainder either cast their eggs in the crates, become plugged, or fail to ripen.

At the Put-in Bay station the Downing jar, an open-top glass vessel with pitcher lip, devised by the superintendent, has supplanted other forms of hatching jars. In each of these jars $4^{\mathrm{T}}{ }_{2}^{2}$ quarts of green eggs to $5 \frac{1}{4}$ quarts of eyed eggs are subjected to a flow of 4 quarts of water per minute. The jars are arranged in so-called batteries, which are described in the Manual of Fish Culture elsewhere cited. The batteries at Put-in Bay are of the type known as single batteries, each having an independent water supply. They have some new features, notably, for economy in arrangement, the alternation in position of the jars in vertical rows, thus making it possible to bring the troughs more closely together. In the batteries at this station there are 1,692 jars and the flow of water through them is so economically arranged that only 330 gallons per minute is required when all are in operation. This type of battery is the one commonly used at the Bureau's stations, caller single battery to distinguish it from the double battery at Detroit. ${ }^{a}$ The Detroit hatchery is equipped with I, 487 Chase and Downing jars, and a total of $44 \mathrm{I}$ gallons of water is required when the entire battery is in operation.

At Cape Vincent station the battery is a single tier, but the arrangement of the jars is not so compact and the tiers are not so well set up as to economy in water supply, 492 jars requiring a total volume per minute of 123 gallons. At Swanton station a single battery of 606 jars requires a total volume of 227 gallons per minute. The batteries at Detroit and Put-in Bay are constructed entirely of wood; the battery at Cape Vincent was originally of wood, but as the troughs began to decay galvanized iron was substituted without removing the original stand on which the wooden troughs rested. At Swanton the supply troughs in the battery are also of galvanized iron, the first cost of which is more than for wood, hut taking into consideration durability of material, may be considered more economical.

\section{PIKE PERCH.}

B3y methods similar to those pursued in the conservation of whitefish egres, pike perch ewes also are extensively collected, the most important liedd, as with the whitefish, heing within a fo-mile radius of the I'ut-in Bay station. HIere and at other points on the Great Lakes the esess are all ohtained from ripe fish as causht, the perming of the pike perch hy methods described for the whitefish having proved not feasible in the sheltered hays where such work might other- 
wise be possible. The method of spawntaking at Put-in Bay is in general as follows:

On account of the adhesiveness of the eggs a wooden or fiber receptacle is used instead of the usual tin spawning pan. A liberal quantity of milt is applied, the mass is thoroughly stirred with a feather or with the bare fingers, and a little water is added. 'Then pan and contents are lowered into a keg, containing about 2 gallons of water, and the pan is carefully emptied. This process is repeated until the keg is about one-third full. The eggs are now left undisturbed until spawning operations are ended-not over two or three hours; then water is added, a little at a time, until the keg is nearly full. Some of the water is then poured off and more added, this process being continued until all the milt is washed off and the eggs are thoroughly water hardened.

The chief precaution during the water-hardening is this constant pouring off and addition of water. Care must be taken in pouring the water to have it fall not directly on the eggs but against the side of the keg. During this period the eggs must not be stirred, for the reason, it is said, that such motion tends to rupture them. It is also important to avoid exposure of the eggs to the air, since because of their adhesiveness they will form in a nearly solid mass. When they are sufficiently water-hardened they may be separated by gently loosening them with the bare hand. After separating them it is necessary to change the water frequently until they can be transferred to hatching jars.

The fact that pike perch spawn in the spring, while fall is the spawning season of the whitefish, makes it possible to utilize the same batteries and other hatching equipment for both species.

In order to overcome the adhesiveness of pike perch eggs and prevent their forming unwieldy masses, it was formerly considered necessary to use muck, or starch in the water into which the eggs are placed immediately after fertilization. 'The use of muck has now been entirely abandoned and neither starch nor muck is used at Put-in Bay.

At Swanton, Vt., the pike perch is regarded as of more value as a game fish than for the maintenance of a commercial fishery. The hatchery is stocked with eggs taken from fish captured purely for fish-culture purposes from the waters of Missisquoi Bay and River. The conditions under which the eggs are taken are more favorable than those existing on the Great Lakes, it being possible to pen the unripe fish for a week or more while maturing, the penning crates being located in a current of water in the river. Delivery of the eggs at the hatchery is also more expeditious.

In the manipulation of eggs here the methods are somewhat different from those just described. After impregnation in the usual manner a little water is added and the eggs are left for five to eight minutes; then more water is added and the eggs are withdrawn carefully into half a bucket of water into which two 
tablespoonfuls of ordinary corn starch have been thoroughly stirred. Here they are allowed to remain ten minutes. The bucket is then filled with clear water and the washing process begins, the water being replaced until only clear water remains with the eggs. They are then stirred continuously with the hands for a period of forty-five minutes, the bucket being at the beginning about one-third full of clear water, to which more is added during this time. At the end of the continuous stirring the worst period of adhesion is over and from that time on the eggs may be stirred and fresh water added every hour until they reach the hatchery. Here they are held in a tub of running water overnight, then screened, measured, and placed in jars on the batteries.

It will be noted that the two methods of manipulating the eggs are quite at variance. There are so many factors to be considered that it has not yet been decided which procedure is best.

Pike perch eggs require more care than do the eggs of any other species handled by the Bureau. When received they are uswally massed together in lumps and must first he separated with the bare hands and passed througl a screen of soft bobbinet before being placed in the jars. While in the jars they require constant attention and must be frequently separated, it often being necessary to take down individual jars several times and pass the contents through the bobbinet screen.

Although pike perch are found in ripe condition in water ranging from $38^{\circ}$ to $60^{\circ}$, more eggs are taken in a temperature ranging from $38^{\circ}$ to $50^{\circ}$ than above $50^{\circ}$, and the hisher temperature seems to be most farorable for hatching the maximum number of fry. Unfortunately, however, the water of the hatcheries is usually of the colder temperature in which the fish spawn, and a high perecintage of fry has therefore been unattainable. In average production in fry of 50 per cent of the eggs taken may be regarded as very good.

\section{LAKE TROUT.}

The station at Northville, Mich., with its several other lines of fish culture, is also the principal center of the lake trout work, and has a record of over $58,000,000$ such eggs in one season. ${ }^{a}$ As the spawning season is short; however, and is at a period of the year when the fishermen, on account of rough weather, often can not set or take up their nets at will, the collection of eggs must necessarily vary in quantity and quality from year to year according to weather conditions.

The data for one season show the average weight per fish to have been $7 \cdot 4$ poumel ; that 66 per cent of the eatch of females yelded eggss; and that the cogs averaged two-thirds of a fluid quart per fish.

a Since this writing another spawning season has yiclded $71,000,000 \mathrm{eggs}$ at the Northville station. 


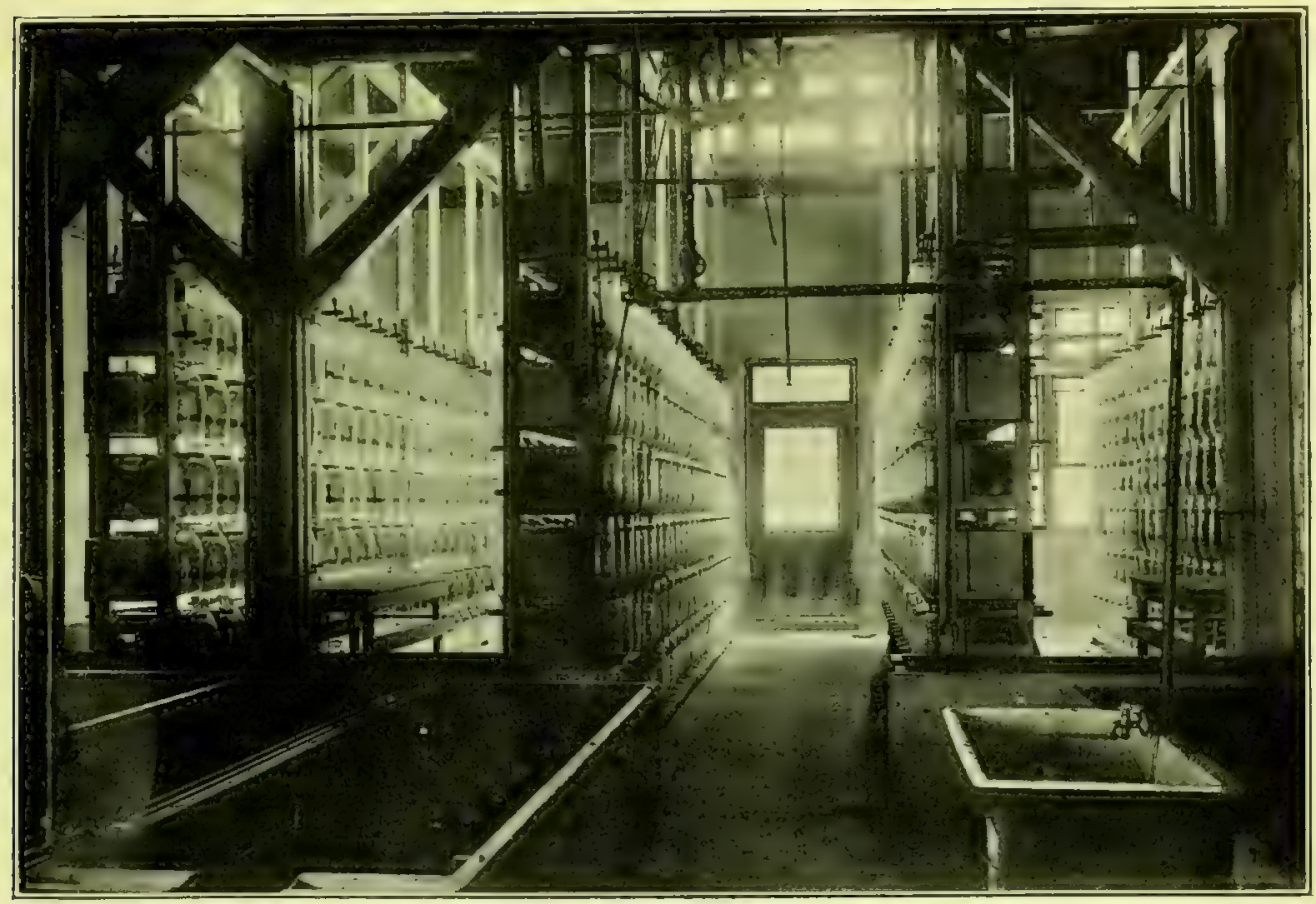

Fig. 7. - Interior of one wing of hatchery at Put-in Bay, Ohio, showing four batteries and the tanks (left foreground) into which the fry are carried by the flow from the jars.

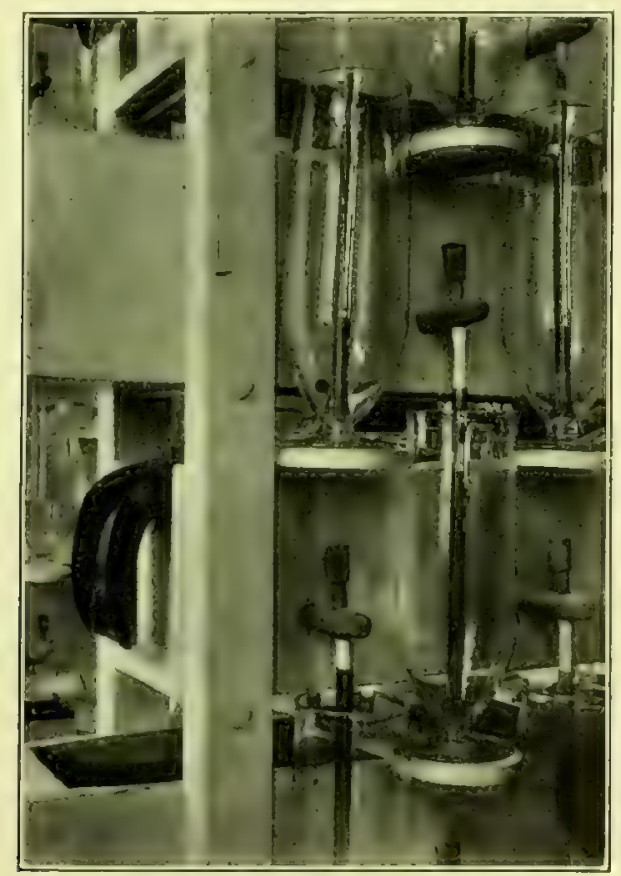

Fir. 8,-Downing jars set up for use on "battery" at Put-in luy station, Ohio. The troughs into which the water flows from the pitcher mouth of the jars serve also to supply the jars in the next tier, by means of the wooden faucets, and there is a small overflow at alternate ends of each trough. fish and pike perch. 

The hatchery equipment for lake trout at Northville is the common form of wire tray, stacked in troughs of the Clark and Clark-Williamson types. ${ }^{\text {s }}$ The collections in this region have increased so greatly in recent years, however. that they have outgrown the capacity of the hatchery, and it has been necessary to deepen some of the Clark-Williamson troushs to accommodate more trays during the eying period of the eggs. The deeper troughs are 15 feet long and $3 \frac{1}{2}$ feet wide, with a division through the center the entire length; the width therefore is that of a pair of troughs having a common bottom. The outside depth is I 8 inches. Each of the deep troughs contains, besides the bulkhead, I 5 compartments 9 inches by ro inches by $16 \mathrm{I} / 2$ inches deep, with a capacity of 16 trays $181 / 2$ inches long by $9 \frac{1}{2}$ inches wide, on each of which may be placed, if crowded, 10,000 eggs. The total maximum capacity of each pair of
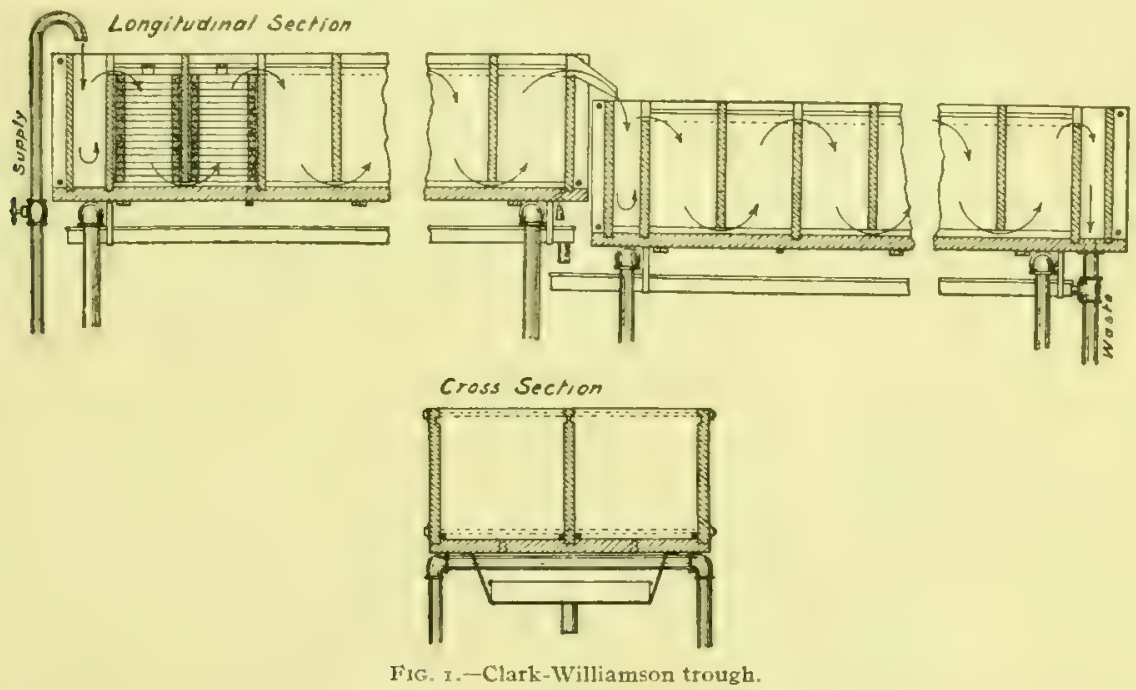

troughs is then $4,800,000$. For best results, 8,000 eggs to the tray, or a total of $3,840,000$ to each pair of troughs, is a proper number.

During incubation the eggs seem to do equally well in either up or down current of the Clark-Williamson troughs; at other stations where eggs are incubated in stacks of trays the Williamson type of trough is used.

As lake trout eggs are taken from fish that have been caught in nets hauled into fishing tugs by steam power, often during rough weather and frequently after the nets have been inaccessible for several days, the percentage of good eggs is not equal to that secured from most of the species manipulated. Consequently a large force of young women, who are more deft with their fingers than are men, are temporarily employed to pick over the eggs. A shallow trough with water flowing through it is provided for this work; in this trough, standing 
above the water on four short legs, are wire baskets, one for each egg picker, into which to throw the dead eggs. The farther side of each basket, to the picker's right, has a high back to stop the eggs as thrown from the tweezers; thus making it unnecessary for the eyes of the picker to follow each egg, and thereby facilitating the entire operation.

\section{THE BROOK TROUTS, CHARS, AND EASTERN SALMONS.}

For brook trout eggs (Salvelinus fontinalis) the Bureau depends largely upon commercial trout raisers, eyed eggs being obtained from them at lower cost than it is possible to collect from wild fish at most places or from brood fish maintained only for their eggs. About 8,000,000 eggs are annually purchased from ten to eleven dealers. For the purpose of making a just comparison as to quality and final cost of fish produced from each purchased lot the eggs receited from each dealer are distributed to several hatcheries, that all may be alike subject to different conditions of quality and temperature of the water supply.

At some stations, however, eggs from wild trout are more satisfactory. It has heen found that eggs from the domesticated fish hatched and reared in spring water which is not subject to seasonal variations do not produce good results where the temperature of the water supplying the hatchery is below $35^{\circ}$ or is subject to variations of several degrees. Vermont and Colorado are the only states in which eggs of the wild brook trout are collected in sufficient numbers to stock the Bureau's hatcheries in those states as well as to have a surplus for distribution to other hatcheries. It is interesting to note, further, that in Colorado, where the eastern brook trout is an introduced species, the eggs can be collected in greater numbers and at less cost than in any other state.

In Vermont ${ }^{\alpha}$ eggs are obtained from trout inhabiting artificial lakes on private preserves. During September and Octoler principally, but in some localities leginning sometimes as early as July and continuing into November, the fish ascend the streams in large schools on each rise of water. The fish culturist has only to provide suitable racks and traps in anticipation of the period of migration, constructing them in the streams that have been dammed to make the lakes. The fish are dipped from the trap into adjacent pens above the rack, the pens being kept covered to guard against the escape of the fish in case of a possible flood.

A field station of this character is sometimes managed by one man, who constructs the trap, rack, and pems, carcs for and strips the fish, and then cares for the eurs, which are incubaterl until ered in stacks of trays in the Milliamson type of troughs, then are packed and slipped to the central station at St. Johnsbury.

a'ritcomb, J. W.: WVild trout spawn; methods of collection and utility. Proceedings of the American lisheries Society for 1897, p. 73-86. 


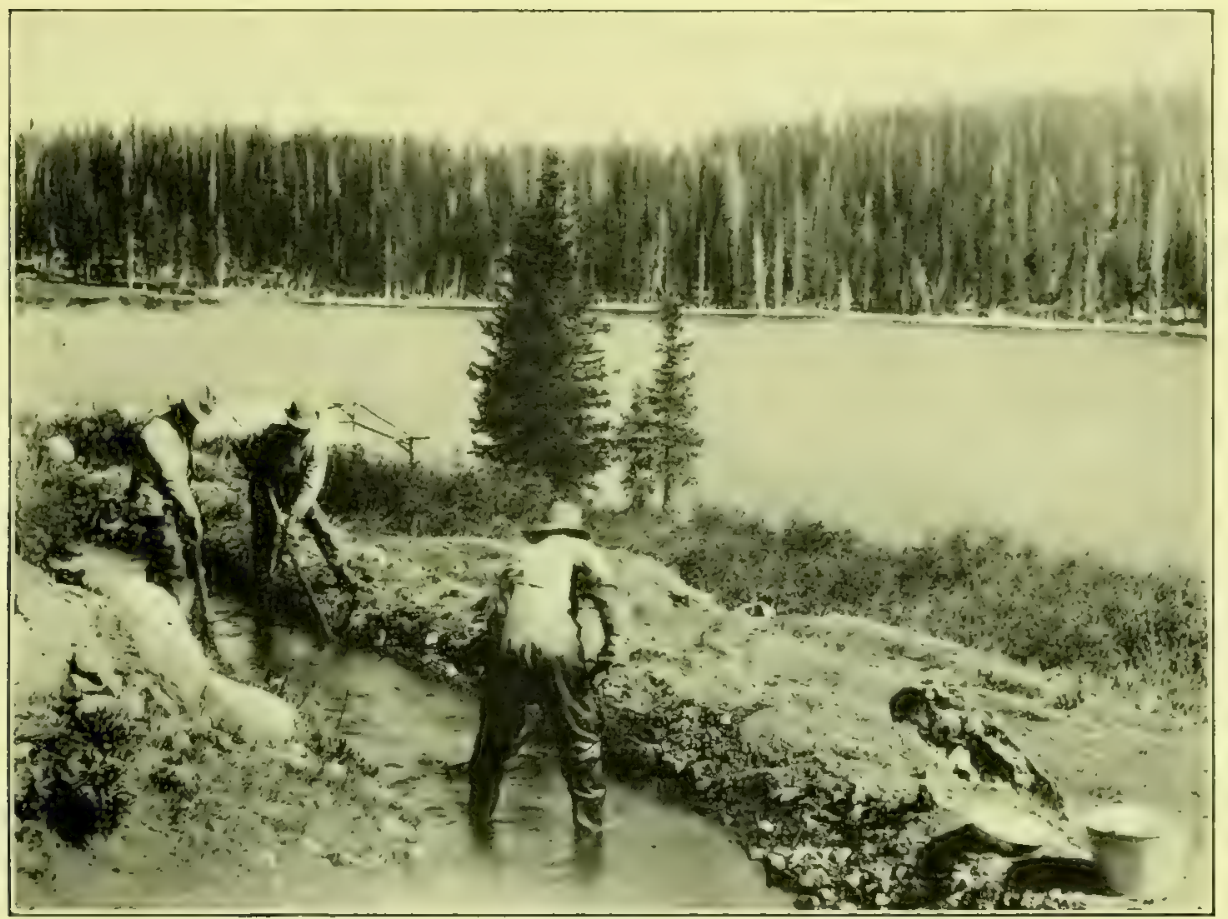

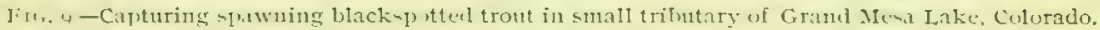

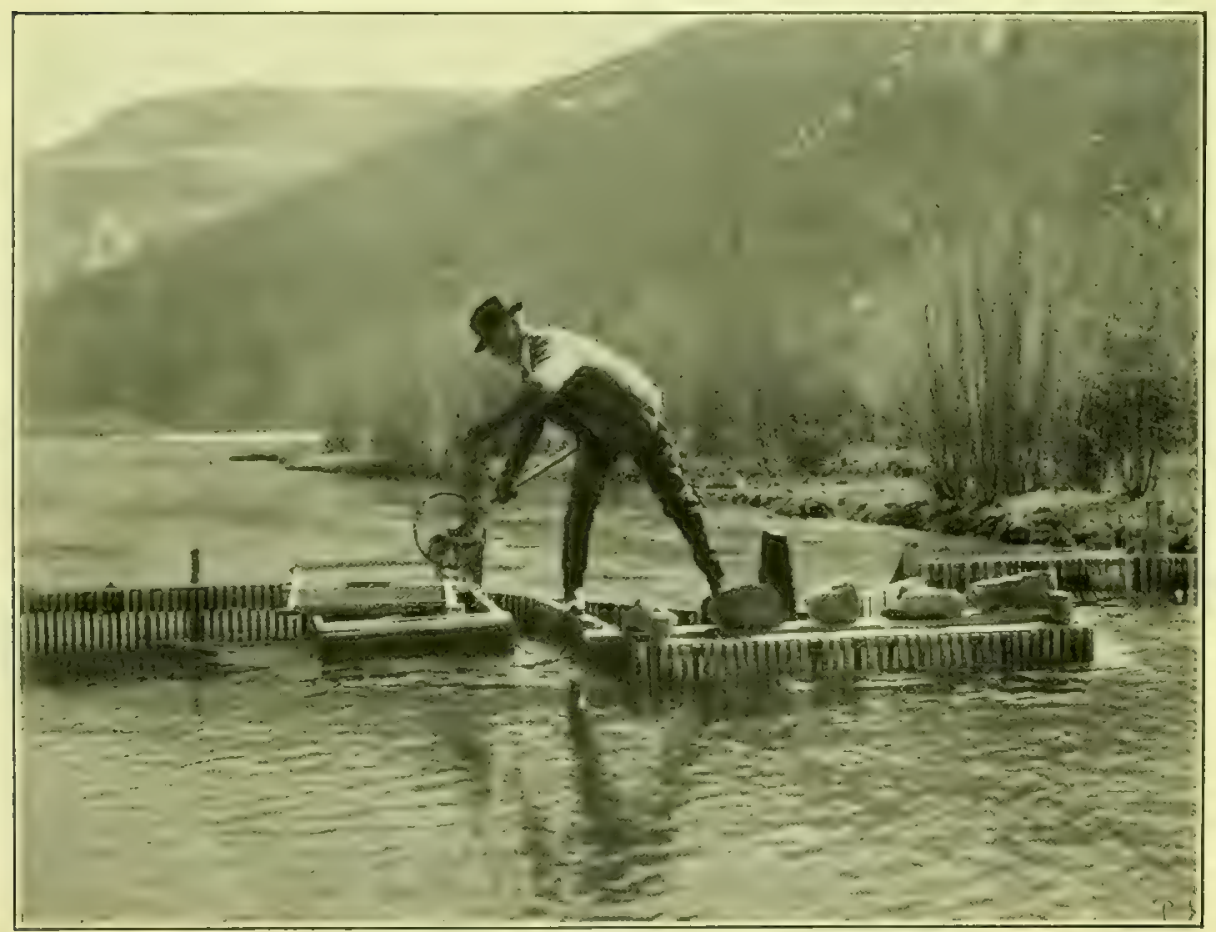

FIG. I0.-Trap for capturing spawning rainbow trout at mouth of principal tributary to I ake St. Christobal, Colorado. 

The construction of the racks under the many varying conditions which are wont to prevail requires good judgment and extreme care. Such barriers must be nuade in anticipation of and providing for floods and must be fish-tight. One small hole large enough for the entrance of one fish may result in the escape of the entire lot.

The eying stations adjacent to these collecting stations are small inexpensive structures, a shanty 12 by 16 feet being adequate to eye a million eggs.

To compensate for the eggs taken from these waters, about 25 per cent of the fish produced therefrom are returned to them, this being an ample proportion to keep them well stocked. The parent fish are always retumed to the waters from which they were captured.

Eggs of the landlocked salmon (Salmo sebago) are collected by methods quite similar to those pursued in the brook trout work. Although the range of this species has been extended, the field of egg-collecting operations is almost exclusively the native habitat in Maine.

Perhaps the most extensive trout-culture operations in the world are conducted from the station at Leadville, Colo., in connection with which are field stations for the collection of eggs of wild trout of three species. The output of the Leadville station for 1908 was as follows:

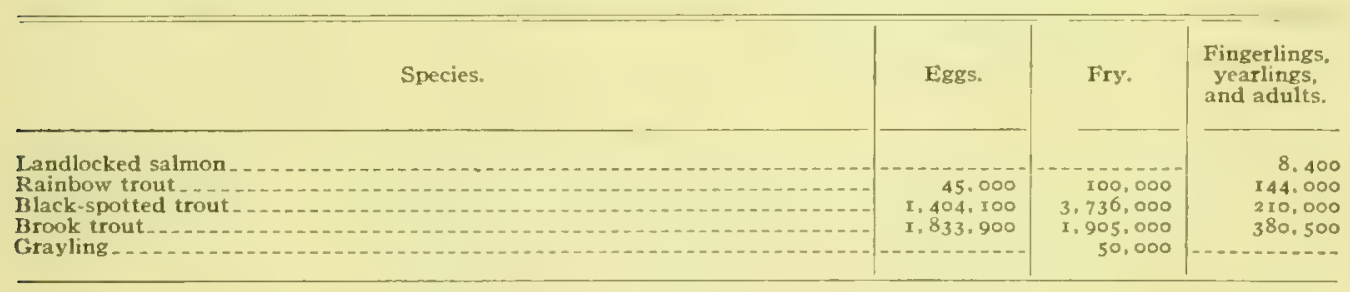

SPAWNTAKING IN COLORADO.

To see the methods of work in Colorado it may be well to follow the spawntakers as they leave their camp on one of the Grand Mesa Lakes for a day's work with the native trout of the Rocky Mountains (Salmo clarki) at Big Island Lake, ro,ooo feet above the sea level.

Each spawntaker is provided with a neck yoke and two ro-quart buckets in which to bring in the results of the day's operations. The fish have assembled in great numbers around the outlet of the lake, where as many as can be conveniently handled are caught at each haul of the seine and the ripe ones immediately stripped. Work at this point may continue all day or it may be advisable after a time to seek other spawning grounds, perhaps at the mouths of small inlets where the water from melting snow is flowing into the lake.

A most interesting phenomenon in connection with this work is the run of trout around the island from which the lake derives its name. Every two or 
three years, and possibly more often, at some period during the spawning season there is a procession of fish in twos, threes, and fours around this island. They follow the indentations of the shore line closely. There is no apparent break in the procession, the line being visible from any view point on the shore. It usually continues, moreover, for several days. A zoo-foot Baird collecting seine run from the shore line of the island to form an obtuse angle intercepting the run for ten minutes will be full of fish. The spawntakers, standing about the hag of the seine, in two or three feet of water, proceed to strip the fish in the seine while the procession closes in, the line of trout winding in and out about the legs of the men and apparently in as large numbers as before.

The spawntakers with their full pails of spawn proceed to a station near their headquarters, where all eggs are spread on trays and the latter are stacked closely in Williamson troughs supplied with water from an adjacent lake. Here the eggs are eyed preparatory to shippines a portion of them to the Leadville and other stations. Some are hatched at the field station to replenish the waters from which they were collected, or other waters in the vicinity.

\section{REARING METHODS.}

At most stations a portion of the fry are reared to fingerlings, and at some stations it has been found advisable to carry brood fish, hoth of brook trout and rainbow (Salmo irideus).

The latter, a native of the streams on the Pacific coast, has been domesticated and successfully propagated at stations in Missouri, Iowa, Virginia, West Tirginia, and Tennessee. At stations farther north whose minimum water temperature is usually lower and subject to extreme changes, it has been cultivated witll varying, but on the whole rather negative, results. It has been successfully acclimatized in some of the more northerly states, notably in Michigan; but it does not thrive in waters subject to extremely low temperatures during the winter months, and in New York and the New Eingland States has proved in most streams a failure.

The domesticated brood fish of either species are usually the product of exes collected from wild fish, and are reared in the usual manner. The young fish may be confined for the first four or five months, or until 3 to 5 inches in length, in the hatching troughs or in a battery of outdoor rearing troughs of dimensions and in other respects quite similar to the indoor troughs, about i 2 feet long by 14 incheś wide. Care must be taken, however, to guard against overcowding as the alevins increase in growth. 'The actual number of young fish of a given age which can be successfully carried is dependent upon the quality of the water supply, temperature leing an important factor, not only as to the number for a given space, but also as to their rapidity in growth. At the White Sulphur Springs (II. Va.) station, with a supply per trough of o 


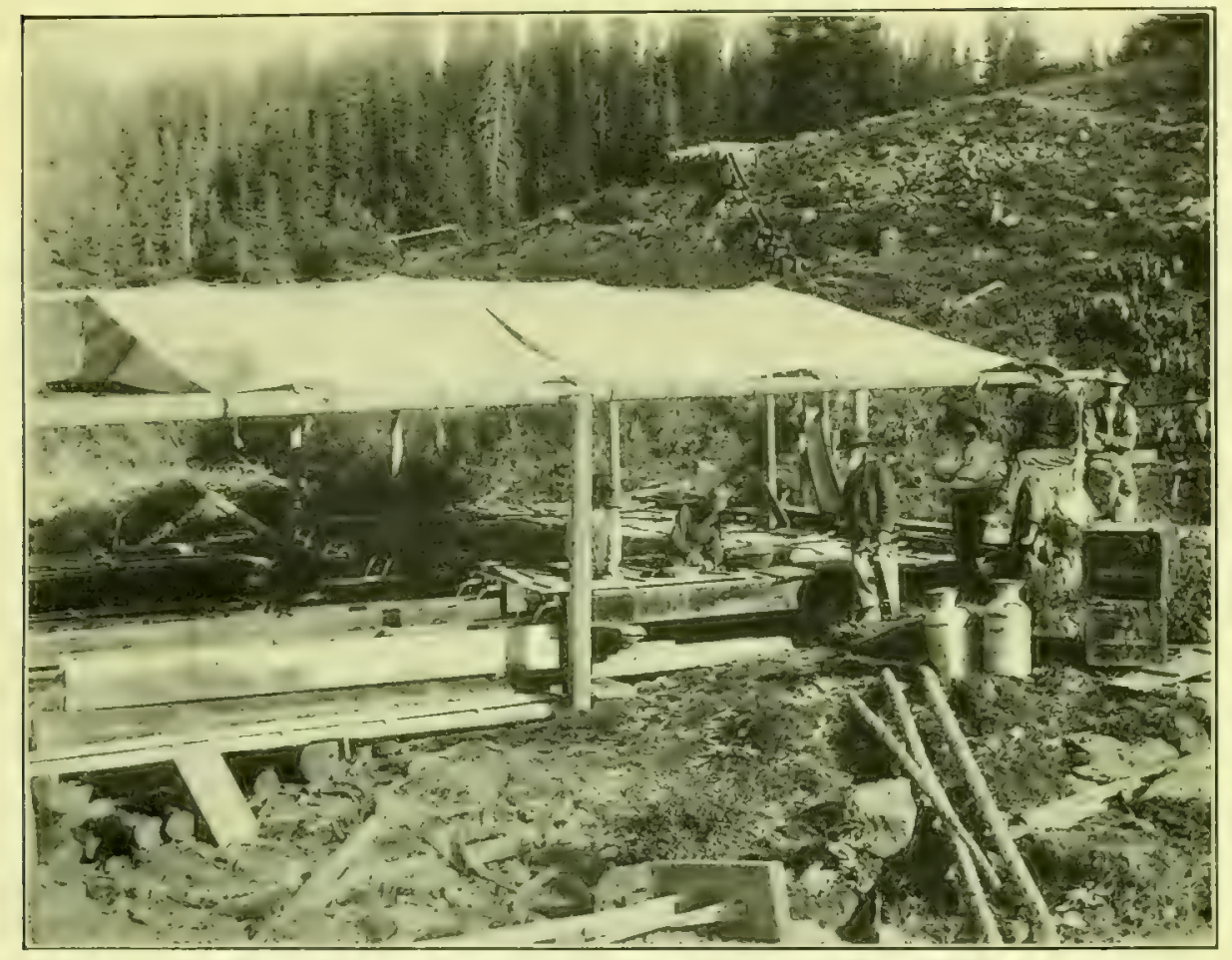

Fig. II. - Field hatchery at Grond Mesa Iakes, Colorado. Blackspotted trout eags to the number of $7,000,000$

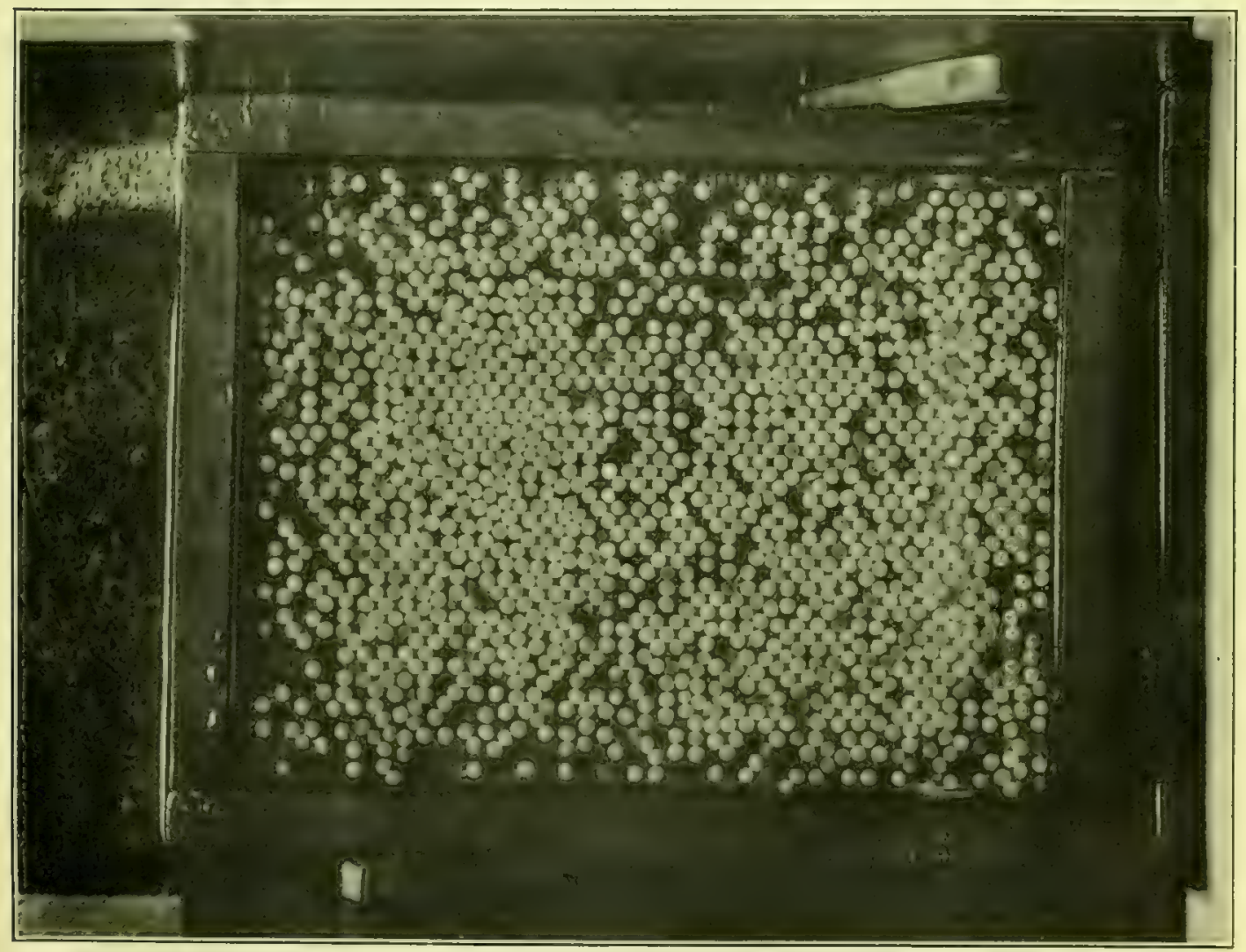

FIG. I2.-Tray of trout eggs in hatching trough. The fry fall or work through the rectangular mesh of the tray bottom incubation, and, for convenience in removing dead eggs from time to time, may be floated by releasing the wedges. 

gallons of water per minute at a temperature of about $50^{\circ}$, it is customary to hatch and hold in each trough 50,000 sac fry, 25,000 advanced fry, $12,500 \mathrm{I} / 4$ inch fingerlings, 4,000 I I 2 -inch fingerlings, 2,000 I 3/4-inch fingerlings, and I, fish 2 to 3 inches in length. Much larger numbers are often carried under similar conditions without serious loss, though often with the result that the fish prove weak in transportation.

At stations where the facilities permit, a congested condition of the hatching troughs is avoided by transferring some of the fish to outdoor ponds as soon as they have learned to take food readily, or, if weather conditions are suitable, after being fed two or three weeks. In rearing fingerlings for four to six months, concrete ponds $r 8$ to 25 feet in length by 5 to 6 feet in width and $2 \frac{1}{2}$ feet deep, with a fall of 8 to 10 inches in the bottom for drainage, give good results at the Manchester (Iowa) station. The stock ponds at Manchester, 76 feet long, I 7 feet wide, and 3 feet deep, supplied with 40 gallons of water per minute at a temperature of $50^{\circ}$ to $60^{\circ}$, have a capacity for 3,500 rainbow trout 2 years of age; $1,800,3$ years old; $1,000,4$ years old, and 900, 5 years old. 'This trough and pond system is typical for rearing any species of brook trout, as well as lake trout and Atlantic and landlocked salmons, for three or four months, which is as long as it is customary to hold young fish intended for distribution. Brood fish may be obtained by selection from the fingerlings intended for distribution, which as they derclop are transferred to stock ponds.

As soon as the fry swim up looking for food they are fed several times a day an emulsion of finely ground liver. This diet is continued as the young fish develop, with the difference that the liver is less finely ground and is given less frequently - two or three times a day being sufficient when the fish have attained a length of 2 or 3 inches. The kind of liver used varies at different stations, that of sheep, beeves, and hogs being extensively used, and the relative value of each being in the order named. The food for the larger fish consists of the liver, lungs, and hearts of the animals already mentioned.

At Manchester, Iowa, it has been found advantageous from an economical standpoint to mix the animal food, after it has been ground, with a mush made by cooking wheat middlings or shorts, to which a moderate amount of salt is usually added. After the mush has been thoroughly cooled the animal inatter, uncooked, is stirred into it in the following proportions: For fingerlings, I part animal matter and 2 parts mush; for adults, I part animal matter and 3 parts mush. Twenty gallons of boiling water and 50 pounds of wheat middlings will make about 202 pounds of mush.

The provision of food for domesticated fish is one of the greatest problems the fish culturist encounters, and has been the subject of considerable experimentation. The intensive production of natural food has not received in the United States so much attention as in Europe nor so much as the subject 
deserves. The American method of raising trout precludes the economic use of natural live food. although unquestionably the edible qualities of the fish might be much improved thereby.

For several years the roe of the branch herring (Pomolobus pseudoharengus) has been used at several stations as a substitute for liver in feeding fry and fingerlings. It is purchased from cannery men, who preserve in tins large quantities of it for human consumption, and consequently are able to sell it at a price close to or less than the cost of liver, due allowance being made for the waste in liver and the labor involved in its preparation as a fish food. The herring roe has the advantage of always being on hand in condition ready to feed and is therefore especially desirable for isolated stations. It is not customary to feed young fishes on this food after they are 2 or 3 months old.

At Craig Brook, Me., fly larvæ, ${ }^{a}$ used for a number of years in rearing trout and salmon to fingerlings, proved to be a very satisfactory food and the fish attained a more rapid growth than when fed on liver and other dead material. From a financial standpoint it was not as economical as freshly prepared liver or other animal foods, and this, coupled with the objectionable odor attendant on its preparation, had much to do with its discontinuance.

It is possible, however, to utilize animal refuse advantageously for the production of fly larre by means of a contrivance in which the material on which flies have deposited their eggs may be suspended over the water. This contrivance consists of a wooden frame, like a box without top or hottom, placed on floats and having an air-tight cover to prevent the escape of foul odors. Within the frame are two trays, the bottoms of which are made of coarse wire cloth (odds and ends of old hatching trays). Fixcelsior or straw is placed on the trays, and waste meat or other animal refuse is placed on top of this material. As the larve hatch they work through the excelsior, cleaning themselves thereby, and drop into the water. Two small trays are preferable to one of larger size, that the meat may alternately be renewed, thus insuring a more constant supply of larve. The noxious animals killed in the protection of fish may advantageously be disposed of in these trays.

\section{SPECIAL DEVICES APPLIED AT TROUT STATIONS.}

Study and experience in recent years have revealed abnormal aeration as a condition existing in various water supplies at trout-culture stations, with consequent mortality among the fish. Of the methods used to correct such abmormalities, that devised by the superintendent of the station at White Sulphur Springs, M. Va., Mr. R. K. Robinson, has proved the most efficient.

a Atkins, Chas. G.: The live food problem, American Fisheries Society, 1903; also Food for young salmonoids, Proceedings Fourth International Fishery Congress, Bulletin Bureau of Fisheries, vol. xxviii, I908, p. 839-851. 
It consists of a series of ordinary milk pans held in a frame, one above another, in numbers to suit conditions, the bottoms of the pans perforated with a nail or other pointed instrument which will leave a ragged edge to cach perforation on the underside of the pan.

This apparatus is set up at the head of the trough in such position that the supply pipe empties into the topmost pan, and the water must pass through the series before reaching the trough. By this separation into fine streams the water is thoroughly exposed to the air, thus rectifying any abnormality of air content.

At nearly all trout hatcheries it has been customary to place horizontally below the supply pipe at the liead of each trough a screen consisting of a light frame, bottomed with wire cloth or perforated metal. 'This is designed not only to break the force of the stream entering the trough but to aerate or deaerate the water and at the same time catch foreign substances and animal life-the latter at times being quite objectionable. Such screens, however, have almost invariably caused the water to spatter over the sides of the trough, resulting in constantly wet surroundings. To overcome this objectionable feature a conical perforated screen has been devised by Mr. M. E. Merrill, of the St. Johnsbury, Vt., station. When the screen is in place the current of water falls directly on the apex of the cone, and thus is spread over the entire perforated surface, accomplishing the objects of all other styles of head screens, and avoiding the spattering of water over the sides.

A device for assorting young salmon and trout was introduced in the Bureau's operations by Mr. J. P. Snyder, an employee at one of the stations. It consists of a series of screens by means of which to separate the fingerlings into sizes.

In length the screens are slightly less than the width of the troughs, to facilitate sliding them along. There should be two screens for each size of mesh. In use one screen is carefully inserted at the foot of the trough close to the tail screen, due precaution being taken that no fish are pinched and that none are left between the foot screens and the end of the trough; midway of the trough a screen should be securely fastened in a vertical position by wedging. After the first screen is in position a similar one is inserted at the head of the trough and then moved along toward the center.

As the two screens are brought closer together the fish between them become frightened, and all that are small enough escape through the mesh of the screens. The distance of the second sereen from the first should depend upon the number and size of the fish in the troughs, and also upon the number that escape through the screen. The second screen should also be fastened by wedging. Then the hand of the attendant is moved about among the fish between the screens to guard against any small ones finding a hiding place. In 
their efforts to escape some of the fish will be liung in the wire cloth, but it will be noticed that every trout which gets its head through the screen can pass or be assisted through without injury. The few which are caught in the mesh should be assisted by grasping the tail and pushing them. It would be well to refrain from feeding for about twenty-four lours before assorting the fish.

By using two or three sets of screens in different troughs at the same time one man can assort many thousands of fish in a day, and the sizes will be much more uniform than when assorted with a scaff net. Wire cloth, 6 bars to the inch each way, painted with asphaltum rarnish, will permit all brook trout under I inch in length to pass through. By varying the mesh of screens brook trout may be assorted into six uniform sizes as follows:

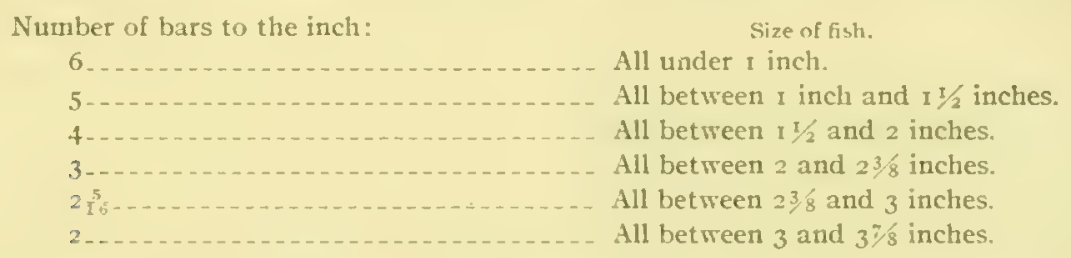

The frames of these screens are made of half-inch wooden strips grooved and tongued at the ends. These frames are one-eighth inch less in length than the inside width of the troughs and in height equal the depth of the troughs, being rectangular in form: They are covered on one side with wire cloth held firmly by copper tacks, both the wire cloth and the frames being painted with asphaltum varnish previous to tacking the wire on the frames. This not only helps to preserve the wood and keep the wire from rusting, but smooths the latter so that there are no rough surfaces or projections to injure the fish as they work their way through.

\section{ATLANTIC SALMON.}

Another important brancl of fish culture is conducted at the Craig Brook station, near the Penobscot River, not far from Bucksport, Me. While not restricted in its work to this one species of fish, the primary olject of this hatehery is the propagation of the Atlantic salmon. The decadence of this important lichery on the North. Itlantic coast, due to the ruthless but natural progress of civilization, is too well understood to call for an explanation here. Suffice it to say that to-day the Bureau is maintaining a commercial fishery for the Itlantic salmon on the l'enobseot River purely hy artificial propagation. It is the only river in the United States where this once abundant salmon is now found in sufficient numbers to support a fishery or to warrant its artificial culture, and here, with the natural conditions so changed, it is with no little dificulty that the extinction of the species is prevented. 
BUL. U. S. B. F., I 908 .

Plate LXXXIII.

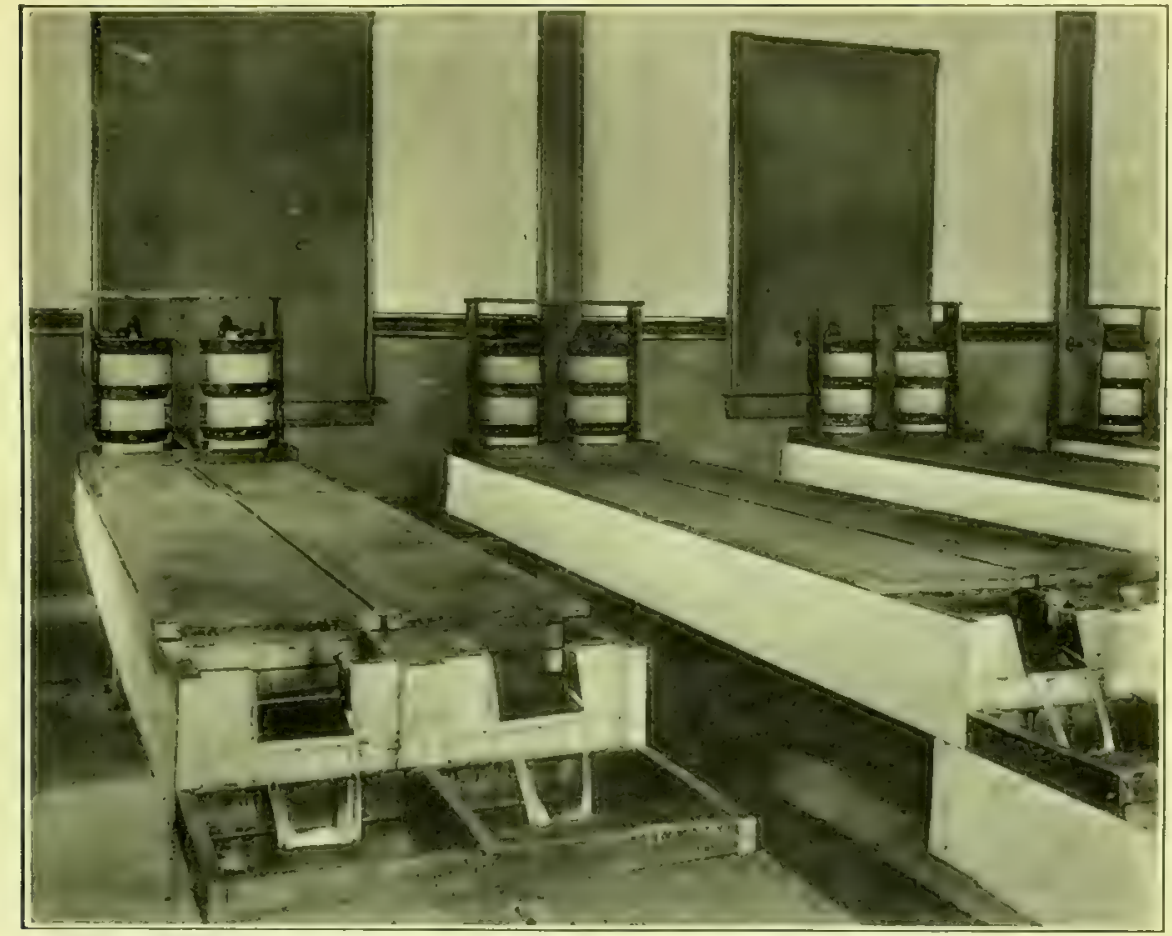

FIG. I3.- Series of covered trout-luatching troughs at White Sulphur Springs station (West Virginia) equipped with the Robinson pan aerator. (See p. 716.)

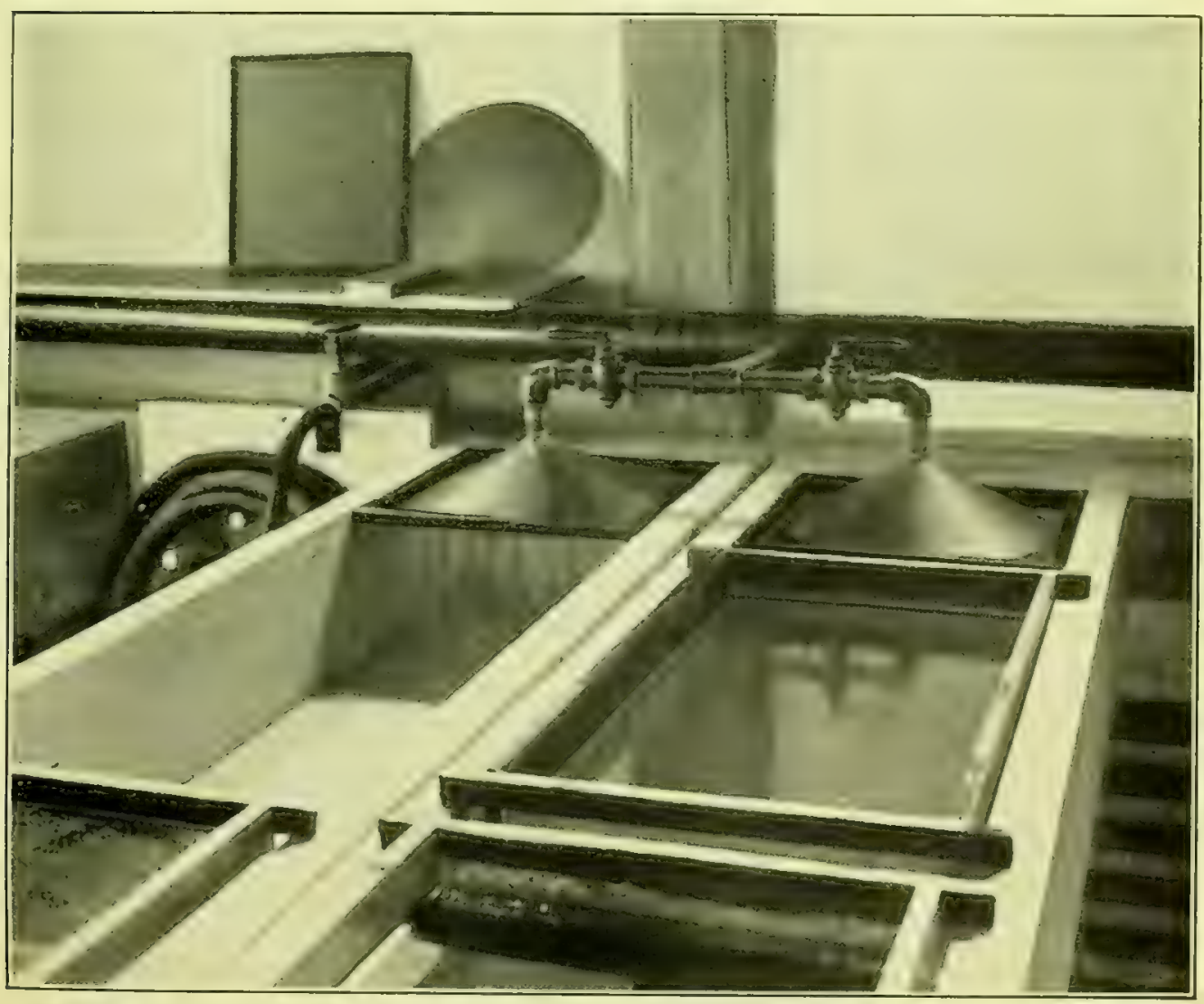

FIG. 14.-Trout-hatching troughs with Mertill aerating cone. (See p. 7.7.) Shows also tray basket of a pattern used at some trout stations, much deeper than ordinary tray and intended to hold fry after hatching. I,eft 

The operations at this hatchery, fully described in the Manual of Fish Culture published by the Bureau of Fisheries in I9oo, have undergone slight change of method and need not be dwelt upon here. The source of egg supply is the catch of the fishermen's weirs usually during the month of June, the fish being purchased and towed in live cars to the station, where they are transferred to inclosures and there retained until the spawning season, in October and November. When ripe they are stripped and the eggs placed upon wire trays, which are stacked in troughs and carefully tended until the early spring, when the eggs hatcli. The young fish are distributed for the most part as fry, but a considerable number are reared to the fingerling stage.

\section{POND CULTURE.}

Pond culture in the United States is applied only to nest-building fishes, such as the basses, sunfishes, and the common catfish (Ameiurus nebulosus). These species do not subnit to manipulation for taking and fertilizing their eggs, but fortunately a very large percentage of the eggs are fertilized when the spawning functions are permitted to occur naturally, and the parent fish care for and protect the young until the latter are free swimmers. The cultivation of these fishes, therefore, consists in providing ponds which shall give to the maximum number of freeding fish and their young all the essential conditions of a natural environment, while at the same time protecting them from their enemies and holding them under control.

\section{THE PONDS.}

Economy in construction usually dictates the shape and area of the ponds, but an independent water supply and drainage to each is desirable. For convenience of the fish culturist the area usually ranges from one-fourth to one acre, although some ponds of larger size are desirable. It was formerly considered essential to have at least one-fourth the area of the breeding pond not exceeding I foot in depth, but it has been found that the deepening of the shallower portions to a minimum depth of from $\mathrm{I}$ foot to $\mathrm{I} / 2$ feet has largely increased the productive area.

The presence of aquatic plants in fish ponds is a prime essential. - The young of the nest-building fishes do not accept artificial food, and must therefore have their natural diet of minute animal life, the abundance of which is dependent to a large extent upon the character and abundance of plant growtl. Plants are also important as oxygenators of the water and afford shelter and shade for the fish. The selection and control of aquatic vegetation, therefore, is a matter to which the fish culturist must give much attention, and experience at the various stations indicates that it olfers a direct means by which the output 
of the ponds may be increased. The subject has not been sufficiently studied, but observations so far made suggest various practical possihilities of much interest. ${ }^{a}$

The supposed loss of young fish by the voracity of their parents induced the practice of partitioning the ponds in such a manner as to confine the adults in one portion while permitting the young to escape through the partitions to safety. It has been found, however, that the loss from cannibalism is due chiefly to the young fish themselves, and accordingly they are separated from their parents or not, merely as a matter of convenience. The principal precaution against cannibalism is, instead, the provision of an abundant food supply, to divert the fish from each other.

\section{FOOD FOR THE ADULT FISHES.}

Food for the adult fishes is largely a matter of local conditions and convenience. Chopped fish is extensively used at some stations, and crawfish, so abundant in some localities, when chopped make arlmirable food for the adult stock. The basses, although not appearing to care for pollywogs as naturally present in the ponds, will devour frog tadpoles voraciously if the latter are seined out and thrown back by the fish culturist, but they absolutely refuse toad pollywogs when similarly served to them. Minnows are a good food, but should not be introduced into the ponds near the spawning season, as they eat not only the small forms of life upon which the fry depend but often eat the fry as well. Dead minnows thrown into the water one at a time are greedily taken by the adult basses.

Adult bass may also be advantageously fed on strips of beef liver about 2 to 3 inches long and from one-half to one-fourth inch in width or thickness; and prepared food consisting of ground liver or other animal substance mixed with a mush of cooked shorts, corn meal, or middlings has been employed in a rather limited way. It is worthy of note that for this prepared food to be attractive to bass it must ordinarily contain at least two-thirds of the animal substance, whereas prepared food containing only so per cent of the animal material is taken witl avidity by trout.

It has been quite conclusively demonstrated that one of the principal causes of loss among brood fish is overfeeding, resulting in a fatty degencration. 'his loss has been largely overcome by reducing the food supply and at the same time varying the kind of food furnished.

ARTIFICIAL NESTS.

In the cultivation of the small-mouth bass, and to some extent the other species, it has been found profitable to provide artificial nests. These are of

a 'Titcomb, J. W.: Aquatic plants in pond culture. Bureau of Fisheries Document 643. 1909. 


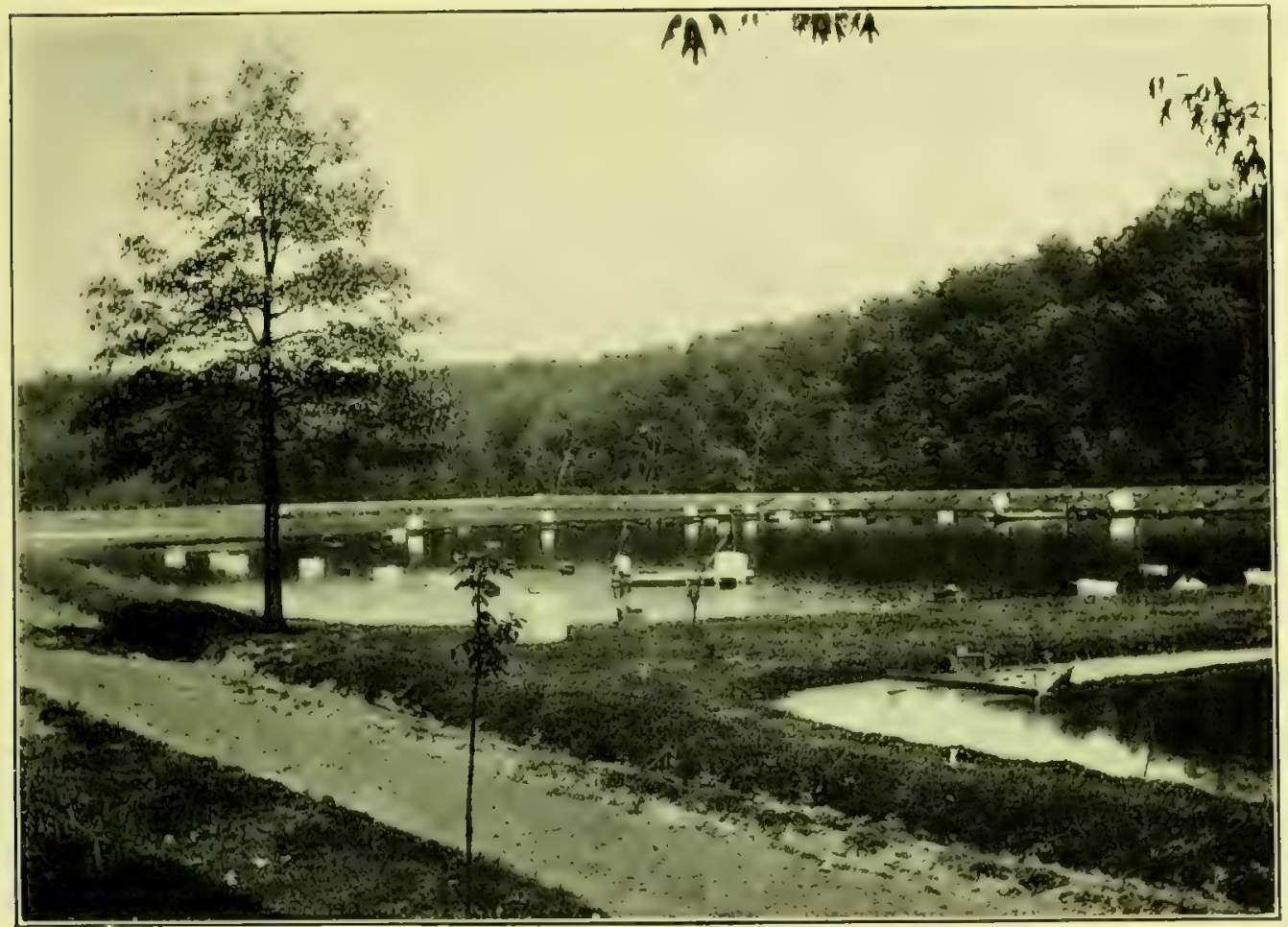

Fic 15 - Placing cheese-cloth retainers over nests containing bass fry about ready to swim up. Most of the mests are seen covered with retainers. When a nest is occupied it is numbered and complete record kept of its different stages. The retainers are to confine the fry for convenience in transferring to other ponds tomake room for following broods. (Mammoth Spring station, Arkansas.)

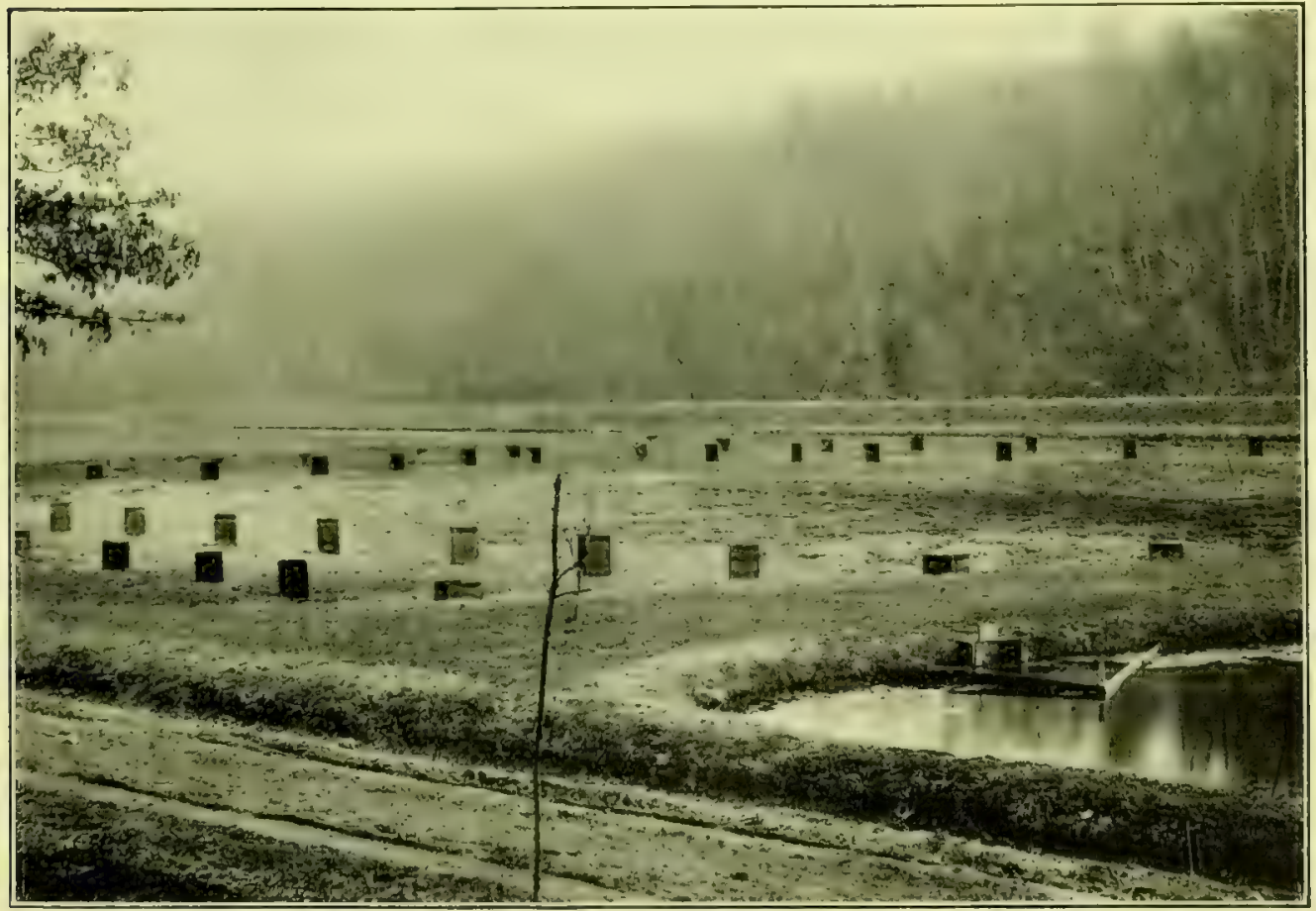

FIG. 16.-Pond drawn down and nest boxes placed for spawning. Area of pond, 55,000 square feet; 50 nests in pond; I50 breeding smallmouth black bass. (Mammoth Spring station, Arkansas.) 

various design, but embody in general some sort of a container for the irarel the fish require, together with a shield or screen on two or three sides. ${ }^{a}$ The primary use of screens was for the purpose of shielding the fish from view of passers-by, but the practice resulted in the discovery that the fish will accept shielded nests at more frequent intervals than when visible to each other. It is therefore of first importance that in the placing of nests the screens be arranged to meet this condition.

When shielded artificial nests are not provided it is customary to deposit here and there in the ponds mounds of coarse gravel, I 8 inches to 2 feet in diameter and about 6 inches in height, that the breeders may select and prepare their nests with these.

Large-mouth black bass, though they sometimes accept gravel mounds as nests, naturally seek a weedy bottom, devoid of gravel. Peat-like sods or similar substances put into the pond prove acceptable to this species as nesting material.

The superintendent of the Cold Springs, Ga., station endeavors to imitate nature by providing "homes" for all adult fishes whether spawning or not. For the large-mouth black bass and rock bass, hoards 3 feet to ro feet in length are laid flat under the water so that by the natural contour of the bottom spaces 5 inches to 8 inches deep are formed under the boards. Catfish (Amemrus ncbulosus), which prefer to dig their own nests, are provided with hoards either laid flat on the pond bottom or where there will be under the center of the hoard a depression an inch or two in depth. Where necessary, the boards are fastened by stakes at both ends, but when placed along the bank, where conditions are favorable for such a course, one end of the board may be driven a short distance into the embankment, while the other end is staked. After having been submerged a month or so the boards will remain in place without fastening. With proper precautions against projections these shelters do not materially interfere with seining operations.

For the crappie, roily water seems to be essential during the spawning season. At stations where there are no naturally roily ponds it has sometimes been found desirable to introduce a few carp, which roil the water in rooting around the bottom of the pond and do not seem to disturb the crappie.

\section{NUMBER OF BROOD FISH.}

The desirability of maintaining a maximum number of brood fish to a given pond area has led to a comparison of experience at the different stations in an effort to arrive at some approximate average for a working hasis. Conclusive

a One form of nest in use is the design of A. E. Fuller, described in his paper entitled "New and improved devices for fish culturists," Proceedings Fourth International Fishery Congress, Bulletin U. S. Bureau of Fisheries, vol. xxviii, I 908, p. 99 r-1000, pl. Crv-CvI.

B. B. F. $1908-46$ 
determination can not be made, of course, owing to the various factors of quality and temperature of water, abundance of vegetation and of natural food, etc., but reports from the several localities are of interest.

At San Marcos, Tex., the best results are obtained with 24 to 30 largemouth bass to the half acre; of the smaller fishes-bream, rock bass, crappie-60 to the half acre.

A I-acre pond at Mammoth Spring, Ark., supports Ioo small-mouth black hass, and an average of 2,000 fry to each productive nest has been obtained, the maximum number from one nest being 5,200.

At Cold Springs, Ga., roo adult large-mouth black bass in a pond of threefifths of an acre in area proved too many, and the number had to be recluced to 60 or 70 for satisfactory results. In general, 50 to 75 brood bass to threefourths of an acre to an acre have been found the best number at this station. Of catfish (Ameiurus nebulosus marmoratus), ioo to the acre have been found satisfactory.

Ponds at Wytheville, Va., accommodate 75 pairs of large-mouth black bass to the acre with good results; of rock bass, 300 fish to the acre.

At Northville, Mich., in a pond three-fifths of an acre in area it has been observed that most satisfactory results were obtained with small-mouth bass to the number of 29 females and 2.3 males, allowance heing made for the occasional polygamous tendency of the male.

At White Sulphur Springs, IV. Va., 36 pairs of small-mouth black bass is considered the number for a I-acre pond.

The maintenance of an abnormally large number of brood fish to a given area results in more or less loss according to species, the mortality among the hrood fish of the small-mouth black bass being greater than with the large-mouth bass and other pond fishes. The replenishing of the stock is most advantareously accomplished by securing wild fish, preferably in the spring of the year, and they may he advantageously transferred up to within two or three weeks of the spawning season.

\section{COLLECTING THE YOUNG FISH.}

It is often desirable to remore the surplus fry from a pond hefore they have left their nests, and there is now in use for this purpose a combination fry trap and retainer which is placed over the nests, taking adrantage of the fact that the fry rise vertically." This trap has proved of practical ralue in fisl-cultural ponds for small-mouth hass, and, where the nest area was not too great, for larere-mouth also. It has been used likewise in collecting small-mouth bass fry from natural lakes, and is believed to be applicable to fry of other nestbuilding fishes than the basses. 
Soon after the yolk sac las been ahsorbed, or after the fry have been feeding for two or three weeks, a portion of them are removed from the ponds and distributed to the waters they are to stock. The first crop may often be obtained by seining around the edges of the pond without the prelininary clearing away of vegetation, and for this purpose a novel casting scine has come into use at Northville, Mich. The web is rigged upon two long bamboo poles, so that the device may be operated entirely from shore, without roiling the water or unduly disturbing the fish. ${ }^{a}$

After the young fish have sought the deeper portions of the ponds, preliminary to drawing off the water to effect their capture, it is necessary to remove the aquatic vegetation, a process of much labor and expense, consisting in general of mowing under water, and carrying away the foliage by means of pitchforks and boats. Various methods and devices for this purpose have been evolved at the different stations, as described elsewhere. ${ }^{b}$

Ordinarily the assorting of young pond fishes by size is accomplished by hand manipulation with a scaff net. To some extent, however, the separation may be accomplished by regulating the size of the mesh in the nets used to effect their capture. The superintendent of the San Marcos, Tex., station suggests having an ample hag to the dip net in which quite a large lot of fish may be taken from the tub or other retainer, then passing the net gently to and fro in the water to allow the fry and smaller fish to escape, while the larger ones are retained. This method is principally used for assorting black bass, as it frequently happens there are schools of both fry and fingerlings in the ponds at the same time. Nets of one-fourth inch square mesh will permit the escape of all fish up to $\mathrm{I} / 2$ inches; one-half inch square mesh will permit the escape of all fish under 3 inches in length.

At the Cold Springs, Ga., station the superintendent uses a box 3 or + feet long by I foot wide and I foot deep, and water-tight to a depth of 2 incles. Above this 2 inches one side is covered with wire cloth instead of being closed in, the size of wire mesh being regulated for known sizes of fish. The box is partially submerged in the pond in which it is intended to place the smaller fish of a lot to be assorted. The young fish as caught are placed in the box, and then are left undisturbed for an hour or two. At the end of this time the smaller fish will have escaped from the box through the screen into the pond, when the box with the larger fish remaining in it may be transferred to another pond and emptied, or the contents may be poured into a suitable receptacle for transportation by tipping the box toward its solid side. Square-meshed galvanized cloth is used for the screen, and if the fish are given plenty of time to separate none of them are gilled, hung, or otherwise injured. 


\section{RESCUE OF FISHES FROM OVERFLOWED LANDS.}

In the upper Mlississippi and Illinois rivers there is an annual spring flood period caused by the melting of the snow in the northern forests and freshets in the local tributaries after heary rains. The period begins with the approach of warm weather, usually about March $\mathrm{I}_{5}$, and continues until about June $\mathrm{I}$, when the crest of the high water has been reached. Soon after this date the water begins slowly to recede, and usually by July is the river has reached its normal stage.

Between the extreme low and high water marks there is a variation of $\mathrm{I} 2$ or 15 feet. There is, of course, a variation in the extremes of the water level in different seasons, but seldom, if ever, does the water fail to rise high enough to flood the lowlands. The adult fishes are thus permitted to enter the overflow basins and bayous, and invariably do so during the spawning season. After spawning most of the adult fish escape to the river before the water has receded sufficiently to cause them to be hemmed in, but immense numbers of their progeny are left in the lakes and bayous where they were hatched. 'These waters gradually dry up, become choked with regetation, or overheated and unfit for fish life; some of the larger and deeper lakes and bayous, although cut off from the main river, may contain water the year around, but on account of the seepage and evaporation during the summer the depth of water in them decreases to such an extent that they freeze solid during the winter months. Sometimes the lakes from which fishes are rescued are in the hollows on farm lands, where in dry seasons crops are cultivated. Thus it will be seen that the fish imprisoned in overflow waters are doomed to destruction in one way or another.

One branch of the Bureau's operations is annually to rescue large numbers of these fishes. At present the work is confined to waters convenient of accessnamely, the overflow lakes and bayous on the low islands in the rivers and on the adjacent mainland. Many of the fisles are returned to the rivers. Another portion of the more desirable species is distributed in various other waters, ofter far from the source of supply.

It has been found, however, that the fishes rescued from these warm waters do not hear transportation long distanees without heary losses if immediately started upon their journey. Therefore a hardening process is resorted to, which concists in holding the fish in large tanks flowing through which are streams of clear cool water. To facilitate the work the Bureau has a number of field stations -one on the Illinois River and three on the Mississippi-convenient of aceess to the railroad, and eacle equipped for lolding one or more carloads of fishes for several days, or until they have become sufficiently hardened to bear transportation by cars. Adjunct to these stations are vessels, launches, and boats of various types suited to the work. 


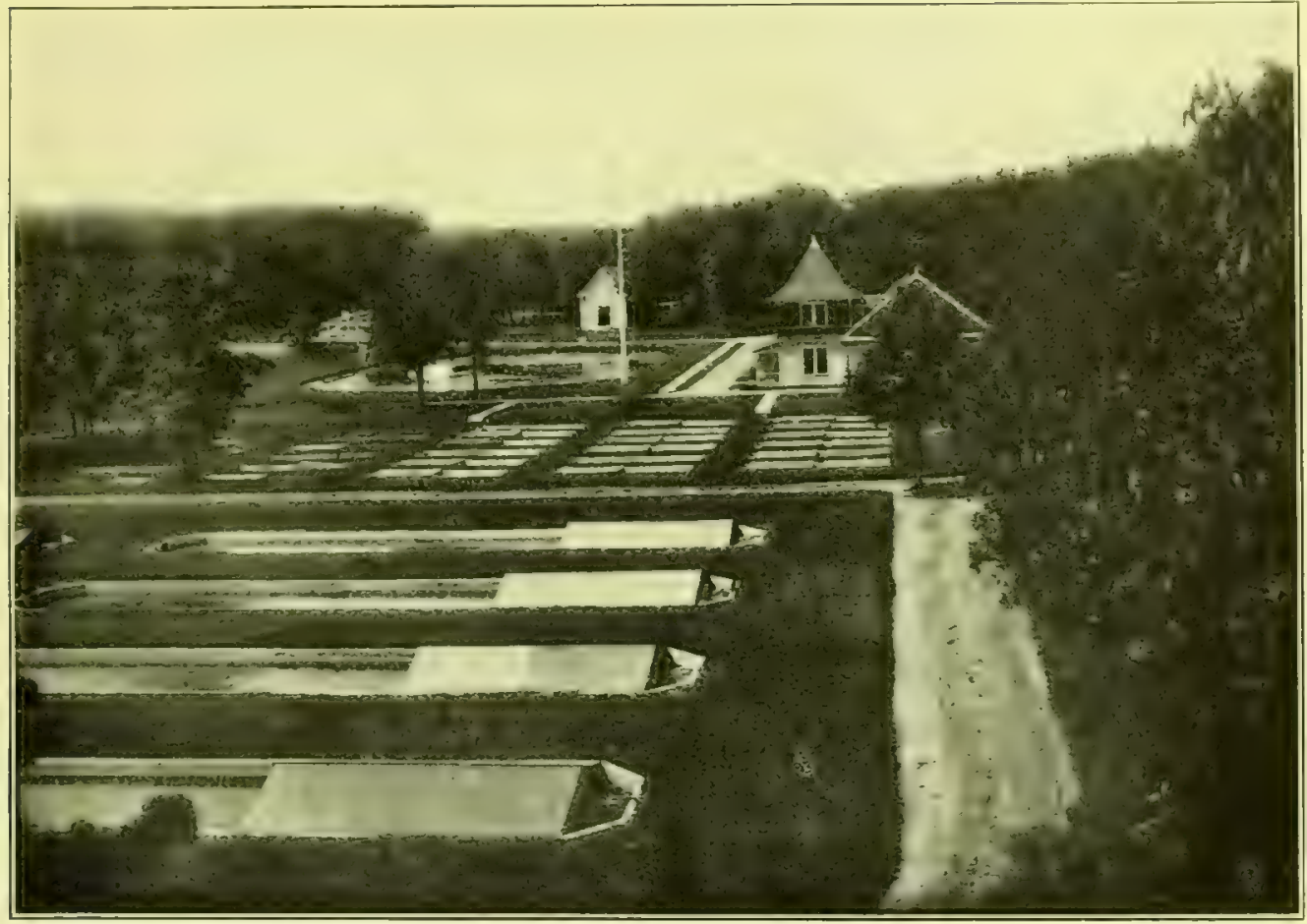

FIG. I7.-Both trout and bass are cultivated at many of the stations. This view of the station at Manchester, Iowa, Bews stock ponds in foreground, then the smallet nursery ponds, all of these for

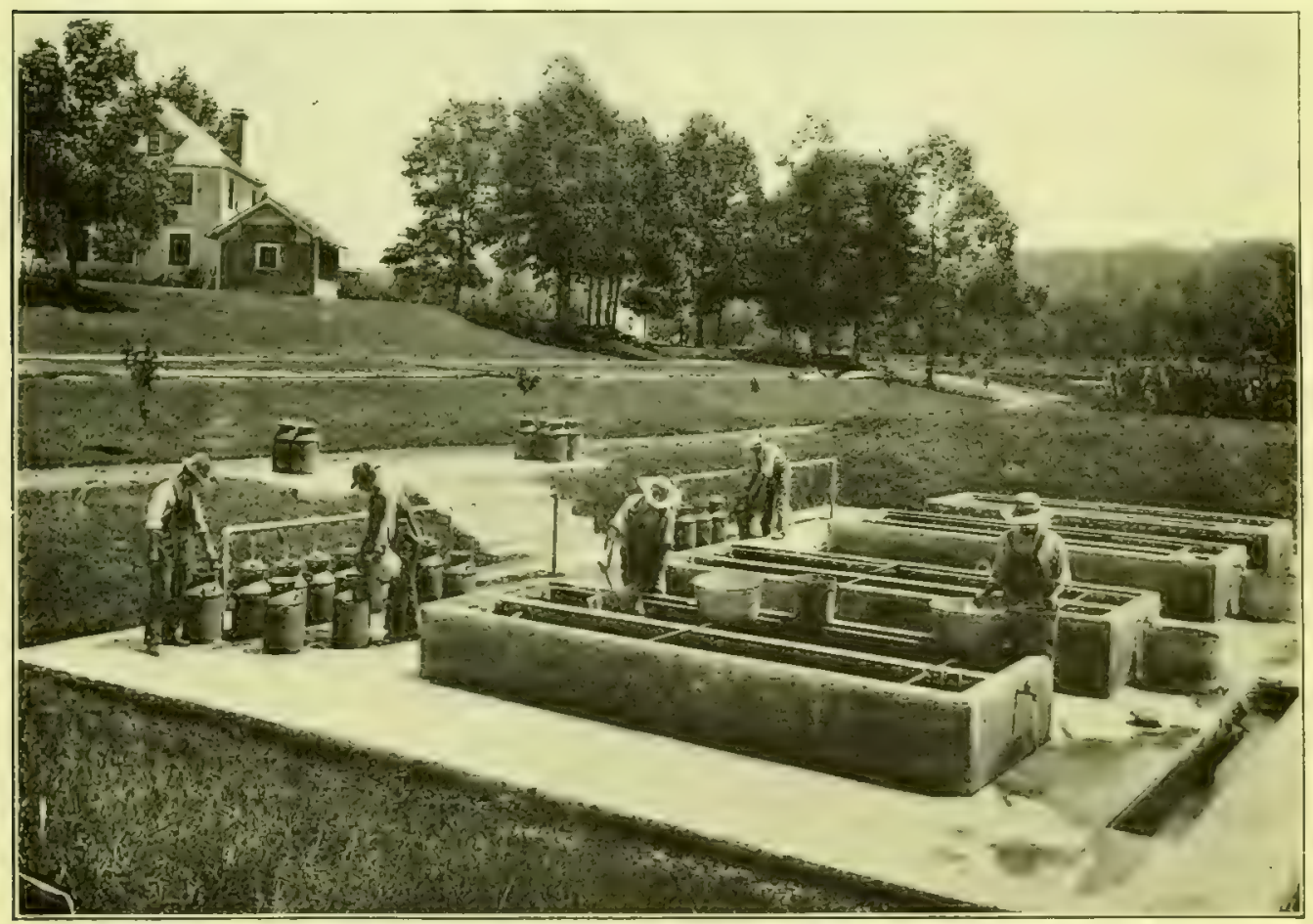

Fig. 13.-Preparing a shipment of smallmouth bass. Tanks used for hardening the young fish prior to transportation "The fingerlings are held for 12 hours in cold spring water, then dipped into tubs, counted into pails, and transferred to the transportation cans. These are then placed under a ? For an early morning shipment the fish are "canned" the evening before. (Itammoth Spring station, Arkansas.) 

By this means not only is a conservation effected but the Bureau is enabled to meet the great demand of applicants for the basses, sunfishes, and perches at a less sum than it would cost to produce them at a station maintained especially for their propagation.

\section{THE PACIFIC SALMONS.}

On the Pacific coast the Bureau has six permanent stations, including two in Alaska, all of them maintained primarily for the propagation of the Pacific salmons. Subsidiary to these there are six important lield stations and other smaller ones where salmon eggs are collected and hatched. An idea of the extent of the work may be olstained from a statement of the output of these stations during the fiscal year I 908 .

OUtPut of THE PACIFIC Salmons IN I908.

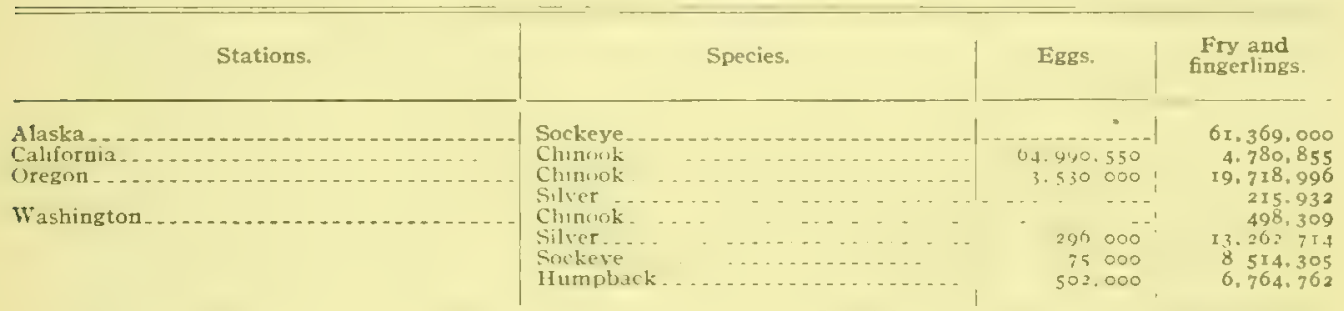

The eggs shown in this table were transferred to state fish hatcheries and other places for incubation. In California, as will be noted, a very large proportion of the eggs taken are so distributed.

Observations at various field stations indicate that a large percentage of salmon eggs deposited naturally are fertilized but for various reasons only a small percentage hatch. Modern fish-culture methods permit of a much higher percentage of impregnation than under natural conditions, it being possible to actually hatch and distribute as fry more than 95 per cent of all eggs collected. So long, therefore, as a proper number of salmon are permitted to escape the various fishing devices in their ascent to the natural spawning grounds, and it is possible to capture them for the purpose of obtaining and impregnating their eggs, perpetuation of the salmon fishery is assured.

In the culture of the Pacific salmon it is impossible to save eggs from the commercial catch, because the latter is made before the fish are ripe, and to retain them until ripe is not feasible. By the time they have ascended the rivers to the spawning grounds and are in condition for the fish culturist the flesh has so deteriorated in quality that they are unfit for market in any form. The Bureau must therefore itself capture the fish it requires, and this is usually done by the construction of harricades to intercept the run at the most suitable point below the spawning grounds. 


\section{BARRICADES AND TRAPS TO INTERCEPT SPAWNING RUNS.}

That successful work at the salmon stations depends largely upon stable and suitable barricades, or racks, as they are more commonly called, may be instanced by the results of the work at Battle Creek, Cal., in I903 and I904. At the height of the season in 1903 a freshet carried away several sections of the rack grating, permitting the fish to escape upstream. ${ }^{a}$ As a consequence only about 27,000,ooo eggs were secured. The following season no flood occurred at Battle Creek until near the end of the spawning season, and the collections that year numbered over $57,000,000$ eggs.

As all of the streams are subject to freshets, the water in some instances rising over 20 feet, the racks must be firmly built, and their successful operation depends not only upon ingenuity in construction but the care that is taken to guard against their becoming clogged with leaves and other débris in times of flood-work which at times is exceedingly hazardous. Methods in the construction of racks vary with local conditions, as do also the methods of capturing the salmon thus intercepted.

At the Mill Creck station, in lieu of a main or upper rack, the Bureau is able to take advantage of a mill dam i 2 feet high, which effectively stops the passage of salmon. Half a mile below this dam a retaining rack with the usual traps prevents the fish from dropping down stream. Seining and spawning operations are conducted on the streams between the dam and the retaining rack.

At Baird, Cal.-At the Baird station on the McCloud River in California are two racks or barriers between which is formed a pool foo feet in length. The upper rack intercepts the further passage of salmon, and the lower or retaining rack gives the fish free entrance to the pool, but effectually prevents their return. The upper rack reaches across the river, a distance of 250 feet, and is primarily supported by o concrete piers averaging 8 feet in height and extending 5 feet above low-water mark. The piers are properly fastened to the bed rock of the river bottom hy means of heavy iron bolts. They have a flat top 4 fect wide and 6 feet long, and from top to bottom is a beveled nose extending upstream at an angie of 60 degrees, making them \& feet wide and io feet long at the bot tom. On either bank a small crib pier filled with rock supports the shore ends of two Io by ro inch stringers laid parallel from shore to shore across the tops of the piers. A 2 -foot walk is built between the stringers and the whole is securely wired to eyebolts built in the pier tops.

Across the river bottom, against the nose of the piers, is a Io-inch sill. At intervals of 3 feet poles + inches in diameter extend at an angle of $60^{\circ}$ from the sill at the botton to the stringer at the top, and are securely fastencel to the

a At Battle Creek the low-water mark is ro feet below the top of the stringers on the rack, and during a recent llood the water was 12 feet above the top, making a 22 -foot rise. 
latter by large spikes. Against these poles or inclined uprights rest the gratings of the rack, which for the sake of convenience in handling are built in sections 6 feet wide and from 6 to 10 feet long to suit the varying depth of water. The gratings are made of $1 \frac{1}{2}$ by $3{ }^{\mathrm{I}} 2$ inch slats of dressed lumber set $\mathrm{I}_{1}^{1} / 2$ inches apart, their thin edge facing the current, the edge being convex to facilitate cleaning, and permit the passage of leaves. The ends of the gratings are nailed between two pieces of $\mathrm{I}^{\mathrm{I}}{ }_{2}$ by + inch material, notched into the slats to make a flush surface. The space between the slats is gaged by nailing on I I/2 by + inch blocks to each end. The longer gratings are hraced with two strips $1 / 2 / 2$ by + inches nailed on 3 feet from the bottom.

In the upper rack is placed a trap ro feet square with vertical slat sides sinilar to the rack gratings and having a solid board bottom. The narrow opening which allows the fish to enter is so constructed as to reduce to a minimum their chance of escape. The trap is primarily used for observing the general condition of the fish in the pool prior to the beginning of seining or spawning operations.

The retaining rack is at the lower end of the pool, where the stream narrows to about 190 feet. It is supported on 6 stone-ballasted crib piers with sides i 4 feet long, made by spiking together logs 8 to 12 inches in diameter until the required height is reached. The piers are built on slıre, floated into place, and filled with rock. Across the upstrean end of each pier are two ro by ro inch stringers laid parallel and supporting a board walk, as in the upper rack. Two small temporary piers are also built, to support the shore ends of the rack. Gratings having 2-inch intersices are placed across the stream, similar to those in the upper rack, with the exception that 5 openings 2 feet wide are left between the piers nearest the center of the stream. These openings are covered by the usual traps, which extend upstream into the pool $9 / 2$ feet. The traps are 4 feet in height and 6 feet in width at the entrance, being shaped to fit the slant of the gratings. The sides are of $1, \frac{1}{4} b y+$ inch material spaced 2 inches apart, and with the broad edge toward the current. Braces are placed across the top, and at the apex of the trap is an opening 3 inches in width from the surface of the water to the bottom. The salmon pass into the pool through this opening and rarely, if ever, find their way out.

Before the installation of the retaining rack, some ten years ago, nany eggs could not be collected by reason of the loss of fish from their running back downstream. This violation of the natural instinct of salmon to work ever upstream was due to fright resulting from the continual sweeping of the seine just below the upper rack. In the early days Indians were engaged to walk on either shore for a mile or so below the rack and beat the water with brush in an endeavor to drive the fish up to the seining ground. Since the installation of the retaining rack such measures have been entirely unnecessary. 
At Battle Creek, Cal.-The main or upper rack at Battle Creek, Cal., is constructed on a comparatively soft and shifty river bottom, and is supported by piling, instead of by the log cribs anchored with rocks, more generally useci. There are 2 bents of piling, each bent consisting of 3 piles driven firmly and braced with heary timbers. The 3 piles comprising a bent are driven parallel with the current, the front one standing some 2 feet above low-water mark and the others about $\&$ feet above. The front and rear piles are placed about ro feet apart. ()n these bents of piling and reaching across the strean are placed three 12 by 12 inch stringers, against which are secured + by 4 inch slanting supports, about 6 feet apart, the lower ends of which rest on a mud sill placed in the bottom of the strean. Stringers and these supports are so placed that the face of the rack will meet the current of the stream at an angle of about $60^{\circ}$. The gratings of the rack are built in sections of varying length but of a uniform wilth of $5^{1 / 2}$ feet. The slats for these gratings are of dressed lumber a by 3 inches, the sides set parallel with the current, the upstream edge convex. At either side of the stream, in the shallower water, single sections of gratings about ro feet long extend from the bottom to the top stringer. In the deeper portions of the stream two 6 or 8 foot sections of the gratings are used, one above the other, with an opening between the upper and lower sections for convenience during the lower stages of water in the removal, with rakes and hooks, of rubbish and trash drifting downstream. When the water rises the closing of this aperture is easily accomplished by knocking out the blocking between the two, thus permitting the upper rack to slide down flush with the upper edge of the lower section. The length of the rack from shore to shore is about 300 feet, its vertical height above low-water mark being about $S$ feet. During low water the front is submerged to a depth of from is inches to 2 feet, but there are holes considerably deeper behind the rack. A walk 2 feet wide is built on the top of the rack. A half mile below the barrier is a retaining rack quite similar to the one described for the Baird station.

At Battle Creek the racks are usually installed during September in time to intercept the fall run of salmon, and unless carried out by high water, remain until the close of the work in December. Gratings, stringers, etc., are then removed and stored for use another season.

At Birdsvicw, Wash.-A permanent barrier at the Birdsview station, an atuxiliary of the I alier Iake station, in Irashington, is of novel construction and calls for more than passing notice. This barrier is located in a portion of I'hinney Creck where formerly there was a dam huilt for the purpose of olstructing the passage of steel-head trout. When the dam washed out, a new channel formed and the river bed was very much broadened.

The first step in the construction of the new barrier was the laying of four heary los stringers across this new channel from the abutment on the north to 


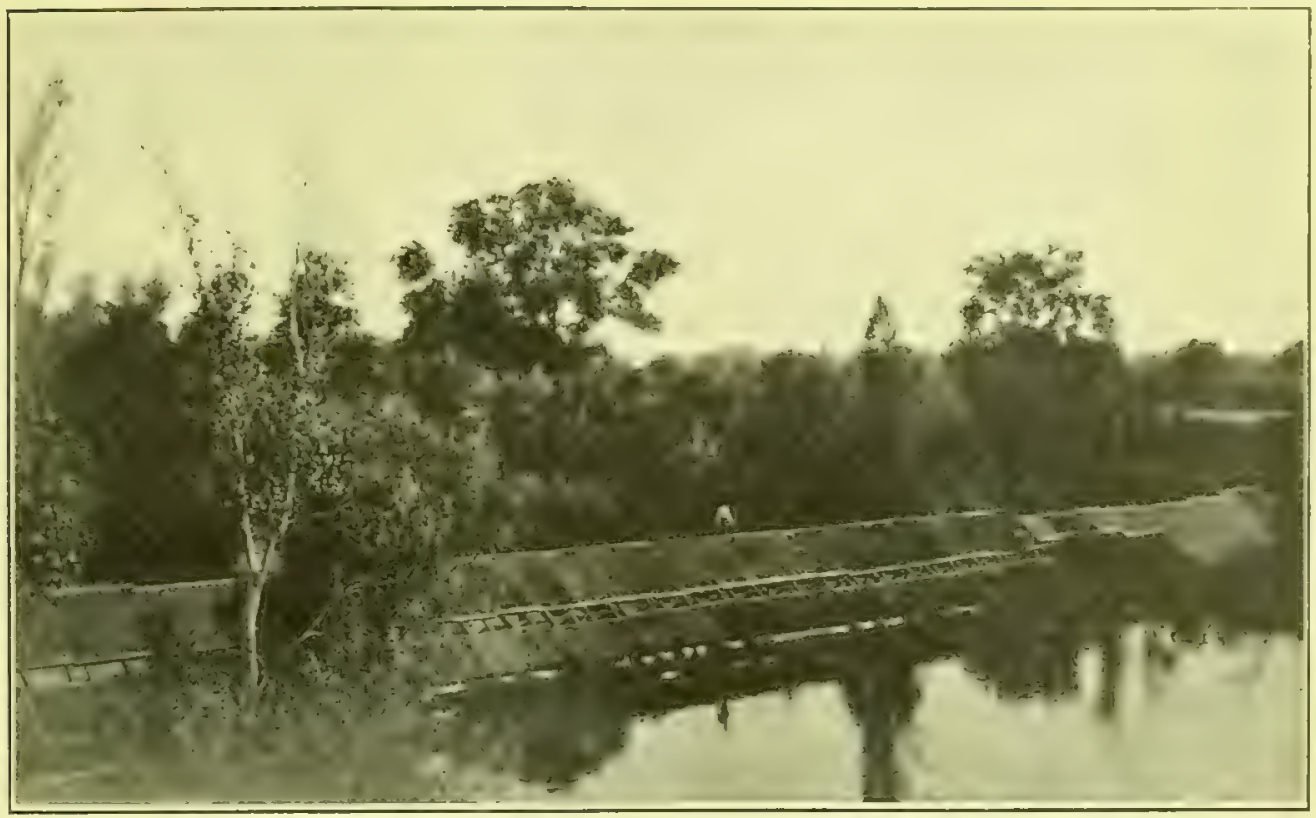

FIG. 10.-Main rack across Battle Creek near the Battle Creek station, California, Upper sections of rack raised to facilitate disposal of leaves and other débris

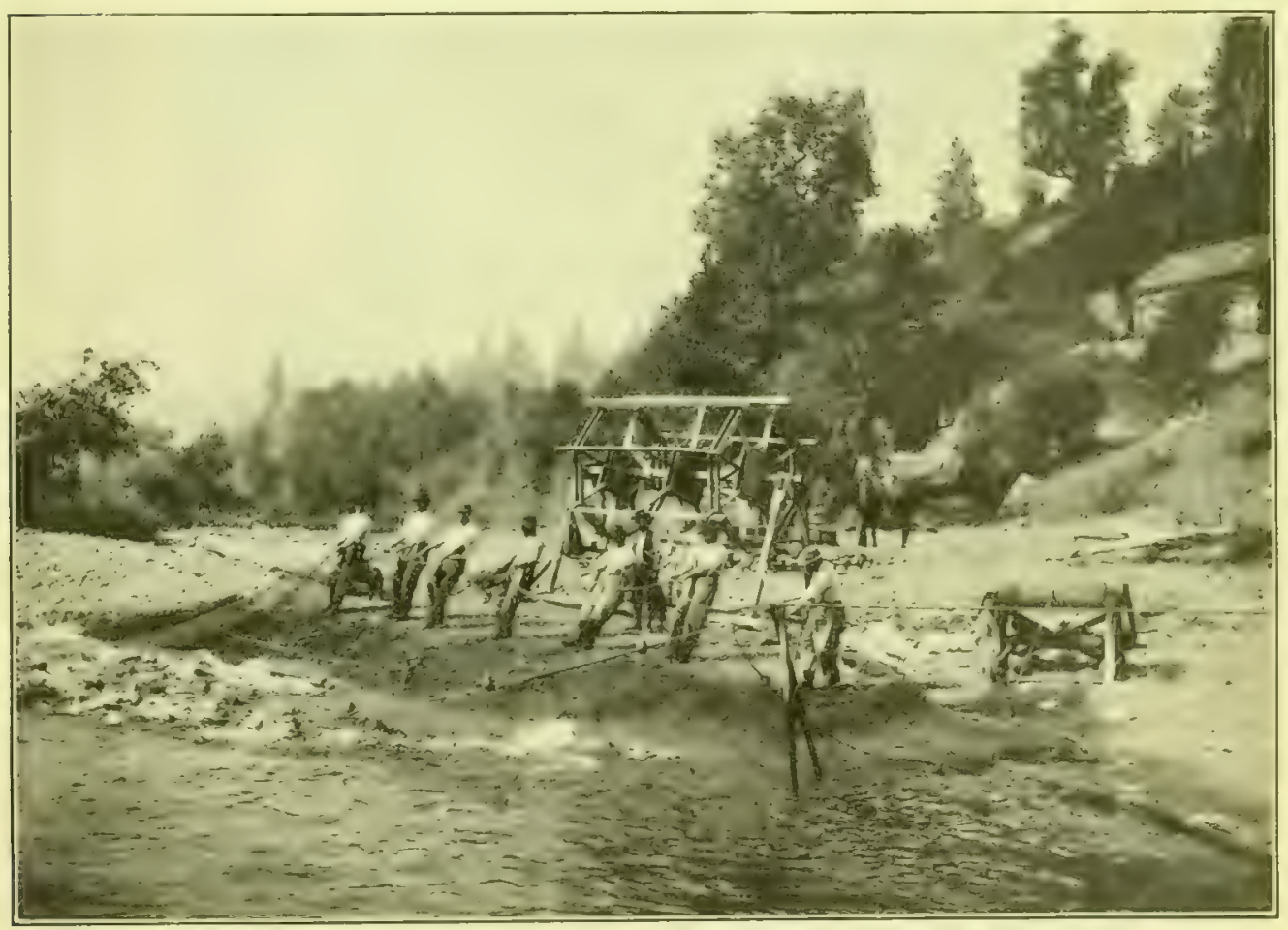

FIG. 20,-Seining sparning salmon on the MeCloud River, California, at the Baird station. Stean power has now replaced the hand windlass. 

the new bank on the south side of the stream. The logs were let down through the dan foundation to low-water level on the north sicle and the deep channel under them on the south side was filled with brush and gravel. The logs were spotted down to form a practically level hed, reaching the width of the stream. Heary piles were then driven helind each stringer to form alternate single and double rows extending up and down stream. The log stringers were next planked over, forning a platform is feet wide, similar to a regular dam apron, extending from the north abutment to the final row of piles on the soutl side, a distance of about i 40 feet.

By planking the sides of the single rows of piles and all around the double rows and filling the space with rochs, piers 4 feet high and approximately 2 feet and 4 feet wide were formed. Through each pier at the bottom, behind the upstream pile, openings I foot square were left, connecting the spaces between the piers. These spaces, $\mathrm{I} 2$ in number, are approximately 8 feet wide and are filled by swinging gates hinged to a 3 by 12 incli timber, spiked securely to the piers on either side and forming a dam or flashloard across the space above. By the insertion of other flashboards above this one a tight dam + feet high can be quickly formed at any time. The utility of this feature will be explained elsewhere.

The gates are made of I by 4 inch fir set on edge and nailed to 2 by 4 inch joist, being strengthened by 2 -inch blocks set between the rack bars and nailed to them and the joists. These blocks thus determine the width of the interstices in the gates. At the upper end of each gate an auger hole is bored through the bars and blocks, to accommodate a 2 -inch iron pipe, which passes through the entire upper end of the gates. Ringbolts clasp these pipes and are fastened to the 3 by $\mathrm{r}_{2}$ inch timber forming the flashboard, acting as hinges upon which the gates swing. At the lower end of each gate a wide board, I $1 / 4$ by 16 inches, is secured by means of braces, forming an angle of $45^{\circ}$ with the lower end of the gate.

At any ordinary stage of the stream the downstream ends of the gates rest on supports which hold them a foot or more higher than the upper ends, the water passing down through them to the floor of the apron, where it runs away. The fish working up under the gates to the dam board find the cross passages through the front end of the piers and finally reach the trap. It was expected that during freshets the current acting on the flashboard would always keep the lower ends of the gates above the surface of the water, and up to a certain point this expectation was realized, but at very high stages of the stream the large quantity of gravel in the water soon clogs and sinks the gates. As the gates are only two-thirds the length of the apron, however, and rise toward the lower end, the water shoots over them with such force that it is projected some distance below the end of the apron, and fish attempting to 

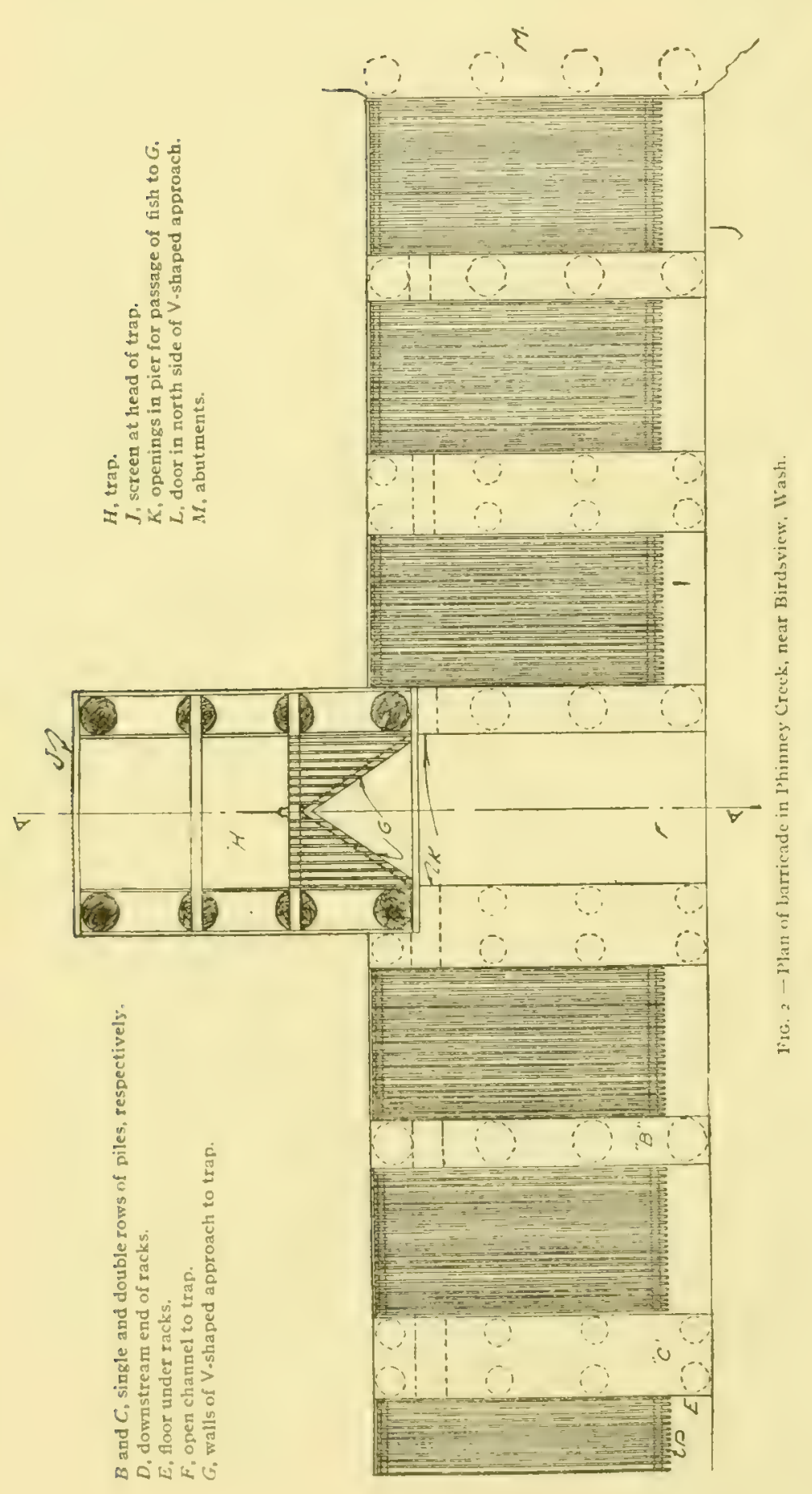

\section{ERIES,}

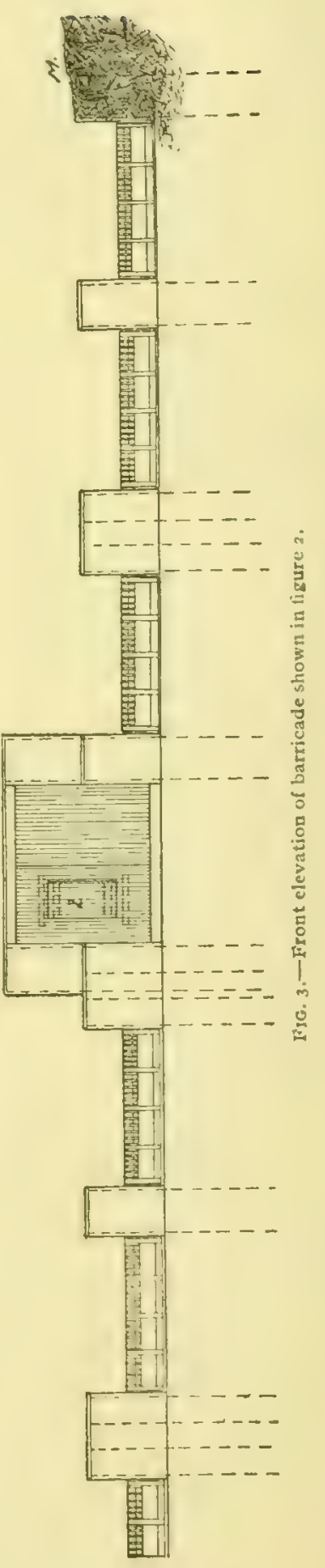



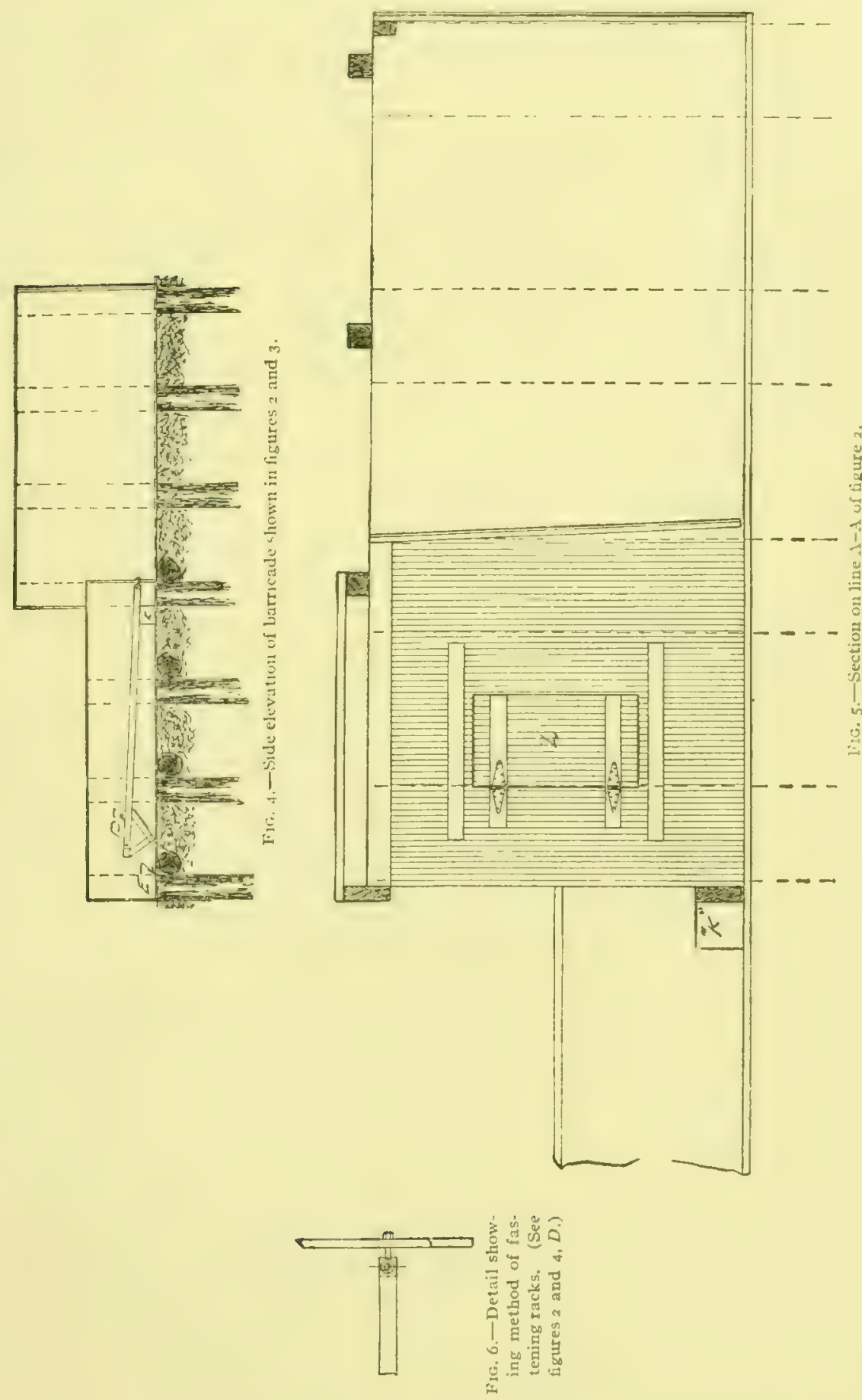
scale the obstruction fall far short of the ends of the gates. The barrier has been watched many times when fish were jumping and when the largest drift ran clear, and none has ever been seen to pass it.

By means of the dam boards entire control of the current can be had during ordinary stages of water and any desired quantity sent to any section of the barrier. Thus a strong current can be maintained through the trap section, leading the fish to it, and when it is desired to remore the fish from the trap the water can practically all be turned to some other section of the barrier.

One of the greatest difficulties in maintaining traps in the streams in this section is due to the tremendous quantities of gravel carried in the water during freshets, a sufficient amount being frequently deposited in front of a trap at such times to change the course of the stream. With the present form of barrier no trouble is experienced from this source, the insertion of the dam boards and the opening of one space at a time quickly clearing away the accumulated gravel.

The ninth and tenth piers were continued upstream by driving three additional piles above each. The piers form the sides of the trap. Its floor is a plank bottom, similar in construction to the apron, and the front is barred by $13 \frac{4}{4}$-inch pickets placed $13 \frac{3}{4}$ inches apart, the fish entering by the usual upstream $V$ of pickets. To protect the trap from high water the two piers between which it is located were carried to a height of 8 feet. When it is desired to fish the trap, the gate at its head is closed and entrance is made from below by means of a door in the north side of the $V$.

The upper end of the fishway of the old dain was left in place, the narrow passage between it and the new trap protecting the spaces at the south end of the barrier from the current and from drift. These spaces have been racked above and below to form commodious pens for males and unripe females. The south end of the barrier is protected by a substantial abutment.

The maintenance of racks in Phinney Creek has been a very heary item of expense in past years, and the trap was frequently carried away by freshets just at the height of the season, allowing large numbers of fish to escape and considerably reducing the season's take of eggs. It is believed the new barrier will stand any possible test that may be put upon it and will fish successfully in almost any stage of water. The design is to be credited to Mr. A. H. Dinsmore, superintendent of the station.

TAKING AND HATCHING THE EGGS.

Seining operations and spawntaking at California stations.-At the Baird station all the salmon are caught by seine with the exception of a very few taken in the trap in the upper rack. Owing to the swift current and the formation of the river banks the seine is always landed at one place, the rope attached to 
the upstream end being hauled by steam engine and the lower or downstream rope by a whim operated by horsepower.

When a haul is to be made the seine is carried by boat upstream about 50 yards from the landing before it is paid out from the shore. The downstream rope is paid out automatically as the hoat moves and is passed through a snatch block to keep the current from closing the ends of the seine until opposite the landing place, when both ends are drawn in at the same time. As soon as the seine has been laid out above the pool the engine is started, drawing the seine downstrean toward the landing. When the last of the seine is in the water the whin is started and the lower end is also liauled down and in. I landing having been made, the ends of the scine are secured to pieces of rope fastened to pins driven into the ground. Hooks on loose ends of these ropes are slipped behind the corks of the seine. A trestle is placed under the rope to hold the cork line high above the water and thus prevent the salmon from leaping over it. The lead line is pulled upon the bank and thrown over iron pins to keep it from slipping back into the deep water.

The ends having thus been fastened, all the men are free to handle the fish, which must be quickly removed to prevent injury from crowding, this being especially true of the summer run when the water is warm. The men stand in the water and lift the fish from the net one by one until all have been looked over, handling them with the aid of heavy woolen gloves, and grasping them by the tail with the left hand while the right is placed just behind the pectoral fins. A gentle pressure of the fingers at this point forces out a few eggs if the fish is ripe; if not ripe it is thrown over the seine into the river. When a ripe female is found it is carried to the pens beneath the spawning platform a few yards distant, care being taken to hold it vent side up to prevent loss of eggs. The males are handled in a similar manner, the ripe ones being placed in pens near the females.

The seining crew are likewise the spawntakers, and after two hauls in the morning they strip the fish caught the day before. The ripe salmon of each day's catch are thus held over as a precaution against any possible immaturity of the eggs.

On the spawning platform is a frame 6 or 8 inches wide, with sides converging toward the bottom and open at one end, into which a spawning pan can be slipped. The pan is rectangular in shape, about 6 inches wide and if inches long, with slanting sides and flaring ends. This shape is preferable to the round pan because of facility in washing the eggs, it being possible to dip a thin stream of water into the pan the entire length of one side. The frame holds the pan secure and at the same time its slanting sides assist in guiding the eggs into the pan.

After washing, the eggs are placed in 6-gallon spawn buckets which have previously been filled with water. These buckets are made of galvanized iron, with a wire-cloth strainer inserted near the rim to permit the escape of surplus 
water as eggs are added; they are painted inside with asphaltum, and are provided with covers. With the exgs in them they are placed on a platform which is built under water at sufficient depth to submerge about two-thirds of the body of the bucket, and thus maintain a proper temperature during water hardening. It is an essential feature of this platform that it be entirely. independent of the spawning platform in construction. The period between the washing and hardening of the eggs is a critical one, and if they are jarred or disturbed there will be consequent greater loss in the hatchery.

In the spawntaking operations five or six male fish are first dipped from the pen and dropped on the floor, where they are allowed to lie until they stop struggling and may be more easily handled. Then several females are dipped out, killed by a hlow on the head with a piece of iron piping, and laid in the dead box. The bottom of this box is inclined and has a narrow slit at the lower end, through which any eggs that may escape from the fish will fall into a pan underneath, where they will be fertilized by occasional applications of milt. The dipping and killing continues until all the fish are stripped, males always being kept on the floor in order to have several allead of the spawntakers. Ifter being stripped the hest-appearing males are returned to the pens, where they usually recuperate and are again used to supply milt.

The female fish is grasped by forcing the fingers through the rills and the thumb into the mouth, the hand being protected by a stout leather glowe. The man who does this, the headholder, stands, holding the fish vertically. The spawntaker, in a kneeling position, seizes the fish by the tail, bending its body: nver the pan, while with a sweeping motion he makes an incision in the thin sicle of the belly beginning near the pectoral fins and extending to the anal. The incision is usually made with a pocketknife, the blade being held between the thumb and index finger within one-half to three-fourths inch of its extreme point to prevent cutting too (lecp. Most of the egrgs follow the knife and fall into the pan, the remaining ripe eggs being released by running the fingers into the body cavity. As soon as the eggs hegin to flow into the pan milt is forced over them and they are stirred by the spawntaker with a few movements of the hand. They are then passed to the washer. 'The milt of one male may serve for several pans of egrs, but it often happens early in the season that several males are required to one pan.

As soon as the washer receives the pan of eggs he dips the edge of it in the river, the inflowing water causing the eggs and milt to boil up. The eggs at once settle back and the milt is poured off over the side of the pan. Ordinarily two such dips suffice to clean the eggs, after which they are poured into spawn buckets, and at once settle to the hottom, the surplus water escaping through the wire-cloth strainer near the top. Spawning operations usually consume about an hour. After water hardening the eggs are carried to the hatchery, about 200 yards distant, and turned over to the hatchery crew. 


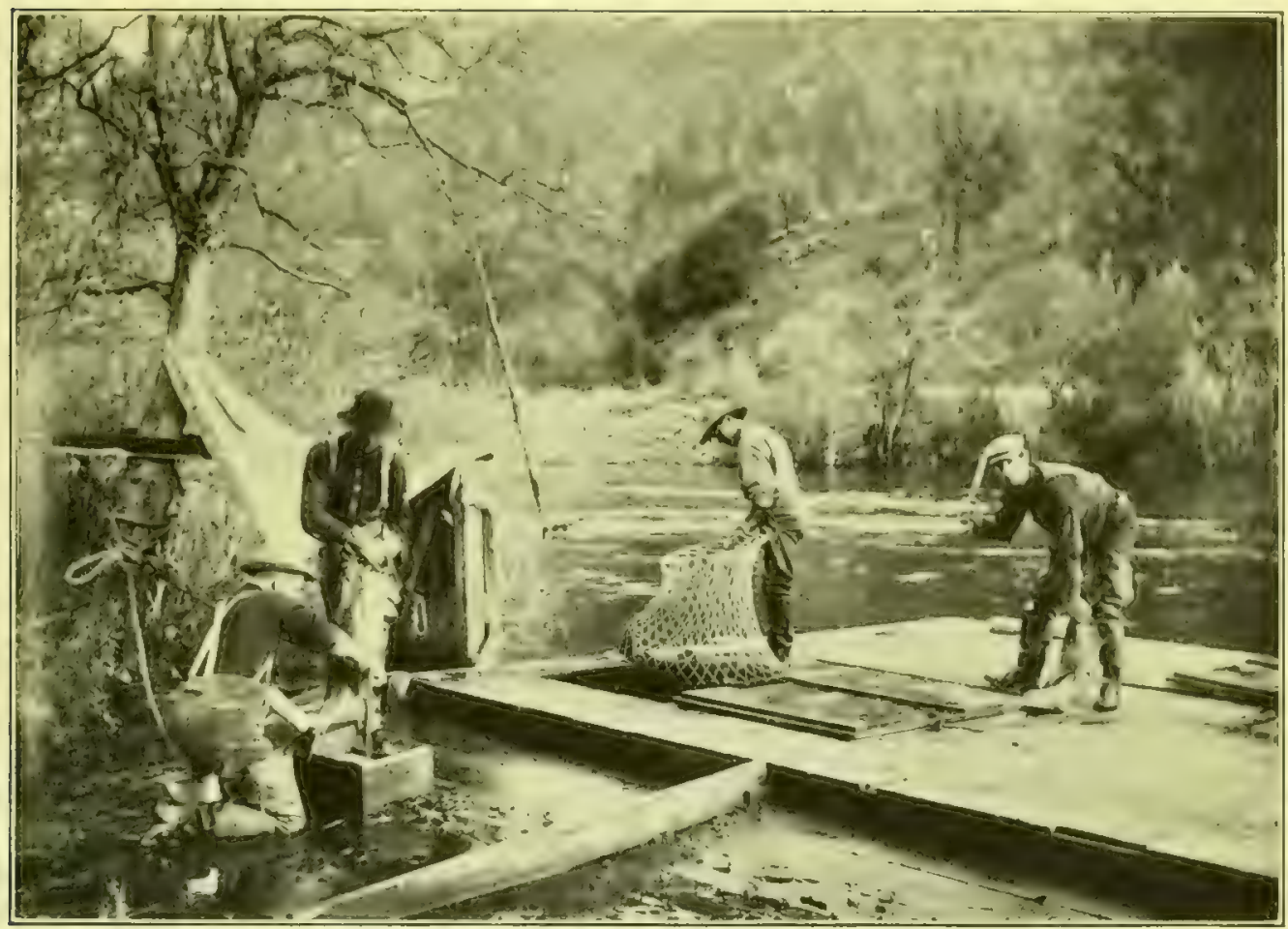

Fig. 2r.-Spawntaking operations, Baird, Ca1. The fish (chinook salmon) are dipped from the pen, killed by a blow on the head, and passed to the spawntakers. The eggs are taken by opening the abdomen, and the stream of eggs may be seen in the picture following the hand making the incision.

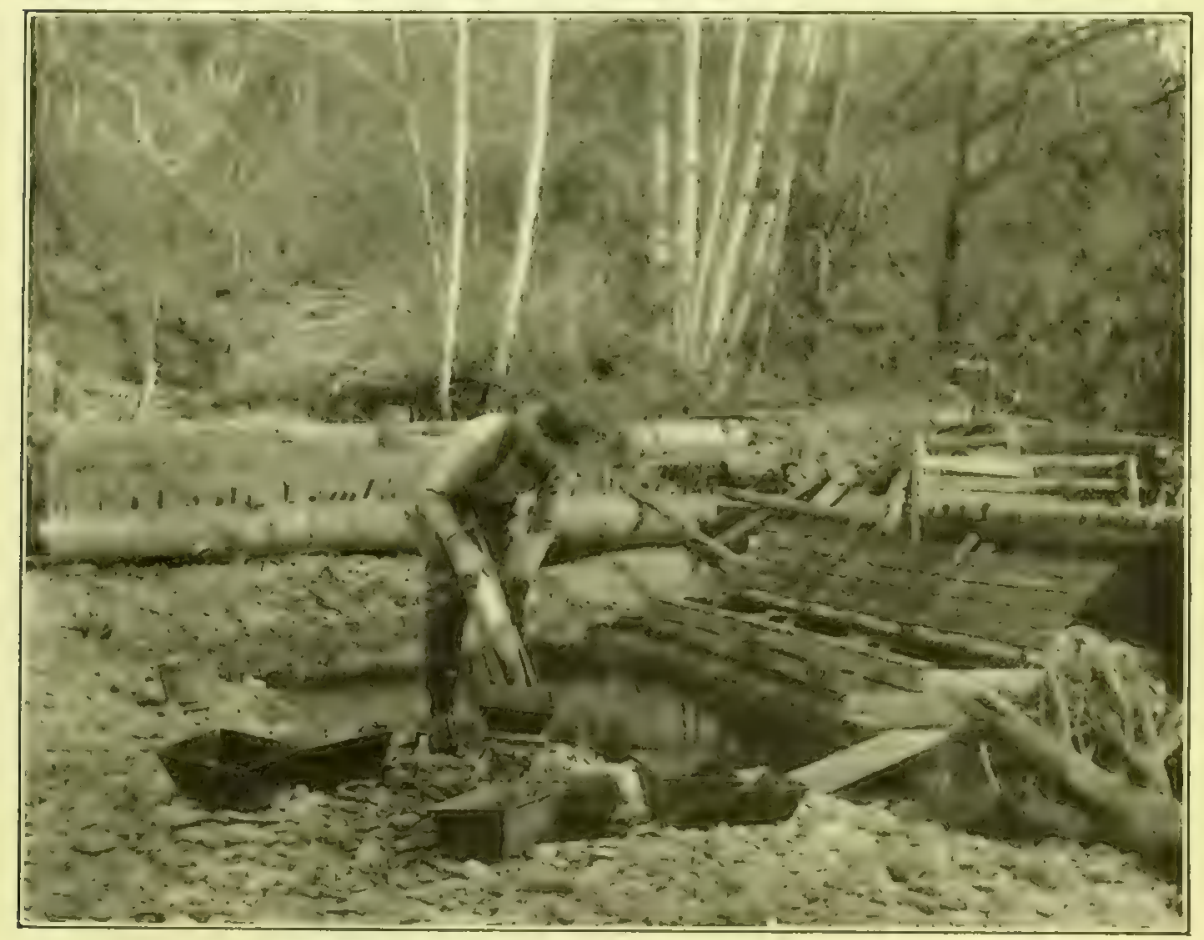

FIG. 22.-One method of stripping steelhead tront. Since this fish normally does not die after spawning. the ripe fish are not killed as are the salmon, and they are so large, and so powerful in their strug-
gles, that the strait-jacket here shown is sometines resorted to. 

The spawning operations at Battle Creck and Mill Creek are gractically the

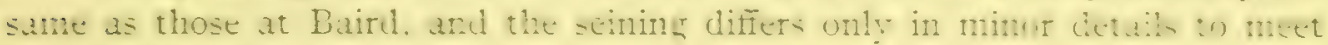
local conditions.

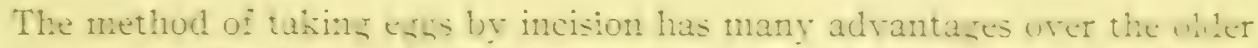

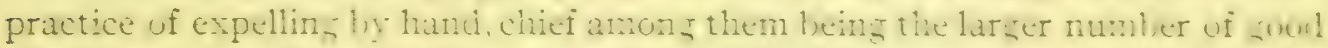
$e_{3}=$ secured and the higher percentage of impremation. There is als' a treat saring of time and labor, and, as all w the Pacin almons dic after once spawn-

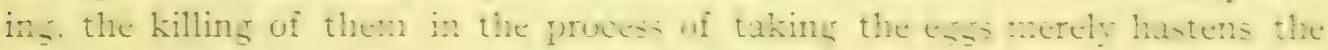
end, and constitutes no loss of adult fish.

The ezs of the Pacitic salmons are cumparatively larse, rangine in dianeter from one-fourth inch for chinow to one-ifth inch for sockere. Fortumaty.

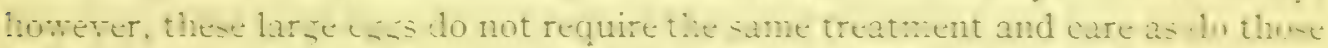

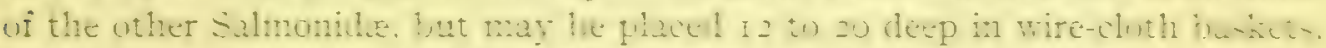

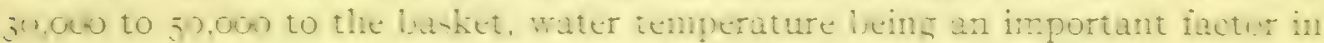
leciling the quantity. The baskets, rectangular in shape, conform in width to the troughs: the latter are of the Maliamson tre up-current, the fiom a

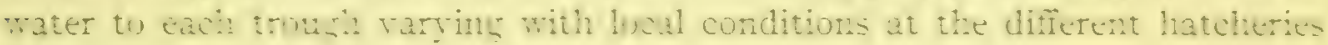
from $S$ to 20 gallons per minute.

Local praciices in difjerent regions.--Experience seems to indicate, with regard to the sockeye, or red salmon, that there is an advantage in bleeding

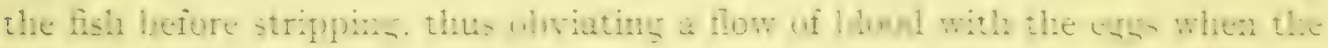
incision is made. It is therefore now customary at sockeye stations to decapitate or else cut off the tails of the female fish as the first step in the spawntaking process. At Baker Lake, Washington, the practice is as follows:

The fish, which have been brought to the pens usually the day previous,

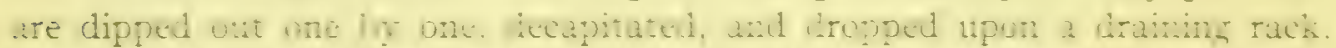
where wate $\mathrm{i}$ thmm ore them to clemse them for handlis y by the spawn-

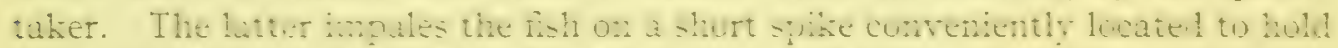
them orer the pan while le makes the incision and removes the ens. Two men ste occupied in lie work sol far. At thirl fertilizes and washes the ez-s, then

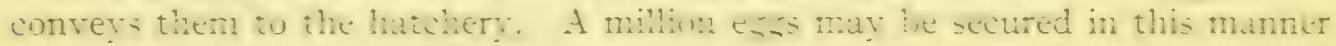
in one forenoon by one such cretr.

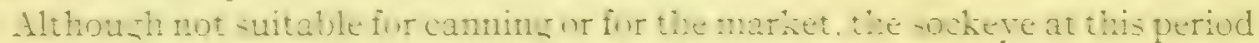
is edible and many are taken by local residents for food. Indians camp at some of the stations and preverve large number- if the almon. The mairity

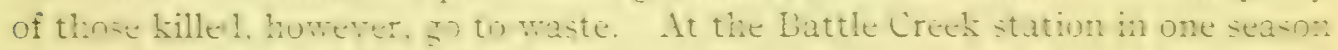

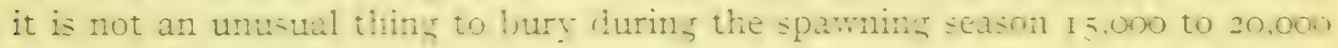
pounds of fish.

A convenient and ecnomical method of separatine dead ers of salmut from living ones is the use of a salt solution. ${ }^{a}$ If a basket of eggs is emptied

a O'Malley, Henz: Salt solution as an aid to fish culture. Transactions of the American Fisheries Society for 1905, p. 49 . 
into the solution, the unfertilizerl and clead eggs rise to the surface, where they may be cluckly skimmed off. The method is not applicable in the manipulation of snall quantities of eggs, but is very useful when, for some cause, there is an abnormal loss. It has not heen successfully extended to the ciges of species other than the chinook, silver, and humpback salmons.

At the Baker Lake station, operated primarily for the propagation of the sockeye salmon, loth sockere and silver salmon are captured hy means of a pound net as they enter the lake. but as the fish are not ripe at this stage of their upstream passage it is necessary to hold them until the spawning season. For this purpose a slough or bay at the head of the lake has been inclosed by racks and webling to make a pound about 20 feet wide and 500 feet long, with an arerage depth of 6 feet. The entire bottom area is of soft mud; in it are two hollows of a maximum surface area of 300 feet and 400 feet, respectively, where the water is approximately I 2 fect in depth. The water supply. from soo to $2,+00$ gallons per minute, is derived from several small mountain creeks fed by glaciers and snow, and from springs.

This has proved an ideal place in which to hold salmon while their eggs are maturing. As many as 8,000 fish have thus been confined for thirty days and 6.000 for three months. After remaining in the inclosure for three or four months the fish are as clean and free from abrasion as fish that have not been penned. A noticeable fact, however, is that very few of these salmon ripen until October or November, while in previous years the spawning season has occurred during September and hefore October $I_{5}$. The difference is attributed to the low temperature of the water in the inclosure, which remains from 6 to 8 decrees below that of the natural spawning beds of the lake. (During the summer the average water temperature on the spawing beds is about $56^{\circ}$.) The success of the impounding of the salmon is attributed to the low temperature of the water.

Silver salmon, as well as socheye, have been successfully impounded at Baker Lake. A few impounded chinook, however-never more than i 2 at a time--fungussed rapidly, and after three weeks usually died before the eggs were taken.

\section{MARINE FISH CULTURE.}

COD, POLLOCK, AND FLATFISH.

On the New England coast the Bureau naintains three stations, for the hatching of marine fishes and the lobster.

Of the fishes the cod is first in importance. Its cultivation consists principally in hatching esris obtained from market fish, the fish being stripped either by the fishermen or by the Bureau's spawntakers. The latter are claily distributed among the fishing ressels for the double purpose of stripping ripe fish as fast as hauled aboard and of collecting and caring for all egss the fishermen may 
have taken. Coming as it does during the winter nonths, from early 1 ecemiler to March on the Massachusetts coast and extending throuen March and April on the Maine coast, the spawning season is a trying one for the spawntakers, who must share many of the dangers and hardships of the fishermen.

At the Woods Hole station advantage has been taken of the presence of a large salt-water reservoir under the hatchery to test the Norwegian method of obtaining eggs. By this process adult fish are penned and allowed to spawn naturally. The eggs float to the outlet, where they are caught in a receptacle placed for the purpose, and thence are transferred to the hatching boxes. It has been demonstrated that a larger percentage of fertilized eggs per fish can be oftained thus than by the former method of stripping penned fish. The increase is not due to a higher percentage in fertilization, but to the fact that in the case of the penned fish there is an almost unavoidable loss of egrs extruded in the crates. Both of these methods are an improvenent over nature, in that the egrs are protected from the time of extrusion until they have hatched and the surviving parent fish are returned to the ocean. This is fish culture in the usual sense and not purely conservation of an otherwise waste product, as is the collection of eggs from market fish.

Prior to the spawning season for cod, or from the middle of October to the latter part of December, spawntakers are distributed anong the pollock fishermen, and fron the eggs thus collected many millions of pollock fry are hatched and distributed annually.

The cultivation of flatfish is conducted on a more extensive scale than any other marine fish-culture work. The adult fish are taken from the fyke nets in which captured, usually the Bureau's own, directly to the hatcheries, where they are placed in tanks and held until they have spawned, the egres being removed daily from the tanks to the hatching apparatus. It is possible to spawn flat fish artificially, and eggs are sometimes obtained in that way.

\section{LOBSTERS.}

Lobster culture also, as conducted by- the Bureau, effects a saving of an otherwise lost resource, berried lobsters purchased from the fishemen furnishing eggs for the hatchery and being later returned to the ecean. At the Boothbay Harbor, Me., station the parent lobsters are held until the eggs are ripe in a pound similar to those used by the lobster men; and as it has been found that eggs taken late in the fall or early winter do not hatch successfully, one such pound is utilized to hold some 10,000 or 12,000 lobsters throughout the winter. The losses of lobsters during the period of confinement are only normal, and the quantity and quality of the eggs are superior to those obtained from freshly caught stoch. It is noticeable also that the eggs of the inpounded stock hatch almost simultaneously and somewhat earlier than those from freshly caught lolsters, undoubt- 
edly hecause of the wamer, shallow, inshore water. By the middle of April the eggs are sufficiently well advanced to be removed from the parent and put up in the hatching jars; and as at this time the lobsters become quite active in a rising water temperature it is quite important that they then be removed to avoid serious losses from mutilation.

The removal of impounded lobsters is effected at low tide, the flood gates being opened and a portion of the water drawn off with care to retain enough water to protect the lohsters from exposure. Men in dories then go about the shallow portions of the pound piching up the lobsters on ordinary clam forks or hoc: the sharp tecth of which have been blunted. It was formerly the custom to use a dray seine for gathering the lobsters, but taken in such quantities they mutilate one another and it has been found preferable to remove them by hand. After a portion of the stock has been removed the water is drawn still lower, until finally only a small area of the pound is flooded, and the remaining lobsters are removed.

As it has not been possible to transport lobster eggs successfully when detached, the berried females are always taken to the hatchery to be stripped, the transfer being made in the wells of fishing smacks or the Bureau's vessels. From this time to the close of the season in July berried lobsters are collected from the lishermen and transferred to the hatchery to be stripped. Immediately after the close of the season the collection of fresh berried lobsters for stocking the pound is begun and continued into November.

It is muquestionable that the impounding of lobsters as practiced in Maine is superior to any other present method of holding the adults for a leninth of time. The character of the Maine coast, with its numerous natural inlets and its unusual rise and fall of tidle, affords especial advantages for the use of pounds. When these conditions do not exist, however, recourse can be had to cars, whough data thus far ohtainable fully demonstrate that a larger number of 1. b) sters can be held for a longer time and with a smaller percentage of loss in pounds than in cars.

Contrary to the custom of the pound fishermen, the ice on the surface of the pound operated by the Bureau of Fisheries is removed from time to time during the winter, with the result that a much larger percentage of lobsters is found in the spring. It has been observed that the rising and falling of ice with the tide frequently crushes lobsters that happen to be in the shallow water near the edges of the pound, and removal of the ice at intervals of viates this difficulty.

Iixperiments have been made as to the poundkeepers' practice of inserting wooden plugs in the claws of penned lobsters to prevent their mutilating one another. Ior lobsters intended for market the procedure seens suitable, though it results in an minghtly discoloration of the muscles. There seemed 

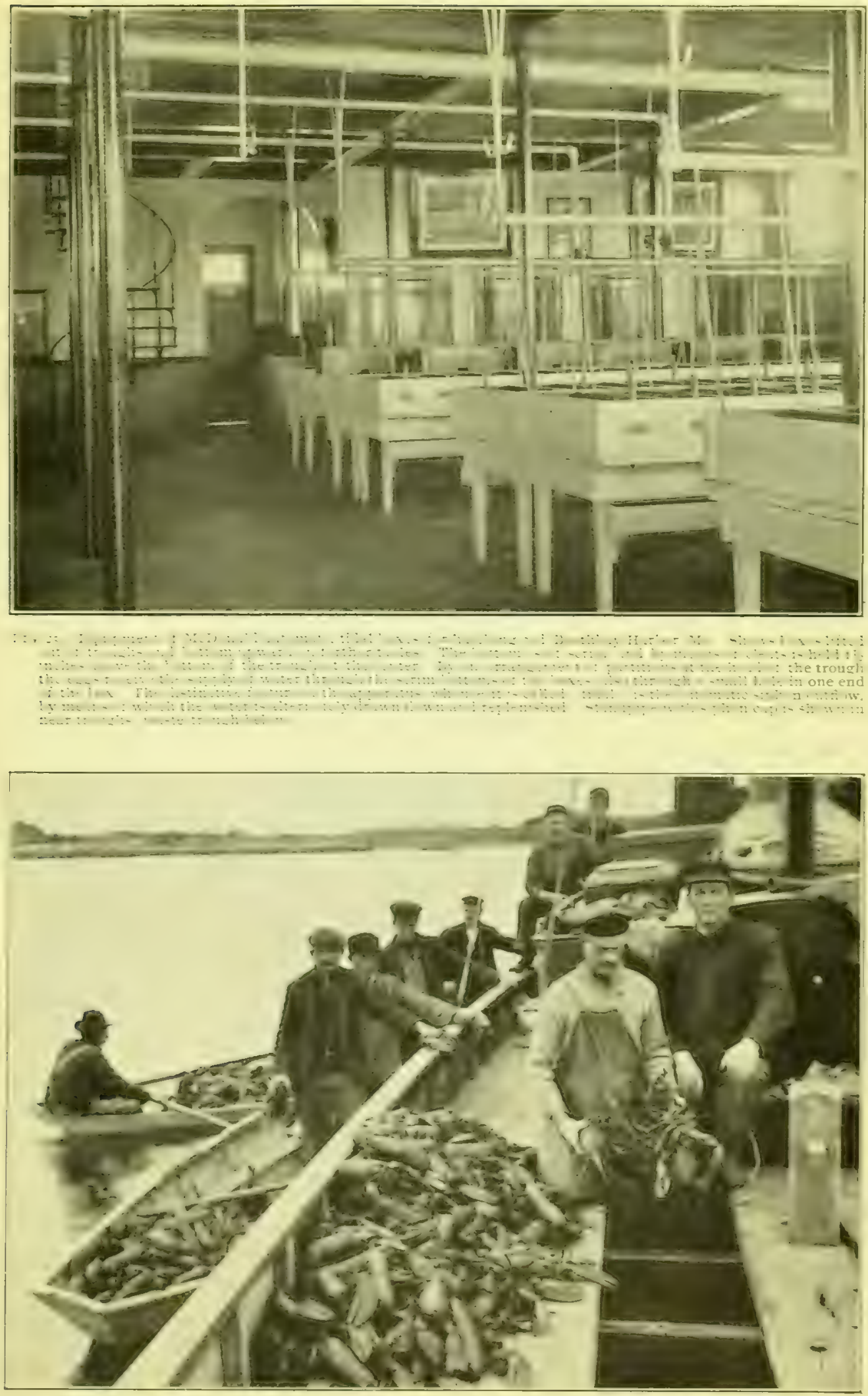

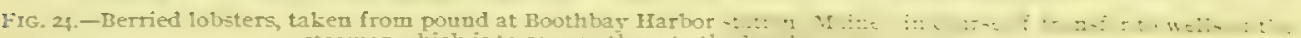



to be a question, however, whether it would be feasible with the impounded stock of the Bureau destined for liberation in the open waters after removal of their eggs. The experiments showed that out of 2, I I lobsters removed from the pound, all of which had heen plugged when put in, 742 had lost hoth plugs, 563 had lost one plug, and 605 retained both. The warm weather when they are first confined, however, is their most active period, when the plugs do most good. Mutilation is thus prevented and the plugs apparently work no permanent injury to the lobsters.

It is important in the impounding of lobsters to take precautions, so far as possible, for the exclusion of eels, wlich have an especial liking for the eggs and will strip a female lobster in a very short time. Even with all precautions it seems impossible to exclude eels entirely; it is probable that many enter when small and grow up in the pound.

The rearing of lobster fry to the fourth molt, as practiced by the Rhode Island Fish Commission and so admirably set forth in a paper read at the congress, ${ }^{a}$ has not as yet been taken up by the Bureau, but is doubtless feasible at the Boothbay Harbor station. Before the first experiments in this direction at Boothbay it was thought that owing to the lower temperature of the water in this more northern latitude the periods of molting would be prolonged and the feeding and care of the fry consequently attended with abnormal losses. It lias since been found that this difficulty can probably be met by installing the rearing plant in a lobster pound, where the temperature is higher and more even than in the open waters. The Bureau therefore hopes to enter upon this undertaking in the near future, for the purpose of rearing a portion of the lobster output. To attempt to rear to the fourth molt the entire product of the Boothbay station would involve an expenditure far beyond present financial resources.

\section{MEASURING AND COUNTING FISH EGGS AND FRY.}

Immediately after water hardening, for a short period varying with the species and water temperature, the careful handling of fish eggs is not injurious. During this period their numbers may be very definitely ascertained by the use of any receptacle suitable for a measure, the capacity of the receptacle laving first been ascertained by counting the whole or a fractional part of its contents.

For eggs of the trouts and those of smaller size an apothecary's graduate or the ordinary graduated quart or pint measure is commonly used. For large quantities the long-handled dipper used in transferring them to the hatching apparatus may be advantageously utilized. As many eggs as possible are poured into the measure, nearly all of the water being forced out over the rim.

a Mead, A. D.: A method of lobster culture. Proceedings Fourth International Fishery Congress, Bulletin of the Bureau of Fisheries, vol. xxvin, 1908, p. 219-240, pl. viI-XI. 
Tniess the eggs are to be transferred to a hatchery beyond the jurisdiction of the shipper, the eggs may not be measured until a more convenient time, it being possible from long faniliarity with the capacity of the apparatus in actual use to estimate quite accurately the number of eggs on hand at any time. Providing they are spread uniformly, the number of egss to a square inch is a fairly accurate basis for ascertaining how many eggs are on each tray. Some fish culturists prefer to ascertain the actual number of eggs on hand hy weighing then after having determined by actual count the basis for sucli calculations.

These methods are especially applicahle to the heary eggs of the Salmonidx, and may be emplored not only after water hardening but also at any stage of inculation after the eggs are eyed up to a day or so before hatching, at which list stage a measurement closely approximates the number of fry that will be in the subsequent hatch.

Eiggs hatched in jars are usually measured by means of a graduated scale in the form of a square made of wood, the units indicated on the long leg of the square. The square is adjusted to the jar as shown in figure $\mathrm{I}$. The scale reads from the bottom line upward, the first or bottom line being at a height corresponding to the level attained in a jar by a measured half pint of water, and each line represents the number of eggs of a given species as estahlished by actual count from a measured half pint. The dead eggs will have been from time to time siphoned off and when the remainder are fully developed or about to hatch the scale is applied to each jar and a very careful measurement is made to ascertain their number. The number of fry available for distribution will be approximately the number of eyed eggs in the jars just before hatching, as the mortality after this stage of development is usually inappreciable.

A novel method of obtaining the number of eggs in a given lot has lately come into use, and as the work can be done without counting a large number of eggs, has proved especially valuable in dealing with eggs of small size at field stations where no measurements have been established. This method, devised by Mr. H. von Bayer, architect and engineer of the Bureau, employs a gauge which quickly gives the diameter of the eggs, knowing which it is possible by reference to a diagram to determine at once the number of eggs to the quart. ${ }^{a}$

In the keeping of accurate hatching records it is important that the basis for computations be ascertained immediately before any general measuring methods are applied hecause it is well recognized that eggs of most species vary in diamcter with stock from different waters and that egos from any given collecting station vary at different periods of the spawning season, those taken at the height of the season being larger and nore uniform than those taken earlier or toward the close of the season. For instance, brook trout eggs taken at a

a von Bayer, H. : A method of measuring fish eggs. Proceedings Fourth International Fishery Congress, Bulletin of the Bureau of Fisheries, vol. xxvir, 1908, p. 1009-1014. 
particular station may run 250 to the fluid ounce during the height of the season, while the first take may have run 300 to the ounce and the last eggs of the season may average 400 or more to the ounce. These variations make it necessary frequently to establish a new measure for ascertaining the actual number of eggs. There is also to be taken into consideration the fact that eggs of almost all fishes increase in size from + per cent to I 5 per cent according to the species, from the time they are water-hardened up to the time they are about to hatch.

This fact, coupled with the fact that eggs of the same species vary in size at different sources of supply and periodically at the same source of supply, is a point in favor of the ron Bayer method of computing the numbers of eggs of small diameter.

Sac-absorbed fry and advanced fry of the trouts, landlocked salmon, etc., may be measured in the same manner as are the eggs-in an apothecary's graduate or other container, straight vertical sides being preferable to the flaring sides of the ordinary glass graduate. The ordinary graduated half pint or pint cup used by cooks is a very convenient measure. The fry are poured in until the measure is overflowing with then to the exclusion of practically all the water, the filling and emptying being done quickly. Actual count of the number in one measure establishes the basis for computation. The growtl during this period being very rapid, however, a new unit must be determined daily.

The numbers of fingerlings are ascertained by actual count of each lot as dipped a few at a time from trough to transportation can or other receptacle by means of a small hand net of tightly stretched bobbinet.

\section{TRANSPORTATION OF EGGS.}

To equalize and facilitate the work of the hatcheries it is customary to transport, sometimes to considerable distances, both green and eyed eggs from one station to another, thus effecting the distribution of fish through the listribution of eggs. Several auxiliary stations are maintained on the Creat Lakes solely for hatching eggs received from Northville, it having been found economy to transfer to them as eyed eggs the portion of the Northville station output destined for distribution to waters in those localities. Both green and eyed eggs are also shipped to state hatcheries and the latter to foreign countries.

The methods of conveying green eggs from the field where collected vary to suit conditions. The stations at which eggs of commercial fishes are hatched in large numbers are usually located conveniently to the source of supply so that it is possible to carry the freshly furtilized eggs to them in the pans, iuckets, or other receptacles which constitute the equipment of the spawn taker. It often happens, however, that the eggs must be held in the field or be in transit for two or more days, and in such cases a packing case is employed. 
USUAL STYLE OF PACKING CASE.

For ordinary purposes a packing case consists of a wooden box which will accommodate a stack of trays and an ice hopper, with 2 to 4 inches of insulation or packing on all sides and under the tray stacks. The frames of the trays are made of light, soft wood, usually white pine, $5 \%$ inch by $7 \%$ inch or $7 / 8$ inch by 7/8 inch, over which is tightly stretched a bottom of canton flannel, nap side up, or of heavy cheese cloth, with perforations in the cloth to facilitate the passage of water.

For long-distance shipments it is customary to make the bottoms of the trays of wire cloth painted with turpentine asphaltum, over which canton flannel or cheese cloth may be spread before putting the eggs upon them, and a thin layer of moss under the cheese cloth in addition is advocated by some fisli culturists. The soft spongy bed of moss prevents concussion in liandling and retains moisture, while at the same time it allows a sufficient circulation of oxygen and free passage for water from melting ice, etc. For very long or warm-weather slipments it is sometimes advisable to use a case with double sides, with insulation between, the space between the inner case and stack of trays being filled with ice.

The ice hopper is about 3 or 4 inches deep, of the same length and width as the tray frames, and rests upon the top of the stack. Its bottom is perforated to allow a drip from the ice through the trays and thus keep the eggs constantly moist and cool. Double cases, the length twice the width, arranged for two stacks of trays side by side with a partition between them, are sometimes used in the Pacific salmon work.

The fish culturist often works in isolated places and must use the material which is most accessible and economical. Moss is therefore very generally used for filling the space between the stack of trays and the packing case; mineral wool, leaves, sawdust, and shavings also well serve the same purpose, though with ice in contact with the insicie lining of the outside case mineral wool is objected to because when damp it has a tendency to sag. Any of these materials may be used for insulation in the long-listance cases. Cork board insulation, also, is very efficient and of lighter weight than the others, but it has not been tested so fully as have shavings, at present the material most popular with caretakers.

The cover to the case may be screwed on, but for shipments requiring the renewal of ice it is customary to provide a hinged cover fastened with hasp and staple.

ADAPTATIONS AND VARIATIONS OF METHOD.

Iived egss of the Atlantic and Pacific salmon and of the steelhead trout have all been successfully shipped in the ordinary case, but the method of packing eggrs of the Atlantic salmon at the Craig Brook (Me.) station has the special 


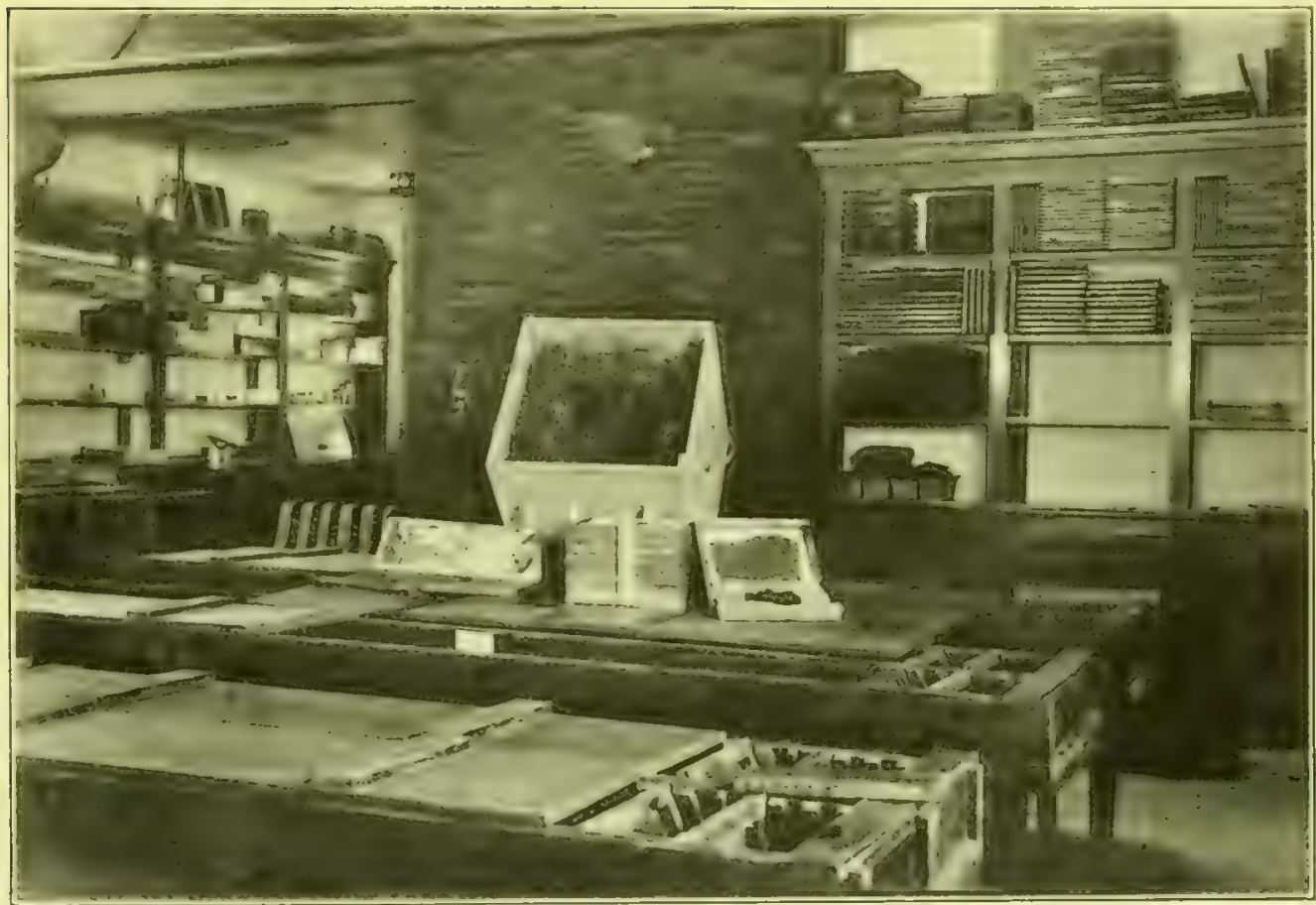

Fig. 25-Box of trout egrs just opered. Showing ice hopper at left, stack of trays which have been taken out of the moss in center of bax, and one tray with covering of mosquito

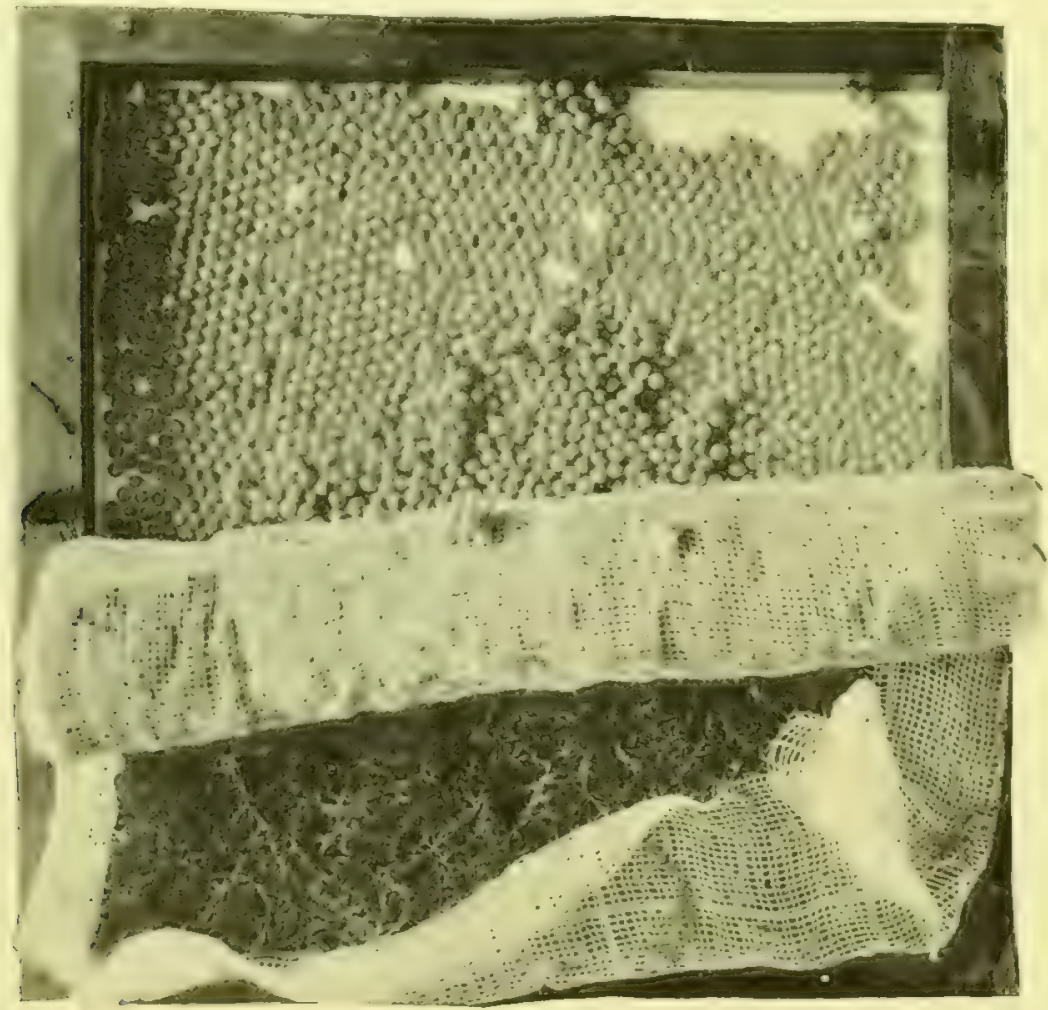

FIG. 26.-Tray of trout eggs with mosquito met and moss in which packed, 

advantage of making a comparatively light package - a factor of mreat economic importance in transportation. 'The outside case may , be an ordinary box of suitable dimensions. In it are packed, surrounded by moss, several boxes made of $3 / 8$-inch boards, and usually 12 inches wide by 15 inches long by $3 \frac{1}{2}$ inches deep, each box containing a mass of 10,000 to 20,000 eugs in mosquito netting, with moss around all sides. No ice is used, care being taken that the packing be done in a temperature below $50^{\circ}$, that all packing material be kept in a place slightly below freezing point, and that the moss in which the eggs are packed be sprinkled with snow. 'This method of packing is an economical one for shipments of egrss of Salmonida during cold weather, but can not advantageously be used for eggs of spring spawning fishes unless there is available a cold-storage room in which to do the packing. Recently the superintendent of the Baker Lake (Wash.) station, who has had occasion to ship eggs of steelhead trout and Pacific salmon in warm weather, has packed them in light cases with alternate layers of moss, and then placed two tiers of these thin cases side by side in an outer case with a large hopper of ice over the whole, the drip passing down between the two tiers of inner cases. The chief advantage of this case for long-distance shipments is in the fact that less ice is required than in other forms of cases using ice, with a consequent saving in transportation charges. It can also be used in warm as well as cold weather. It is believed it will be economy to extend the use of this case in packing eggs of other species of Salmonidæ.

Green eggs of the brook trout and chars are carried in spawning pans or buckets, the spawntakers sometimes, by the use of a neck yoke, carrying two pails of trout eggs several miles. It is possible to ship the green eggs a half day's journey without serious loss, but it is preferable to eye them at places convenient to the traps where the parent fish are caught, after which they are packed by the ordinary method.

For grayling eggs cheese cloth is used for the bottoms of the trays instead of canton flannel and it is preferred by some in packing other kinds of eggs because it permits of a better circulation of air and is not so apt to hold water. No moss is used on the trays over the eggs, but only mosquito netting, as the exrs will not stand pressure. Both the hopper and the cliamlers around the tray stack are kept filled with ice, thus maintaining in warm weather a temperature of about $40^{\circ} \mathrm{F}$.

In transferring hy messenger large numbers of eggs, whether green or eyed, of any species, it is customary to omit the packing on and around the trays, ice being used to regulate the temperature.

Liggs of the shad and other species of which the period of incubation is but a few days are usually shipper within forty-eight hours after heing collected. Shad eggs are seldom shipped for more than a few hours' travel. For this 


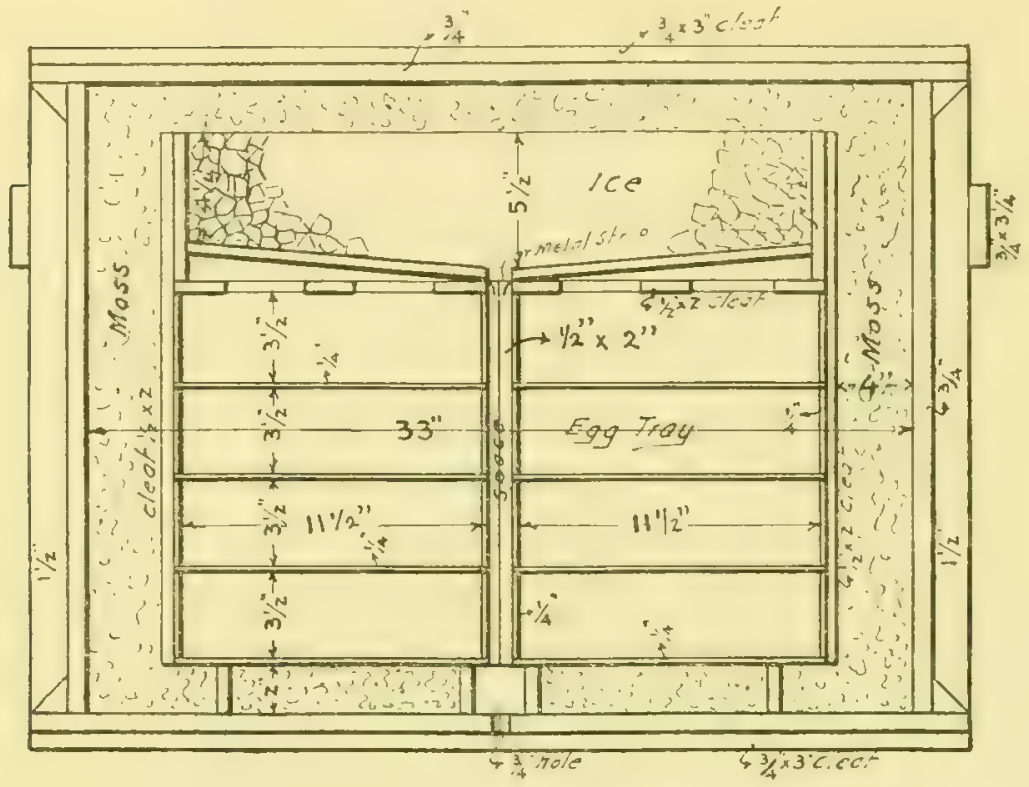

FIG. 7.-Atkins-Dinsmore shipping case. Longitudinal section.

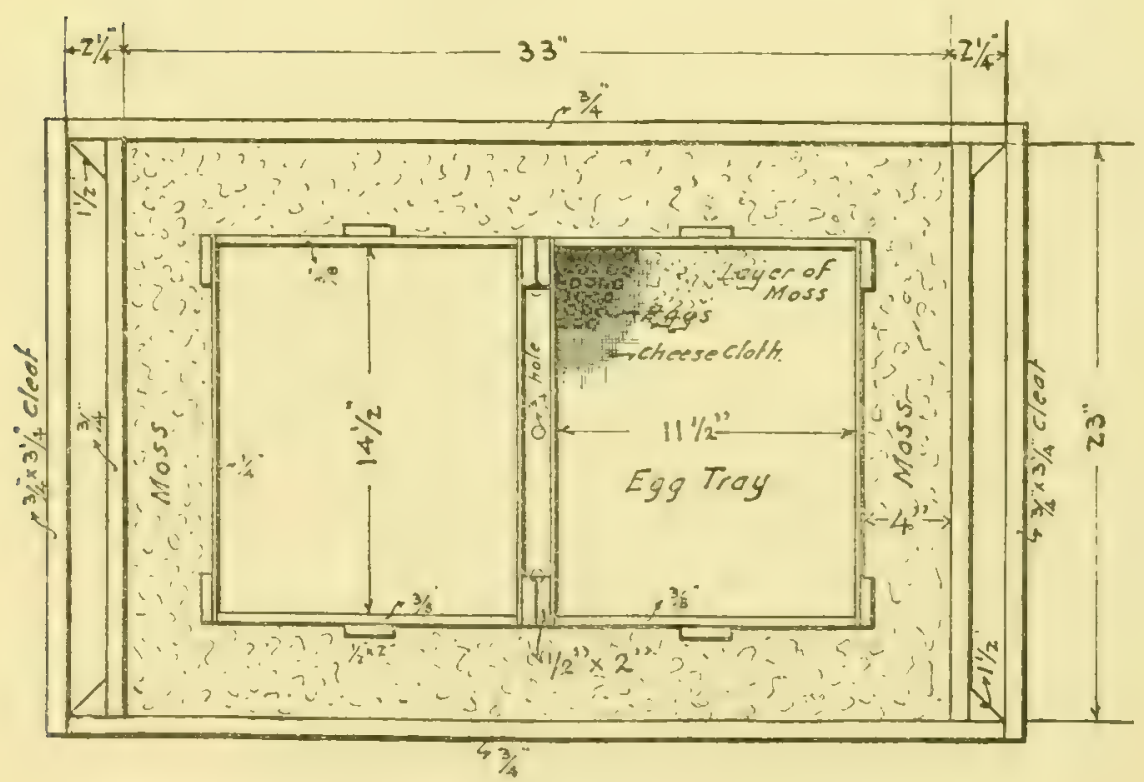

Fig. 8.-Atkins-Dinsmore shipping case, Plan. 
purpose they are laid in cheese cloth on wire-bottom trays, between wooden frames also covered with wire cloth, strapped together, and shipped without further packing.

Experiments at Havre de Grace, Md., seem to demonstrate that it is practicable to pack eggs of the white perch in the ordinary trout egg case with ice hopper and ship them on journey's of thiry-six hours" duration without apparent injury. Two lots of green eggs taken at a temperature of $56^{\circ}$ and $70^{\circ}$, respectively, and held in trout egg cases for twenty-four to twenty-six hours, hatched as well as eggs placed directly in the hatching jars. In the first experiment there was no change in temperature, but in the second experiment there was a fall from $70^{\circ}$ to $64^{\circ}$. White perch eggs to the number of $3,000,000$ have in several instances been shipped by express from Havre de Grace, Md., to Washington, D. C., a half day's travel, in four McDonald jars packed in sawdust, ice being used in the packing when the air temperature seemed to require. The jars were equipped with the usual glass tubes, which extended above the packing, but whether this provision for aeration was necessary has not been tested. To insure proper aeration, however, it would seem advisable, with present knowl-

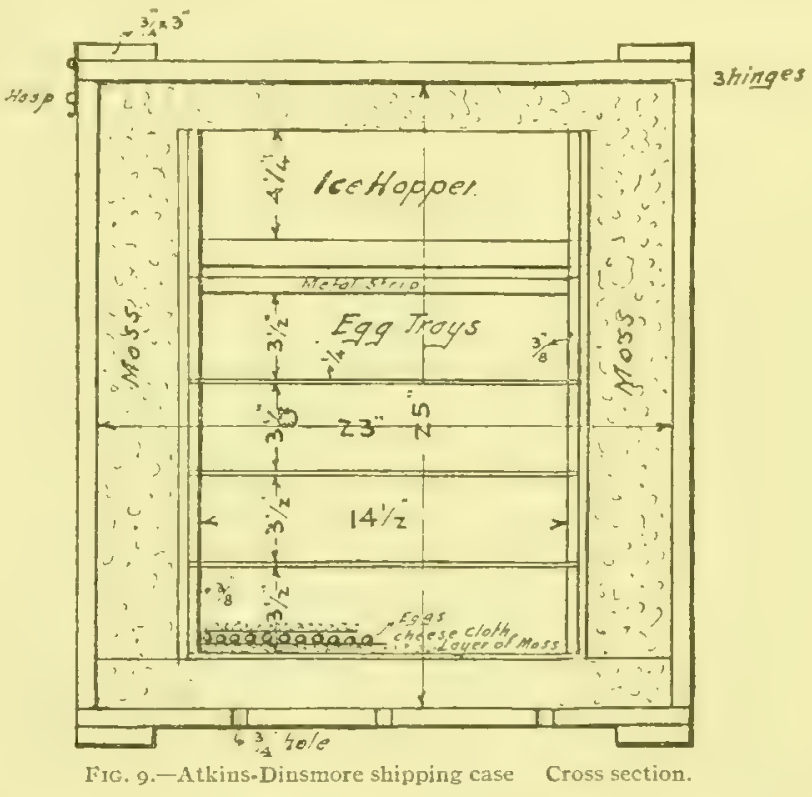
edge of the subject, not to ship large numbers of white perch eggs in water for travel of four or more hours without a caretaker.

Attempts to transport yellow perch eggs on trays have not given satisfactory results, but it is apparently possible to carry them successfully almost any reasonable distance in the ordinary transportation cans, I to 2 gallons of eggs to 8 gallons of water, the proportion varying with the distance to be traveled, and care being taken to aerate and temper the water.

Green pike perch eggs may be carried from near-by collecting grounds to the hatchery in tubs or transportation cans, care being taken to renew the water frequently, to keep it well aerated, and of a proper temperature. Ice must be prevented from coming in contact with the eggs, because, unlike most 
other eggs, they are very sensitive to such exposure. Half-barrel fish kegs or kits with one end knocked out and iron handles attached make very sood and economical vessels in which to transport pike perch eggs. It is customary to insert a wire-cloth drain in the top of the kit on one side and the kits are asphalted inside. Canvas is thrown over the top to serve as a cover. When the eggs are held over night in these kits it is expected to supply them with running water whenever possible to do so; otherwise the water must be periodically renewed or aerated. At some of the field stations a pipe arranged with pet cocks and rubber tubing for supplying water to a number of hits or transportation cans saves much lahor in the matter of aerating eggs which must be lield for a day or more.

Pike perch eggs collected at a distance from the hatchery are conveyed thereto in the usual transportation case on trays, a small amount of ice being placed on the top tray, which is substituted for the usual ice hopper; an inch space around the sides of the stack is also filled with ice. Ice over the stack must be used sparingly or the green eggs may be injured by the cold water where it trickles upon them. For large shipments it is customary to have a caretaker accompany the packages to regulate the temperature, cte, the use of moss on the trays as well as the insulation material then being omitted.

Since eyed pike perch eggs are usually shipped luring the month of May, for safety ice is used around the stack of trays as well as in the hopper, even on a two days' journey.

IVhitefish eggs are transported from the field of collection by both of the methods employed in the transfer of pike perch eggs, although they do not require quite so much attention. Eyed whitefish eggs are packed on trays in the ordinary way.

The fields for the collection of lake trout egrgs being widely distributed, it sometimes happens that green eggs are held in transportation cases for several days hefore their arrival at the hatchery. 'They carry as well laid directly on the wire-cloth bottoms as on a layer of cheese cloth. No packing is necessary if they are in the care of an attendant, since the latter can regulate the temperature by the use of ice and with water of the proper temperature, the trays being removed and sprinkled at least once in twenty-four hours.

In packing lake trout eggs for short distances, say up to a thousand miles, the ice hopper is omitted. Mosquito netting and moss are put on in the usual manner and the top of the moss is slightly frosted lufore the trays are stacked on the basehoard. A light piece of lumber is used in place of the ice hopper and hine shavings are solidly packed under, ahore, and on all sides of the stack of trays. For the longer shipments the ordinary ice hopper is used, fine shavings being placed around the stack of trays for insulation. 
In the handling of egges of the cod and other marine fishe's a so-called kettle, oval and with a concave top, is used to retain them on board ship in a choppy sea. The water in which they are kept must be frequently changed or acrated. The eggs are shipped to the latchery in large fruit or butter jars, rockweed or moss, together with ice or snow, being used in packing them. It is regarded as impracticable to ship egss of marine fishes for travel of more than two or three days.

\section{ARGENTINE, CASE.}

While the various methods above described have all been successfully employed in the transportation of errs across the I'nited States and also to Europe without an attendant, shipments of eggs to points south of the equator, usually leaving this country in winter and arriving at their destination in summer, have called for more than usual attention to the methods of packing them, and a caretaker is quite essential.

A highly efficient form of shipping case has been developed during the past few years for the transportation of eugs of the Salmonidie from this country to Argentina. It is 3 feet 6 inches long, 2 feet wide, and not exceeding 30 inches high, outside measurement, and is constructed of selected tongued and grooved lumber. It has double walls, with bottom and top common to both, the 2-inch space between the walls being filled with nonconducting material, preferably tightly packed shavings. Between the inner wall and the stack of trays is a $23 / 4$-inch space for ice, separated from the trays by perforated zinc. Between the latter and the trays, in a "inch space, are the vertical supports of the zinc, viz, double corner supports, one being $1 / 2$ by $x \frac{1}{2}$ inches, the other being $I / 2$ by $\mathrm{I}$ inch; two intermediate supports of $1 / 2$ by $\mathrm{I}$ inch material, which are provided on either side of the case and one at each end; and cross braces of $\mathrm{I}_{2}$ by I inch material, which extend from the uprights to the inner walls of the case.

The ice hopper, 3 inches in depth, and having the same outside dimensions as the trays, rests upon the latter and fills the space between the uppermost tray and the top of the case. It has a perforated zinc bottom, and, to facilitate handling, cleats of small ropes are attached to it. The top of the case is insulated with a 2 -inch thickness of nonconductor covered with sheet zinc, this insulation fitting closely into the chest when closed, and thus covering not only the ice hopper but the ice spaces around the sides as well. In the bottom grooves lead to a ${ }^{3}$-inch drain hole, which is provided with a cork. Two cleats $7 / 8$ by 3 inches are attached lengthwise to the bottom on the outside.

The trays are one-half inch deep, 27 inches long, and 9 inches wide inside measurements, the frames being of $I_{2}$ by ${ }_{4}$ inch material. The bottom of each 
tray is covered with wire cloth no. 25 gauge, about 12 meshes to the inch, stretched tightly to prevent sagring and consequent uneren distribution of the drip water. A narrow binding of cloth is tacked around the bottom of each tray to prevent the wire edge from catching on the mosquito net covering of the tray beneath. On the inside ends of the trays are fastened short lifting cleats, and wedges hold the trays securely in place. The bottom tray rests on three 1/2-inch cleats extending lenthwise of the case, one at either side and the other in the middle. It is important to have the trays of uniform size, that they may be interchangeable.

The trays and interior of the case are coated with asphaltum. To facilitate opening from either side, four hasps are used, two on each side of the case. Two rope handles side by side are placed on each end of the case, with a cleat of three-fourth inch material just above the holes for each handle.

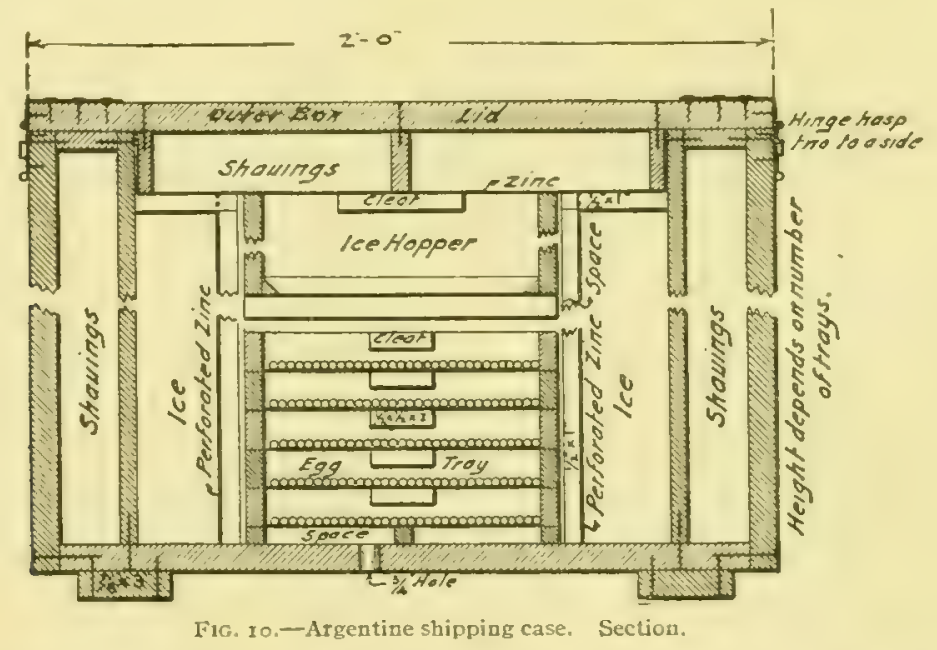

Eggs selected for shipping should barely show the ere spots without the aid of a glass. In packing, a layer of damp moss is spread one-fourth of an inch deep as evenly as possible over the tray bottom, and upon this is placed a covering of mosquito net or bobbinet. 'Whe egss are laid upon the netting one or two layers deep, spread to within one-half inch of the tray frame and covered with another piece of netting to keep them separate from the moss, which is sprinkled in a light layer over it, flling the tray. The netting is cut large enough to extend over the outer edges of the tray, so that the eggs may not be disturbed when a tray is lifted for examination.

On shiphoard, as the greater part of the journey is made, the cases of eggs are kept in one of the fruit or cold storage rooms having a temperature of about $38^{\circ} \mathrm{F}$. To this room the attendant has access, and it is his duty daily to moisten 
the ewgs by pouring through the ice hopper water of the same temperature as the eggs, $34^{\circ}$ to $35^{\circ}$. The ice compartments are frequently replenished and the eggs are picked over whenever necessary.

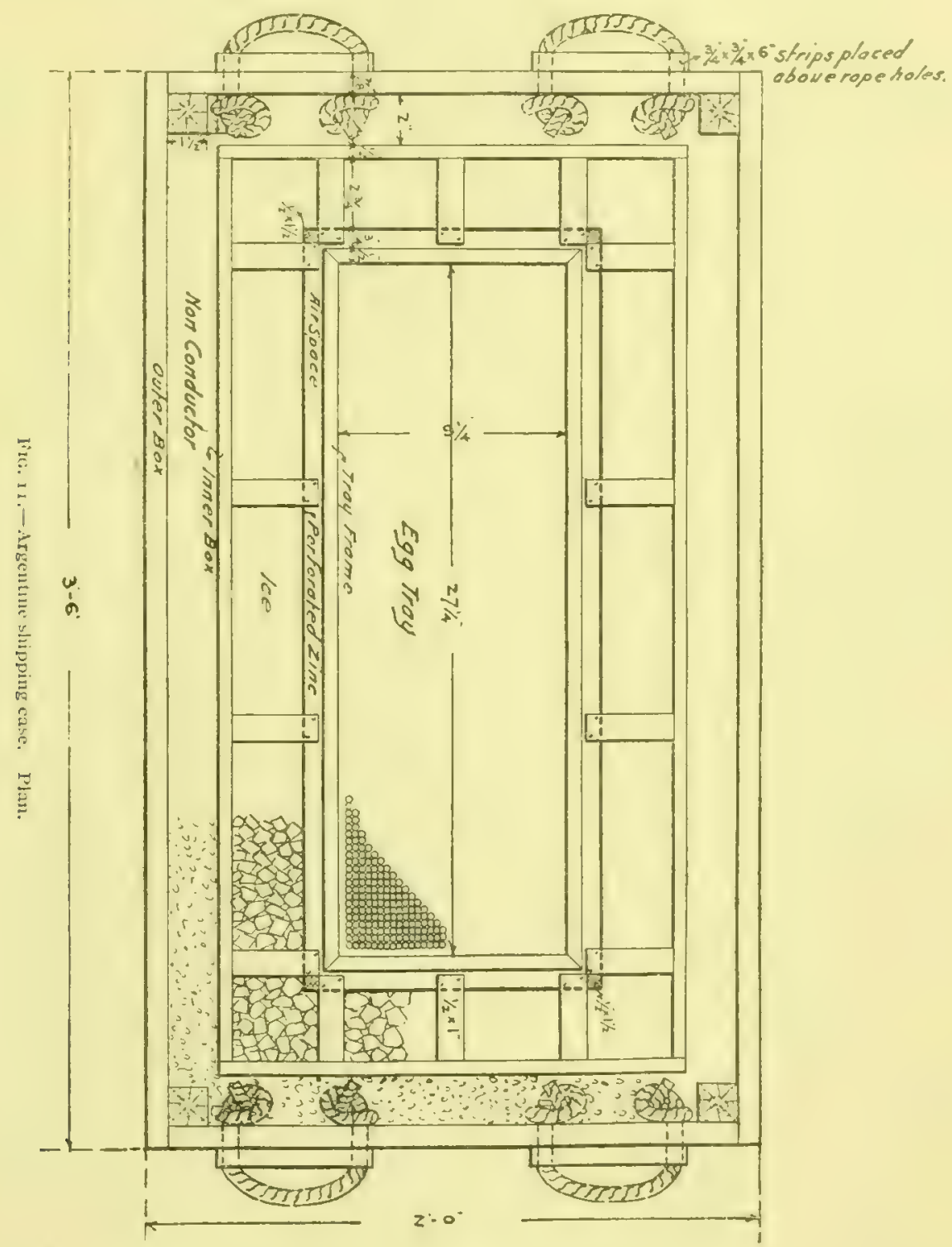

It will be seen that the method of caring for the eggs is not novel. The chief improvements in the case are to nake it casy for the carctaker to tend the eggs in the crowded quarters of a hip's uturage compartments and to facilitate handling each individual tray. 
Another case used on journeys in which the care of the eggs is the same as above described is the German-Chile case, so called by reason of having first been employed by German fish culturists in shipping trout eggs from Germany to the Chilean Government. It was brought to the attention of fish culturists in this country by Mr. E. A. Tulian, chief of the section of fish culture of the Argentine Govermment. In 1907 and 1908 this case, somewhat modified, was used by Mr. Tulian in transporting trout and salmon eggs from the United States to Argentina with better results than had been secured with any other form of case. Owing to the absence of moss directly on the eggs, the GermanChile case is especially adapted to the handling of rainhow trout eggs, the membrane of which is more delicate than that of any other species of the Salmonidx. lirom the latest olservations it is undoubtedly true that the icleal form of longdistance shipping case for all species, at least when accompanied by an attendant, is the one wherein no moss or other substance is placed directly on the eggs.

The German-Chile case is constructed on the same principles as the Argentine case above described. The case proper is built of selected lumber and is $29^{\mathrm{I}} \frac{2}{2}$ inches long, 20 inches wide, and I 5 inches ligh, outside measurements. It is so similar in construction to the Argentine case that, aside from a general description, only the differences between the two will be pointed out.

The German-Chile case accommodates two stacks of trays $73 / 4$ by $81 / 2$ inches, in a double-chambered compartment having walls of unperforated galvanized iron, which is strengthened by a heary wire around the top edge. A removable metal partition separates the two stacks of trays. The compartment itself is made one-fourth inch larger each way than the tray frames, to allow for swelling and the binding twine which will be placed around the trays. Next to and surrounding the tray compartment is the ice, outside of which is the dry moss or other nonconductor, within wooden walls, the sanne as in the Argentine case, while resting upon the top of the trays and ice compartments is an ice hopper. For purposes of insulation the ice in the hopper is covered with a cushion filled with dry moss, oilcloth being placed between the cushion and the ice. The metal bottom of the hopper lias perforations only over the trays, that the eggs may receive the benefit of all drip water. Small cleats are fixed at either end of the ice hopper to facilitate handling. Under the tray compartment and coextensive with it is a perforated wooden false bottom to the case, between which and the botton proper is a $\mathrm{x}$-inch air space. A drain hole is provided in the bottom proper. 'The egre trays are made a trifle deeper than the diancter of the eggs; and the latter are placed on then a single layer deep without any 
covering of moss. The tray frames are seven-eighths inch wide, and usually three-sixteenths inch to five-sixteenths inch thick, with a bottom either scrim

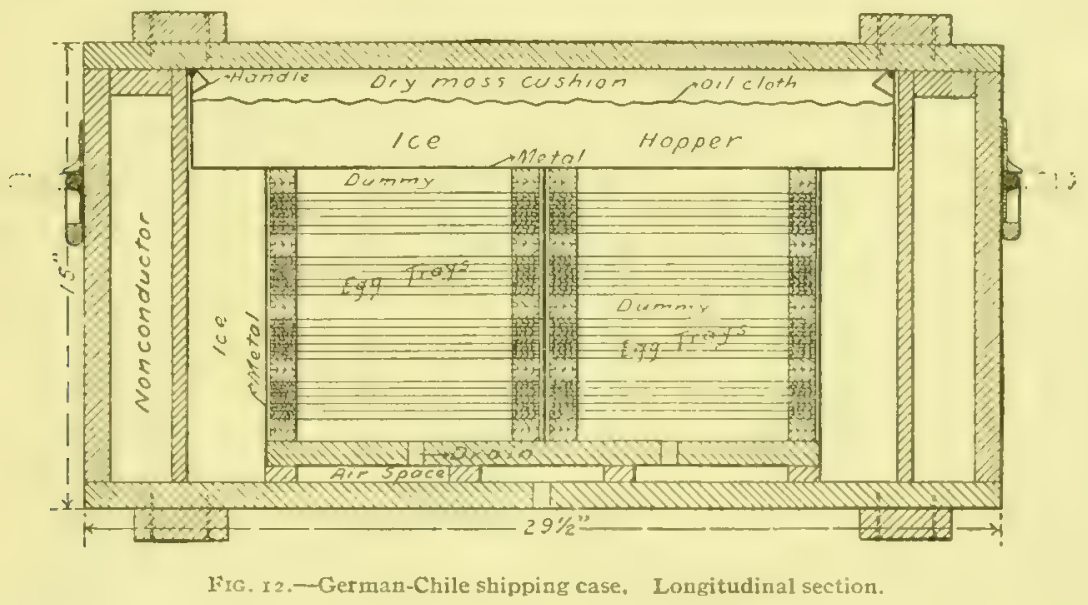

or canton flamel. Instead of being made intu one package for each chanber, the trays are bound together in fives, with strong twine for binding material. and alternating with each package are double-deptl trays, or dummies, filled

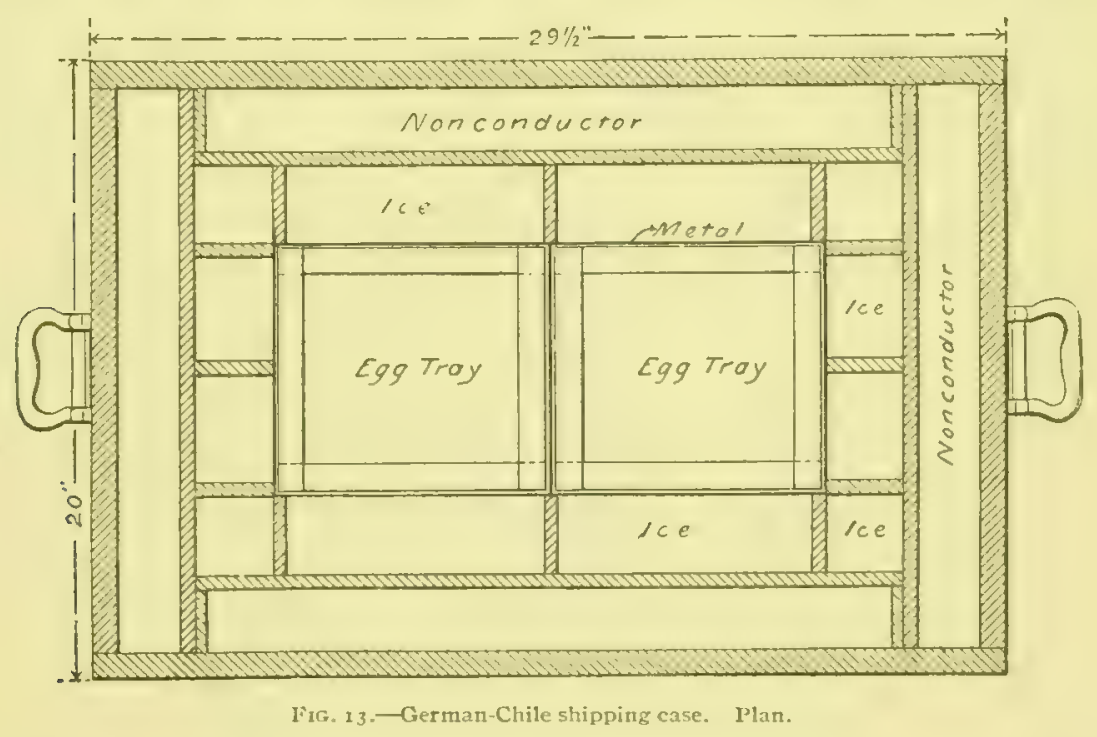

with wet moss. One of these moss-filled trays is placed also in the bottom of each of the two tray chambers. 


\section{TRANSPORTATION OF FISH.}

In distributing young fish from the hatcheries to the waters they are to stock, six special cars are employed. They are equipped with all necessary apparatus for the safe carriage of young and adult fishes and cach is provided with a buffet and sleeping accommodations for a crew of five men. The cars are attached to passenger trains, and many of the railroad companies, appreciating the henefits arising from stocking waters along their lines, haul the cars gratis; others make special rates for cars and crew. When plants are made off the main railroad lines, the fish are carried in baggage cars in charge of members of the car crew.

In addition, distributions are made from many stations without the aid of the special cars, the station employees caring for the fish in hasgage cars. For this service the railroad companies usually clarge regular fare for the attendants but transport the fish and return the empty cans gratis.

Fry and young fish are usually transported in ro-gallon round-shouldered iron cans, tinned for fresh-water work and galvanized for marine work. With fresh water galvanized iron often proves toxic, and should never he used in the transportation of fresh-water fishes. On the cars it is possible to aerate the water in each fish can hy air pumped through a reservoir, from which it is taken through lines of piping along the sides of the car. The piping is equipped with pet cocks, from which the air is carried to the cans in 5 -inch rubber tubing and forced into the water through liherators made of porous wood, preferably the American linden (Tilia americana), placed in hard rubber holders. For best results these liberators must not be placed in the water until air pressure is on and must be removed when air pressure is stopped.

In putting up cod fry and fry of other marine fishes for shipment it is customary to have several quarts of water in the transportation cans and then carefully dip the fry from the hatching boxes, lowering the dipper to the water in the cans before emptying it. When the box is nearly empty the remaining fry are removed from it to a can by means of a siphon. When transported on a vessel having a conveniently arranged well, linen scrim is securely fastened over the top of each can containing fry and the cans are laid horizontally in the well, the top toward a perforated supply pipe through which water is pumped into the well, thus maintaining a constant current.

Lobster fry may be carried in scrim-walled containers, or boxes, suspended in the well of a vessel, the motion of the ressel and the constant circulation of water in the well keeping the fry in good condition and preventing their settling in a mass at the bottom. The boxes are made of a framework covered on the four sicles and hottom with scrim, which allows a free circulation from all sides. Each box, 42 inches by 29 inches by 29 inches, will hold from 2,000,000 to 
$3,000,000$ fry. It is customary to take from I 2 to I 5 cans of fry in addition to those taken in the well, the fry in the cans being the first planted.

On vessels having no wells, aeration for all species of the marine fry, including the lolsters, is accomplished by siphoning off and dipping the water freely, as will be described for whitefish, pike perch, etc. For tempering the water ice is suspended from the cover of the can in a cylinder.

Temperature is a most important consideration in the transportation of fishes, and owing to the different conditions under which they are hatched in the various localities, is a feature that requires skilled discretion on the part of the attendant. The general rule is to keep the temperature at least as low as that of the water from which the fish were taken, and lower if the species is not sensitive to changes.

The maximum number of fishes to be carried most advantageously in a Io-gallon can is another equally important question. The distance to be traveled partly prescribes this number, but must he considered also with reference to the temperature; and these factors, interdepenclent as they are, go to prevent the formulation of any hard and fast rule. In the following table, however, attempt is made to generalize by means of average conditions, and show the number of fishes of specified kind and size as ordinarily transported in a rogallon can. The cooler period of the year in which handled accounts for the lower temperature for fry of the trouts as compared with the higher temperature of fingerlings. It also accounts for the lower temperature for landlocked salmon fingerlings as compared with fry. Ordinarily if landlocked salmon, rainbow trout, and brook trout fry from the same source should be distributed in warm weather it would be desirable to reduce the water temperature for the brook trout considerably lower than for the other two species.

Number of Fisues of Given Kinds and Sizes to be Transported in a ro-Gallon Can under AVERAGE CONDITIONS.

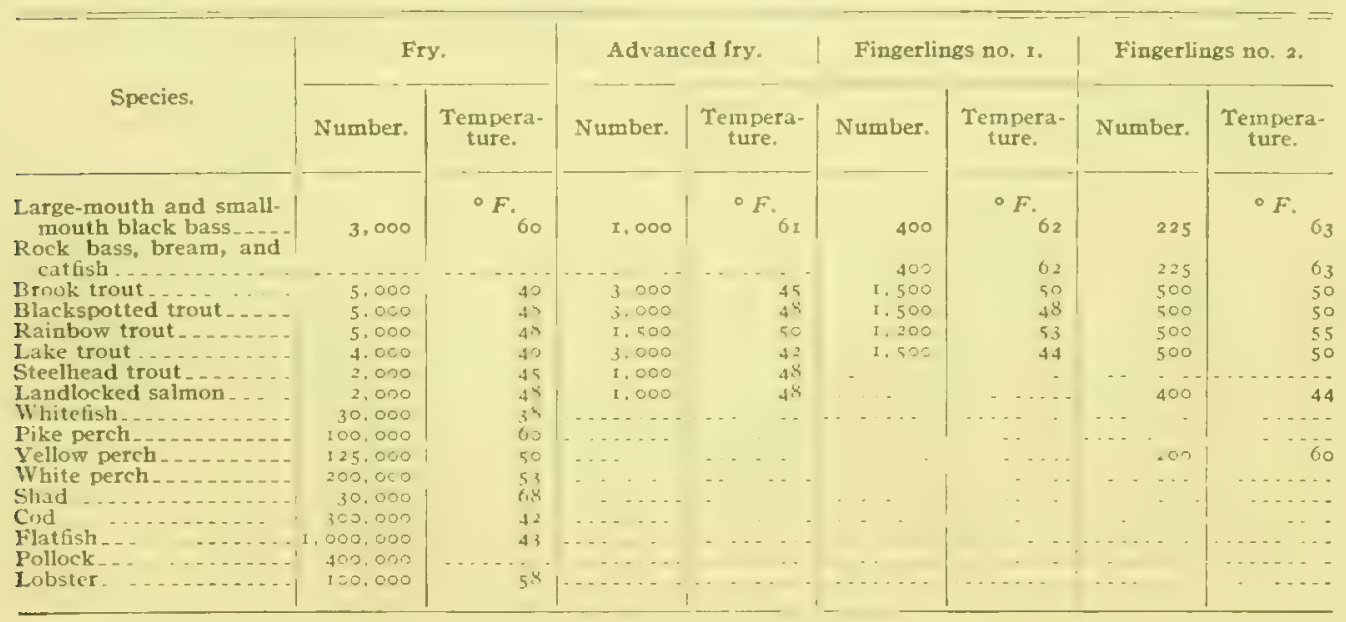

B. B. F. $1908-48$ 
Number of Fishes of Given Kunds and Sizes to be Transportedd IN a io-Gallon Can Under AVERAGE CONDITIONS-Continued.

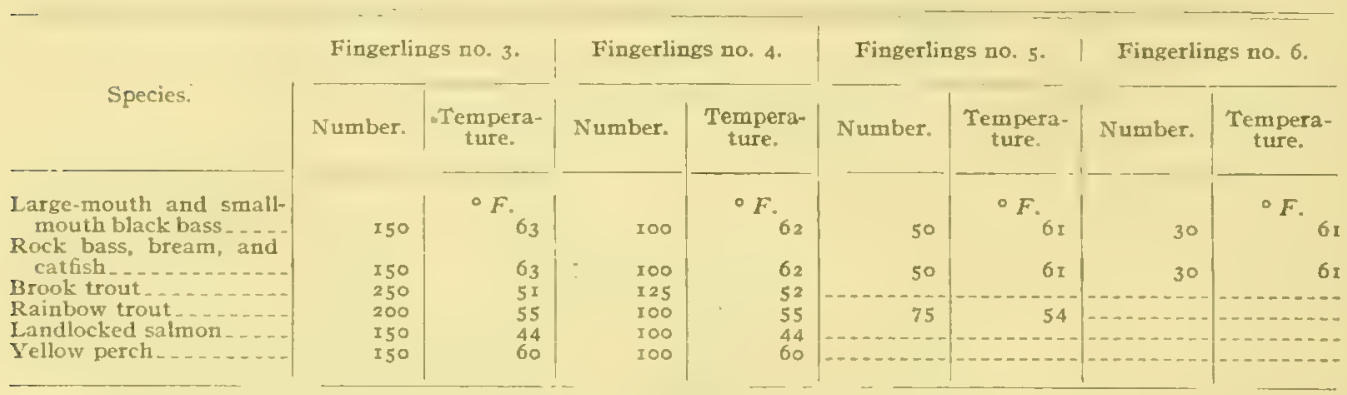

NorE.-The varying usage in the classification of young fish as to size has caused such confusion and difficulty that the Bureau has adopted uniform definitions, as follows:

Fry $=$ fish up to the time the yolk sac is absorbed and feeding begins.

Advanced fry $=$ fish from the end of the fry period until they have reached a length of $\mathrm{I}$ inch.

Fingerlings = fish between the length of $\mathrm{I}$ inch and the yearling stage, the various sizes to be designated as follows: No. 1 , a fish I inch in length and up to 2 inches; no. 2, a fish 2 inches in length and up to 3 inches; no. 3 , a fish 3 inches in length and up to 4 inches, etc.

Yearlings $=$ fish that are 1 year old, but less than 2 years old from the date of hatching: these may be designated no. I, no. 2 , no. 3 , etc., after the plan preseribed for fingerlings.

In the.care of fish away from the air circulation of the cars, aeration is usually accomplished by the use of a long-handled dipper, and this method for Io or 15 cans, which is the usual number handled by detached messengers, if energetically operated has no equal. Several forms of aerating devices have their good points, their use is permitted, and efforts are being made to improve upon the present methods of hand acration in order to lighten the labors of the messengers, who not infrequently care for the fish for two or three days before they arrive at a destination.

For aeration in cans containing small fry, such as the shad, pike perch, white perch, yellow perch, and whitefish, it is customary to siphon a portion of the water into a pail (the head of the siphon being in a wire cage covered with cheese cloth), aerate it with a dipper, add ice to temper it if necessary, and then pour it back through a large funnel which reaches nearly to the botton of the can, the lower part of the funnel for about 6 inches being made of perforated tin to break the force of the water. On short trips little, if any, aeration is necessary.

Cans holding the larger fry and young fish may be aerated by dipping the water up and pouring it hack again from a height of 15 or 20 inches. When transportation is by water it is customary to renew the water in the cans en route instead of resorting to hand acration. With fishes of the Salmonida family, ice may be placed directly in the water in the cans. 


\section{DISTRIBUTION AND PLANTING OF THE COMMERCIAL FISHES.}

It being infeasible for various reasons to rear the young of the commercial fishes, practically all are planted as fry and the distributions are usually made by agents of the Bureau.

Fry of the marine species are often transferred to small boats in order to plant in shallow water or they are carried from the hatchery in launches. In such cases the cans are lowered into the water by two men and there slowly inverted. When planting from a vessel two lines are made fast to the can, one about the top and one about the bottom; by this means the can is lowered over the side and when partially submerged is emptied.

On the Great Lakes the distributions of lake trout, whitefish, and pike perch are usually made by means of steam vessels. In such instances the water in the cans is renewed as often as necessary by siphoning off a portion and replenishing directly from the lake. The manner of liberating the fish after the point of deposit has been reached varies in practice. In planting lake trout and whitefish the method employed by the superintendent of the Duluth, Minn., station is to pour the water and fry, one can at a time, into a large tub full of water, from which the water and fish are siphoned through a heavy 2 -inch rubber hose attached to a pole or outrigger. Thus they are deposited in the lake about $\&$ feet from the side of the vessel, very close to if not beneath the surface of the lake, the speed of the ressel being slackened while the planting is in progress. As it is customary to transport the fry on passenger or package freight steamers, where they are necessarily stowed in a limited space and as close to one gangway as possible, the cans may be emptied into a tub sitting firmly on the deck more easily and expeditiously than they could be poured directly into the lake, and the element of danger to the men doing the work is avoided also.

The superintendent of the Northville station follows a somewhat similar procedure in planting lake trout, pike perch, and whitefisl fry. If the deck of the vessel is near the water surface a picee of ordinary tin pipe is attached to a tub and arranged with elbows so as to bring the lower end near the surface of the lake. If the deck of the ressel is high alove the water the tub is used with I 5 or 20 feet of 2 -inch fire hose instead of the tin pipe, a weight being attached to the lower end.

From the Put-in Bay station the fry are planted by pouring them over the sides of the ressel as it moves slowly along, and the superintendent of this station, from experiments he has made, helieves this method preferable to the use of hose or tin conductor as just described. 
None of the salmon stations on the Pacific coast is of sufficient capacity to hold more than io per cent of the fry until sac absorption, and in California a large portion of the product is clistributed to hatcheries operated by the California Fish Commission. The portion distributed by the Bureau from the Baird station, however, is held until sac absorption. The method of distributing from Baird is as follows:

The inflow to a trough is slut off, the drain pipe removed, and the water and fry allowed to pass into a double receptacle consisting of a perforated bucket inside a regular 5-gallon spawn bucket, the inner container being about i inch less in diameter and raised an inch from the bottom by wooden blocks. This receptacle has been filled with water, to prevent injury to the fry as they are poured in, and the surplus water escapes through the perforations and over the rim of the outside bucket, leaving the fry in the center. If the trough is some distance from the floor a box is used to clevate the buckets to proper level, and any fry remaining in the trough after the passage of the water are brushed through the opening with a broad, flat paint brush. By this method the fry can be removed from a trough in two minutes with absolutely no loss. From the bucket the fry can be easily poured into a 10 -gallon can, but frequently they are carried to the river (about roo feet from the hatchery) and planted direct from the buckets. So far as possible the plants are made during flood water and always where there is a strong current. By this means few, if any, free swimmers are caught by the ever-present trout, as their natural tendency quickly to scatter is facilitated by swift water.

\section{DISTRIBUTION OF GAME FISHES.}

The Bureau does not as a rule attempt to plant the game fishes produced at its hatcheries, but consigns then to individuals, anglers' clubs, protective associations, etc., by whom they are used to stock both public and private waters. It is customary to deliver the fish free of charge to the applicants at the railroad stations nearest the point of deposit.

The number of fish allotted to individual applicants is, of course, largely determined by the supply available, which depends to great extent upon the difference in methods of hatching applicable to the different species. The area and character of the water to be stocked must also be considered, of course. Moreover, the same water area that would receive a million pike pereh fry would perhaps be assigned no more than 200 or 300 black hass 3 or + inches long, or four to eight times that many if the bass are planted as fry. The explanation is in the fact that pike perch can be propagated by the hundred million, while blactbass, hatched by other methods, or collected from overtlowed lands, are pro- 
duced only in comparatively small numbers. The Bureau does not attempt to assign any applicant more than a liberal brood stock of the basses or sunfishes. With brook trout, which are distributed both as fry and fingerlings, assignments of fry are twenty-five to fifty times larger than assignments of fingerlings 3 to 4 inches long.

Applicants for fish are advised by mail of the approximate date on which the fish will be shipped and later by wire of the hour on which they may be expected to arrive. The advance mail notice also contains the specific instructions for the care of the fish from the time of delivery until they are planted. 


